\title{
WestVirginiaUniversity
}

THE RESEARCH REPOSITORY @ WVU

Graduate Theses, Dissertations, and Problem Reports

2013

\section{Essays on Resource Allocation and Energy Commodity Markets}

Oleg Kucher

West Virginia University

Follow this and additional works at: https://researchrepository.wvu.edu/etd

\section{Recommended Citation}

Kucher, Oleg, "Essays on Resource Allocation and Energy Commodity Markets" (2013). Graduate Theses, Dissertations, and Problem Reports. 3654.

https://researchrepository.wvu.edu/etd/3654

This Dissertation is protected by copyright and/or related rights. It has been brought to you by the The Research Repository @ WVU with permission from the rights-holder(s). You are free to use this Dissertation in any way that is permitted by the copyright and related rights legislation that applies to your use. For other uses you must obtain permission from the rights-holder(s) directly, unless additional rights are indicated by a Creative Commons license in the record and/ or on the work itself. This Dissertation has been accepted for inclusion in WVU Graduate Theses, Dissertations, and Problem Reports collection by an authorized administrator of The Research Repository @ WVU.

For more information, please contact researchrepository@mail.wvu.edu. 


\title{
Essays on Resource Allocation and Energy Commodity Markets
}

\author{
Oleg Kucher
}

Dissertation submitted to the

Davis College of Agriculture, Natural Resources and Design

at West Virginia University

in partial fulfillment of the requirements

for the degree of

Doctor of Philosophy

in

Natural Resource Economics

Jerald J. Fletcher, Ph.D., Chair

Alan R. Collins, Ph.D.

Alex Kurov, Ph.D.

Donald J. Lacombe, Ph.D.

Tim T. Phipps, Ph.D.

Division of Resource Management

Morgantown, West Virginia

2013

KEYWORDS: Real Options, Coal and Biomass to Liquids, Spatial Panel Fixed Effects, Energy Prices, Inventory, Business Cycle 


\title{
ABSTRACT \\ Essays on Resource Allocation and Energy Commodity Markets
}

\author{
Oleg Kucher
}

The dissertation consists of three essays directed towards energy resource allocation on micro-, regional- and macro- levels:

1. Economic Analysis of Coal and Biomass to Liquids Investment Decisions,

2. Spatial Dependence in Wholesale Gasoline Markets across the United States, and

3. Energy Prices, Inventory and the Business Cycle.

The first dissertation essay entitled "Economic Analysis of Coal and Biomass to Liquids (CBTL) Investment Decisions" examines the economic feasibility of converting coal and biomass into liquid fuels in the U.S. The study investigates the investment decisions into the CBTL technology under fuel price uncertainty. The CBTL technology scenario draws upon the specifications of a 50,000 barrels per day CBTL plant with 7.7 percent biomass by weight as designed by the National Energy Technology Laboratory. By applying a discounted cash flow analysis and real options valuation assessment, the study develops an estimate of the net present value and the value of the investment opportunities relevant to the projected CBTL plant. The results show that the value of the option to invest is in excess of six times the net present value. This suggests that the current capital cost is too high to support investments in CBTL plants in the U.S. based on the assumptions and construction of CBTL plants can expect to be delayed.

The second dissertation essay entitled "Spatial Dependence in Wholesale Gasoline Markets across the United States" examines the spatial effects in wholesale gasoline markets across 48 contiguous U.S. states. By employing spatial panel econometric techniques to analyze a monthly panel data set over the period 1995-2006, this study finds that the variation in wholesale gasoline price variables exhibit regionally dependent, cross-section differences across states with the spatial autocorrelation parameter of about 0.75 that is statistically significant at the $1 \%$ level. In the presence of spatial autocorrelation, the gasoline content regulation affects the wholesale gasoline margin on the state level. The proliferation of gasoline content regulations in newly designated areas of a state is estimated to increase the state wholesale gasoline margin by about $1 \%$. Another finding is that a fall in gasoline inventories by $10 \%$ increases the wholesale gasoline margin by an average of $0.6 \%$ and the wholesale gasoline price change by about $0.1 \%$ in the state on a monthly basis. Similarly, a reduction in the refinery utilization rate below $85 \%$ will likely increase wholesale gasoline margins in both the state where the refinery is located and in neighboring states.

The third essay entitled "Energy Prices, Inventory and the Business Cycle" analyzes the effects of the state of the national economy and inventory levels on the interest-adjusted basis and expected returns for five energy commodities. Using daily and weekly data for crude oil, 
natural gas, heating oil, gasoline and propane, the interest-adjusted basis and returns are shown to follow a business cycle pattern. Consistent with the theory of storage, demand shocks near business cycle peaks generate negative interest-adjusted basis and positive returns. In recessions, the basis become positive and the average returns are negative. For petroleum commodities, inventories have a significant effect on interest-adjusted basis at low levels of inventory, whereas at high inventory levels the effect of inventory on the basis is weak. Finally, the basis and economic conditions predict spot returns in energy commodity markets. The main result is to show that the state of the economy plays an important role in price variation in energy markets regardless of the level of inventory. 


\section{ACKNOWLEDGMENTS}

I thank my advisor and colleagues at West Virginia University for their contribution, suggestions and help. I am highly indebted to Jerry Fletcher, my graduate advisor, for his guidance, advices and constant support in my graduate studying at WVU. I am thankful to Alex Kurov and Donald Lacombe for their contribution to my research. I thank Alan Collins, Tim Phipps, Peter Schaeffer, Wesley Burnett, Mark Sperow, Gerard D'Souza, Cheryl Brown and other faculty members from Division of Resource Management at WVU for their graduate classes and help with this research. I express my thanks to Douglas Stratford, Nishioka Shuichiro, and other faculty members from Economics Department at WVU for their classes and advices. I thank Lisa Lewis, Ellen-Hartley Smith and all personnel from Division of Resource Management at WVU. Finally, I would like to thank my wife Anastasia and family for their patience. Sincere thanks! 


\section{Table of Contents}

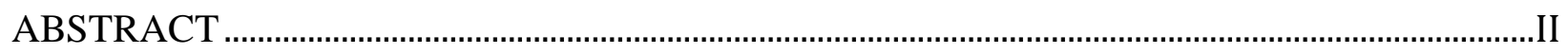

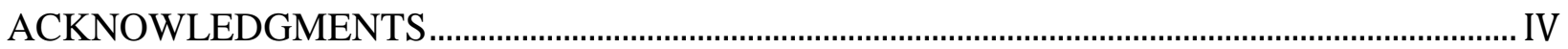

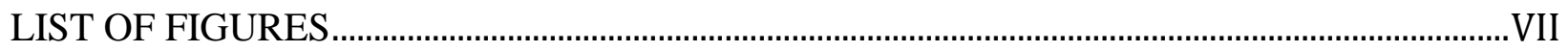

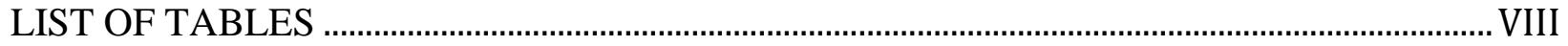

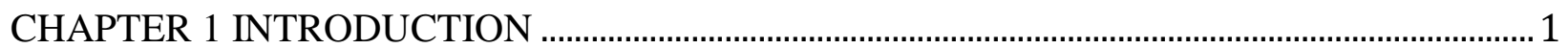

CHAPTER 2 ECONOMIC ANALYSIS OF COAL AND BIOMASS TO LIQUIDS INVESTMENT DECISIONS .................................................................................................... 4

2.1. INTRODUCTION...................................................................................................

2.2. RESEARCH FRAMEWORK AND MODEL …………………………………………......

2.3. COAL AND BIOMASS TO LIQUIDS PROJECT EVALUATION ………………............... 13

2.3.1. DCF and Sensitivity Analysis................................................................................ 14

2.3.2. Risk Assessment and Monte Carlo Simulation ..................................................... 18

2.3.3. Real Options Application …………………….................................................. 22

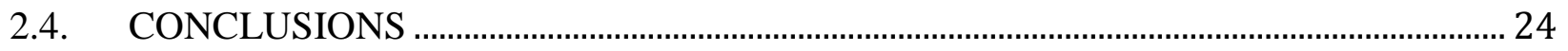

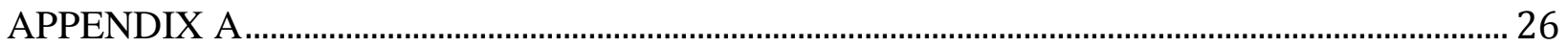

CHAPTER 3 SPATIAL DEPENDENCE IN WHOLESALE GASOLINE MARKETS ACROSS THE UNITED STATES ...................................................................................... 27

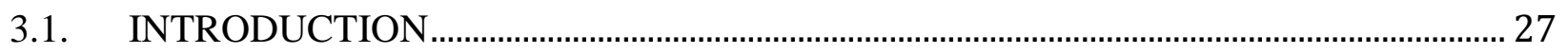

3.2. RELATED LITERATURE ……………………......................................................... 30

3.3. MODEL AND DATA ……………………………..................................................... 32

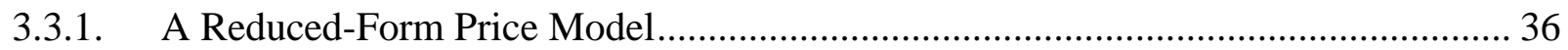

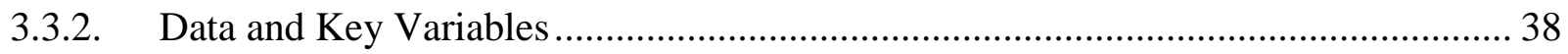

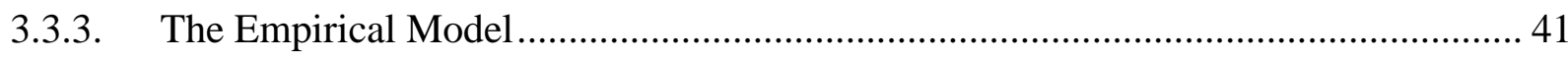




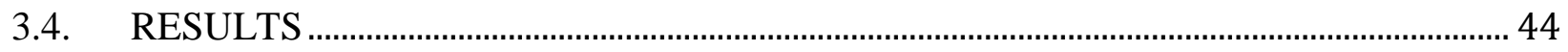

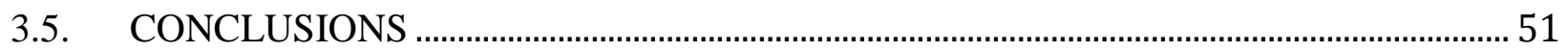

CHAPTER 4 ENERGY PRICES, INVENTORY AND THE BUSINESS CYCLE ....................... 53

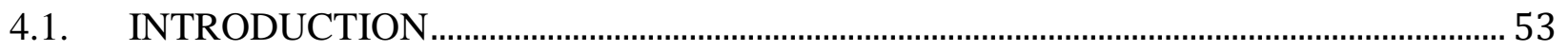

4.2. THE FUTURES AND SPOT PRICE RELATIONSHIP......................................................... 55

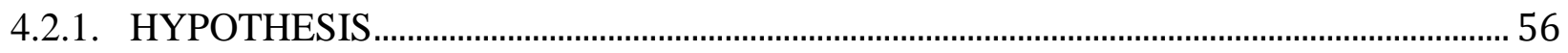

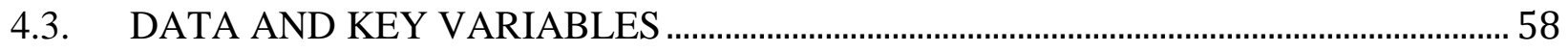

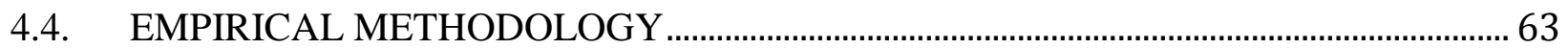

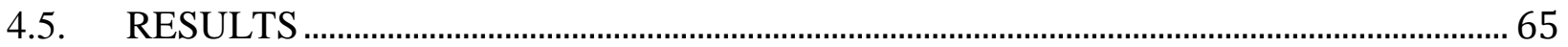

4.5.1. The Theory of Storage and Evidence on Futures and Spot Prices ............................. 65

4.5.2. Evidence on Futures and Spot Prices over the Business Cycle ……………….......... 70

4.5.3. Spot and Futures Price Variation, Inventory and the State of the Economy .............. 72

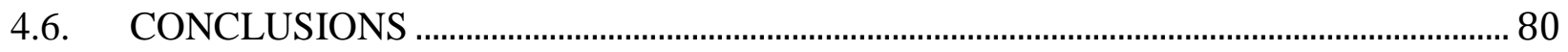

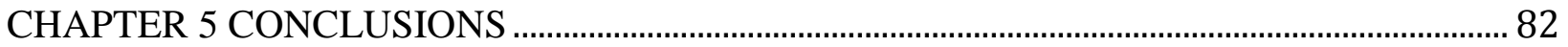

5.1. DIRECTIONS FOR FUTURE RESEARCH …………………………………………...... 83

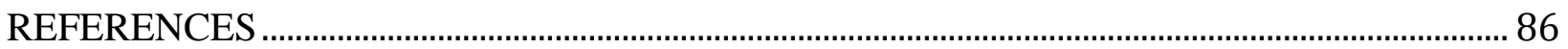




\section{List of Figures}

Figure 2.1 Cash Flow from the CBTL Plant....................................................................... 15

Figure 2.2 Free Cash Flow to the Firm and Net Present Value for the CBTL Plant .................. 16

Figure 2.3 Impact of major sensitive parameters $( \pm 10 \%)$ on NPV .................................... 17

Figure 2.4 Net Present Value and Internal Rate of Return (4000 Iterations) ........................... 21

Figure 2.5 Present Value of Free Cash Flow (4000 Iterations) …........................................ 22

Figure 2.6 Value of Investment Options for the CBTL plant in the U.S.............................. 23

Figure 3.1 Regular Wholesale Gasoline Prices by State, 2010......................................... 33

Figure 3.2 Regular Wholesale Gasoline Price Pattern across States, 2010 ........................... 34

Figure 3.3 Regular Gasoline Wholesale/Resale Price for All Sellers, 1995-2006 ................... 35

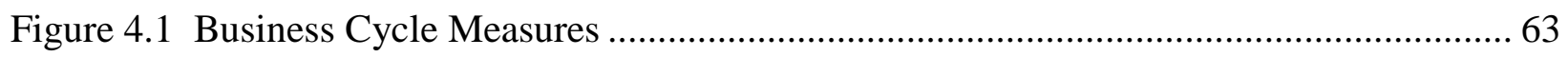

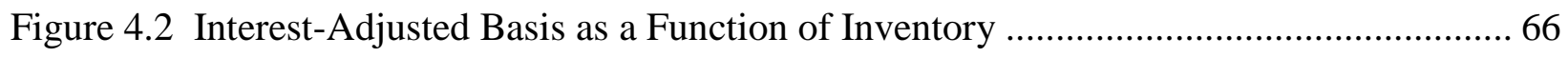

Figure 4.3 Return Correlation and Interest-Adjusted Basis ................................................ 69 


\section{List of Tables}

Table 2.1 Capital Expenditures of CBTL 50 kbpd, 7.7 wt.\% Biomass ................................. 14

Table 2.2 Fitted Distribution Parameters for Input Variables............................................. 19

Table 2.3 Real Options Model Parameters for the CBTL Plant ............................................. 23

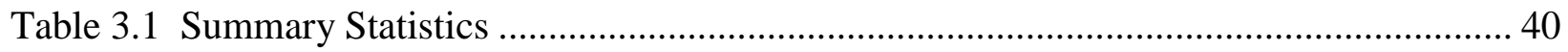

Table 3.2 Regression Results for the Wholesale Gasoline Margin (in Log) ........................... 45

Table 3.3 Regression Results for the Wholesale Gasoline Price Change (in Log)................... 49

Table 4.1 Energy commodity futures and inventory …................................................... 58

Table 4.2 Statistics for Interest-Adjusted Basis, Inventory and Return Volatility ................... 61

Table 4.3 Comparative Statistics for Relative Variation of Futures and Spot Prices ................ 67

Table 4.4 Relative Spot Prices around Business Cycle Peaks and Recessions ........................ 71

Table 4.5 Averages and Standard Deviations of Interest-Adjusted Basis and Returns over the Business Cycle (Daily Data) ......................................................................... 72

Table 4.6 Regression Results for Interest-Adjusted Basis (Daily Data)................................ 74

Table 4.7 Regression Results for Interest-Adjusted Basis (Weekly Data) .............................. 77

Table 4.8 Regression Results for Expected Returns (Daily Data)....................................... 79 


\section{Chapter 1}

\section{INTRODUCTION}

Energy resources play an important role in our economy. In 2011, the United States consumed about 19 million barrels per day of crude oil and petroleum products, down about $9 \%$ from the 2005 peak. The average annual spot price of benchmark WTI crude oil increased to 95 dollars per barrel in 2011, up to 68\% from its level in 2005. During the same period, U.S. demand for natural gas, the second largest energy resource, rose $11 \%$ from the 2005 level to about 67 billion cubic feet per day in 2011 while the average spot price at Henry Hub decreased to about $\$ 4$ per million BTU (British thermal units). These changes are consequences of improvements in energy technologies and fuel efficiency, surging energy output from shale-gas fields in the U.S. and changes in macroeconomic activity.

Efficient energy resource use with minimal environmental impact is a key priority to society. The underlying umbrella and overall goal for this research is to investigate the main economic and policy factors that guide the allocation of energy resources. Specifically, this dissertation addresses three topics in energy resource economics, namely economic feasibility of alternative fuel technologies, spatial dependence in the state wholesale gasoline market and interrelations among energy prices, inventories and the state of the economy. An understanding of these topics is important to energy practitioners, policy-makers and academia.

This dissertation presents three essays on economic analysis of energy resource allocation and energy commodity markets on micro-, regional- and macro- levels. The first essay uses a discounted cash flow analysis and real options approach to analyze the economic feasibility and investment decisions of producing transportation fuels from coal and biomass (CBTL) in the U.S. The second essay employs spatial panel econometric techniques to examine spatial 
dependence in the wholesale gasoline market across the 48 contiguous U.S. states. The third essay provides an empirical analysis of the relationships among energy prices, inventories and the state of the economy for five major energy commodities.

The first dissertation essay entitled "Economic Analysis of Coal and Biomass to Liquids Investment Decisions" focuses on economic factors that determine the long-term economic feasibility of developing a coal and biomass to liquids (CBTL) plant in the U.S. with a particular focus on the investment decision. The CBTL technology scenario draws upon a CBTL plant of 50,000 barrels per day (bpd) with a biomass input of 7.7\% by weight designed by NETL (2009). This study employs a discounted cash flow (DCF) analysis and real options valuation to assess the projected CBTL plant operations. After accounting for uncertainties in fuel prices, operating capacity and capital costs, a Monte Carlo simulation is performed in the DCF model to derive the volatility of the net cash flow from the CBTL plant. The derived volatility is then applied in a real options continuous-time model of irreversible investment to evaluate the CBTL investment options. The results show that the value option to invest is in excess of six times the net present value. The primary contribution of the paper is the application of the real options approach to a large-scale CBTL investment project. The research framework utilized in this essay can be applied to the micro-economic analyses of large-scale, commercial energy projects in the U.S.

The second dissertation essay entitled "Spatial Dependence in Wholesale Gasoline Markets across the United States" examines spatial effects in the wholesale gasoline market at the state level. Using a monthly panel data set over the 1995-2006 period, this study examines spatial dependence in the wholesale gasoline margin and wholesale gasoline price change at the state level. Conventional panel fixed or random effects models rely on the hypotheses that the elasticities are the same for all regions and over the study period (Pirotte and Madre, 2009) and 
have ignored spatial effects that could result from the spatial differentiation of gasoline prices across regions and their location over time. If gasoline prices are spatially correlated among competitors across geographic space, it is necessary to control for spatial effects in the econometric analysis of gasoline price determinants. The results show that the wholesale gasoline price variables exhibit regionally dependent cross-section differences across states with a spatial autocorrelation parameter of 0.75 (statistically significant at the $1 \%$ level). In the presence of spatial autocorrelation, gasoline content regulations affect the wholesale gasoline margin at the state level over the sample period. Another finding is that a $10 \%$ reduction in gasoline inventory increases the state wholesale gasoline margin by about $0.6 \%$. This essay's contribution is to show that spatial autocorrelation within wholesale gasoline markets is a significant factor in wholesale gasoline price determination at the state level.

The third dissertation essay entitled "Energy Prices, Inventory and the Business Cycle" examines the effects of the state of the national economy and inventory on interest-adjusted basis (the difference between futures and spot prices net of the interest rate) and expected returns for crude oil, natural gas, gasoline, heating oil and propane over the period 1987-2011. The results show that the energy basis and returns have a business cycle pattern. Consistent with the theory of storage, demand shocks near business cycle peaks generate negative interest-adjusted basis and positive returns. In recessions, the basis become positive, and the average returns are negative. For petroleum commodities, inventories have a significant effect on interest-adjusted basis at low levels of inventory, whereas at high inventory levels the effect of inventory on the basis is weak. The contribution of this study is to highlight the energy price dependency on the state of the economy. 


\section{Chapter 2}

\section{ECONOMIC ANALYSIS OF COAL AND BIOMASS TO LIQUIDS INVESTMENT DECISIONS ${ }^{1}$}

\subsection{Introduction}

Coal and biomass to liquids (CBTL) technologies can produce synthetic fuels such as diesel and jet fuel with lower $\mathrm{CO}_{2}$ emissions than petroleum-based fuels (NETL, 2009). Recent studies suggest perspectives of CBTL production of "affordable and low-carbon diesel fuel" on a large scale in the U.S. (NETL, 2007, 2009; Bartis et al., 2008; Hileman et al., 2009; Darmstadter, 2010). In particular, a study by NETL (2009, p.51) underlines that CBTL technology enables the “economic production of 20 times more diesel fuel from secure, domestic energy resources." The U.S. Department of Energy reports further financing of research in carbon capture and storage (CCS) technologies to reduce life-cycle $\mathrm{CO}_{2}$ emissions by investing $\$ 4$ billion in CCS with an expected $\$ 7$ billion from the private sector (U.S. EIA, 2010).

At the same time, the economic feasibility of CBTL production depends not only on availability of technology but also on economic and policy factors that may not be favorable in

\footnotetext{
${ }^{1}$ Acknowledgment: "This material is based upon work supported by the Department of Energy under Award Number DE-FC26-06NT42804.

Disclaimer: "This report was prepared as an account of work sponsored by an agency of the United States Government. Neither the United States Government nor any agency thereof, nor any of their employees, makes any warranty, express or implied, or assumes any legal liability or responsibility for the accuracy, completeness, or usefulness of any information, apparatus, product, or process disclosed, or represents that its use would not infringe privately owned rights. Reference herein to any specific commercial product, process, or service by trade name, trademark, manufacturer, or otherwise does not necessarily constitute or imply its endorsement, recommendation, or favoring by the United States Government or any agency thereof. The views and opinions of authors expressed herein do not necessarily state or reflect those of the United States Government or any agency thereof."

Special thanks to Thomas J. Tarka, Office of Systems, Analyses, and Planning, National Energy Technology Laboratory for suggestions on the CBTL capital costs.

This essay is based on the conference proceedings accessible on-line (Kucher and Fletcher, 2011).
} 
the U.S., in particular, high capital costs of CBTL plant development. CBTL is an emerging technology; no CBTL plants have been constructed. Beginning in 2011, only three CBTL projects have been considered for commercial deployment in the U.S. with a combined production capacity over 110 thousand barrels per day (bpd) of synthetic fuels. In 2012, two of the projects have been switched to natural gas, and only one of them could be possibly ready after 2015. It is not clear whether such a project is financially viable in the long-run due to uncertainty. Indeed, the efficiency of investment in CBTL assets in the U.S. cannot be predicted with confidence because of the indefinite capital costs, high volatility of energy prices and uncertain carbon requirements.

In this study, the main concern is high investment outlays for a new CBTL plant. Investments in a CBTL plant possess two important characteristics: irreversibility and flexibility as described by Pindyck (1991) and Dixit (1992). First, the investment in CBTL plant could be a sunk cost if the project expenditure cannot be fully recovered due to uncertainty in future energy prices and costs. Second, the investment outlays have an opportunity value, since the firm has flexibility to delay investment until better project conditions prevail. These economic factors need to be included in the overall project assessment and economic analysis in order to correctly assess the economic feasibility of CBTL projects.

This study focuses on the economic factors that determine long-term economic feasibility of implementing CBTL technologies in the U.S. A micro-economic analysis is applied to a projected CBTL plant operation by providing a discounted cash flow (DCF) estimation and real options valuation to assess the economic feasibility and investment decisions for a CBTL plant. After performing the DCF analysis, this study identifies the major sources of uncertainty that affect investment decisions to proceed with CBTL plant construction. The analysis then 
incorporates uncertainties in the DCF model to perform a Monte Carlo simulation for determining the payoff of the CBTL project and its volatility. Incorporating the derived estimates into a real options model allows the assessment of the option value to invest that arises from irreversibility of capital costs and the uncertainty over future payoffs from CBTL investment in the U.S.

The micro-economic analysis is based on up-to-date economic and financial assumptions for a commercial CBTL 50,000 bpd plant as designed by NETL (2009) with 7.7\% by weight (wt. \%) biomass. The CBTL plant configuration analyzed is based on technical production estimates for a base case of coal and biomass acquisition as modeled by the RAND Corporation using the energy conversion criteria designed by the GREET model and EPA MOVES model (NETL, 2009). This CBTL plant configuration, one out of five CBTL options analyzed, is considered by NETL (2009) to be "the most pragmatic" solution to economic efficiency and carbon compliance. The motive to use a CBTL configuration is based on meeting a required greenhouse gas (GHG) emissions profile reduction that is $20 \%$ below the petroleum-derived diesel GHG profile at minimum cost.

The micro-economic analysis extends the NETL (2009) research by introducing real options valuation while dealing with the uncertainty in fuel prices and costs. The uniqueness of this study is the use of a combination of economic and financial approaches including DCF analysis, risk assessment and real options valuation in the assessment of a large-scale CBTL plant. This study draws insights on investment opportunities for the CBTL in the U.S. 


\subsection{Research Framework and Model}

The research framework explores the micro-economic analysis of a CBTL plant in the U.S. The research approach incorporates DCF analysis, risk assessment and real options valuation to value CBTL economic viability and investment decisions under uncertainty over time. The basis for economic feasibility for this CBTL plant is determined by a firm's maximization objective function - maximize the value of the firm. Here, the value of the firm is the present value of its expected free cash flow from the projected CBTL plant, discounted at the cost of capital. Hence, investment to build the CBTL plant happens if the project receives positive net present value at an acceptable rate of investment return. However, because of uncertainty, this investment rule may be wrong as stochastic changes in the project value would result in overinvesting or underinvesting in the CBTL project. Therefore it is important to correctly assess the CBTL investment value to avoid an economic loss in building a large-scale plant. Thus, this study employs the basic continuous-time model of irreversible investment originally developed by Mcdonald and Siegel (1986) and extended by Dixit and Pindyck (1994). Empirical application of the variations of this model for energy projects has been undertaken by Kiriyama and Suzuki (2004), Rothwell (2006), Yang et al.(2008) and Blyth (2010).

The overall approach incorporates traditional DCF analysis, risk assessment and real options valuation. First, a linear DCF model is constructed to estimate NPV by discounting the free cash flow to the firm. Following traditional analysis, this approach assesses whether the investment return exceeds the minimum acceptable rate of return after incremental costs and revenues have been taken into account. Regarding the CBTL project, the static DCF determines whether the CBTL NPV is positive and whether investment return is satisfied after assessing all costs and revenues. 
The DCF linear deterministic model is constructed to estimate the CBTL payoff by discounting the net free cash flow to present value. The DCF model is based on the free cash flow for a prospective CBTL facility, using the concepts of asset valuation, free cash flow to firm (FCFF) and free cash flow to equity (FCFE). The free cash flow is comprised of operational cash flow, capital expenditures, working capital and financing capital. The NPV is estimated as a sum of the present values of the expected net cash flow and calculated as a function of operating revenues, operating expenses and costs, including operation and maintenance costs, taxes, interest rates and investment expenditures. The input-output physical parameters in the DCF model are taken from the NETL designed CBTL configuration plant (NETL, 2009).

Second, the risk analysis is performed by fitting probability distributions to key input variables and specifying correlations among those variables (Belli et al., 1998). Specifically, the probability occurrence technique assigns the best-fitting probability distribution parameters based on historical data (Mun, 2006). If historical data are not available, this study uses the best available estimates from the literature. It allows assessing the volatility of the present value of the free cash flow by running a Monte Carlo a simulation. Estimated volatility is then used in the continuous-time real options model.

Finally, this study employs a real options basic continuous-time model of irreversible investment following Dixit and Pindyck (1994). Here, investment decisions for the CBTL project account for uncertainty through the investment options opportunities, including value option to invest and value option to wait. These values are based on the expected present value of free cash flow from the CBTL plant derived in the DCF analysis. The latter option suggests that the firm can improve investment conditions by optimizing project payoffs. Following Mcdonald and 
Siegel (1986), the value option to invest (V) is based on uncertainty of the future cash flow, i.e. high volatility of energy prices and uncertain capital costs.

The notation follows Dixit and Pindyck (1994, chapter 5, sections 1, 2). Define:

$V_{t}-$ the present value of the net free cash flow per year $t$ from CBTL plant;

$I$ - present value of investments or capital expenditures in DCF analysis;

$\rho$ - discount rate;

then the value option to invest, $F(V)$ can be defined as the payoff from investing in the plant:

$$
F(V)=\max \varepsilon\left(\mathrm{V}_{\mathrm{T}}-I\right) e^{-\rho T}>0
$$

where $\varepsilon$ is expectation and $T$ is the future time when investment is made into the CBTL project.

Equation (1) says that investor maximizes the payoff subject to the value change of cash flows which follows GBM:

$$
\mathrm{dV}=\alpha \mathrm{Vdt}+\sigma \mathrm{Vdz}
$$

where

$\alpha$ - a drift parameter or growth parameter that increases at a factor of time $d t$,

$\mathrm{V}$-current value of the project with $\sigma$-volatility; and

$d z=\varepsilon_{t} \sqrt{d t}$ the increment of Wiener process

represent a normal random variable to capture uncertainty.

Since $V$ is stochastic, this study values an expected payoff from investing, $F(V)$ and the critical value, $\mathrm{V}^{*}$, at which it is optimal to invest in the CBTL plant. In order to solve this investment problem, the approach is to use a dynamic programing model with uncertainty, represented by the volatility of the present value of cash flow, $\sigma$ with drift $\alpha$, that creates a value of waiting. In addition, a risk neutral investor is considered in order to replicate $\mathrm{dz}$ component in dynamic optimization. 
The starting point is $F(V)=V$, that is the value of the option to invest into the CBTL project equals to the expected present value of cash flow. Because the investment opportunity, $F(V)$ yields no cash flow until the time, $T$ the only return is its capital appreciation, which is represented through the Bellman equation, after Dixit and Pindyck (1994), as:

$$
\rho \mathrm{Fdt}=\varepsilon(\mathrm{dF})
$$

The above equation says that over time, $\mathrm{dt}$, the return on investment $\rho \mathrm{Fdt}$ equals the expected rate of capital appreciation. When expanding $\mathrm{dF}$ using Ito's Lemma, the first and second order differentiation of the value is represented as:

$$
d F=F^{\prime}(V) d V+1 / 2 F^{\prime \prime}(V)(d V)^{2}=(d F / d V) d V+1 / 2\left(\partial^{2} F / \partial V^{2}\right) \partial V^{2}
$$

Substituting the GBM equation for $\mathrm{dV}$ and noting that $\varepsilon(\mathrm{dz})=0$ because $\varepsilon_{t}$ is normally distributed with mean 0 gives:

$$
\varepsilon[\mathrm{dF}]=\alpha \mathrm{F}^{\prime}(\mathrm{V}) \mathrm{dt}+1 / 2 \sigma^{2} \mathrm{~V}^{2} \mathrm{~F}^{\prime \prime}(\mathrm{V}) d t
$$

Substituting equation (5) into (3) and dividing both sides by $d t$ and rearranging, yields:

$$
\alpha F^{\prime}(V)+1 / 2 \sigma^{2} V^{2} F^{\prime \prime}(V)-\rho F=0
$$

Because of the stochastic changes in payoff, two parameters are incorporated: growth rate, $\alpha$, and volatility, $\sigma$. For simplicity Dixit and Pindyck (1994) suggest a substitution for $\alpha$, such as $\alpha=\rho-\delta$, where $\delta$ is dividend yield, assuming that $\alpha<\rho$, or $\delta>0$. The dividend rate $\delta$ is the rate of a capital gain. Given this condition, Bellman's equation becomes:

$$
1 / 2 \sigma^{2} V^{2} F^{\prime \prime}(V)+(\rho-\delta) F^{\prime}(V)-\rho F=0
$$

In order to have a solution, the value of investment opportunity $F(V)$ must satisfy the boundary conditions:

$$
\begin{aligned}
& \mathrm{F}(0)=0 \\
& \mathrm{~F}\left(\mathrm{~V}^{*}\right)=\mathrm{V}^{*}-\mathrm{I}
\end{aligned}
$$




$$
\mathrm{F}\left(\mathrm{V}^{*}\right)^{\prime}=1
$$

Equation (8) says that there is no option value of investment opportunity if net cash flow goes to zero. Equation (9) says that critical value of investment opportunity equals to net of the critical value of the present value of net cash flow and investment. In other words, value of the project equals to the full cost (opportunity cost + direct cost) of making investment: $\mathrm{V}^{*}=\mathrm{F}\left(\mathrm{V}^{*}\right)+\mathrm{I}$. Obviously, the first order differentiation of the value equals to 1 .

Finally solving equation (7) subject to the boundary condition (8) yields the solution as:

$$
\mathrm{F}(\mathrm{V})=A V^{\beta 1}
$$

where $A$ and $\beta_{1}$-positive constants to be determined which account for changes through volatility and cost of capital.

The other important outcome of these applications is ability to estimate, trigger value, $\mathrm{V}^{*}$, and positive constants: $A$, and $\beta_{1}$ by substituting equation (9) into equation (8) and (9) and rearranging, as following:

$$
\begin{aligned}
& \mathrm{V}^{*}=\beta_{1} /\left(\beta_{1}-1\right) * \mathrm{I} \\
& A=\left(\mathrm{V}^{*}-\mathrm{I}\right) * V^{\beta 1}=\left(\beta_{1}-1\right)^{\beta 1-1} /\left[\beta_{1}{ }^{\beta 1} * I^{\beta 1-1}\right]
\end{aligned}
$$

Equation (12) derives the trigger value of the investment option which makes investor indifferent between the investment right away and waiting. It enables to determine the value of options to invest.

To solve for $\beta_{1}$ the general solution to the second order differential equation (7) is expressed as a linear combination of the solution $A V^{\beta}$ and by substitution it satisfies the quadratic equation:

$$
1 / 2 \sigma^{2} \beta /(\beta-1)+(\rho-\delta) \beta-\rho=0
$$

with the quadratic roots: 


$$
\begin{aligned}
& \beta_{1}=1 / 2-(\rho-\delta) \sigma^{2}+\sqrt{\left[(\rho-\delta) / \sigma^{2}-1 / 2\right]^{2}+2 \rho / \sigma^{2}}>1 \\
& \beta_{2}=1 / 2-(\rho-\delta) \sigma^{2}-\sqrt{\left[(\rho-\delta) / \sigma^{2}-1 / 2\right]^{2}+2 \rho / \sigma^{2}}<1
\end{aligned}
$$

The general solution is:

$$
\mathrm{F}(\mathrm{V})=A_{1} V^{\beta 1}+A_{2} V^{\beta 2}
$$

Since the boundary condition implies that $A_{2}=0$, the equation (11) is an outcome.

The solution is the value of opportunity to invest, that can be expressed as following:

$$
\mathrm{F}(\mathrm{V})=\left\{\begin{array}{lcl}
A V^{\beta 1} & \mathrm{~V} \leq \mathrm{V}^{*} & \text { Value of option to wait } \\
V-I & \mathrm{~V}>\mathrm{V}^{*} & \text { Value of option to invest }
\end{array}\right.
$$

where $\beta_{1}=1 / 2-(\rho-\delta) \sigma^{2}+\sqrt{\left[(\rho-\delta) / \sigma^{2}-1 / 2\right]^{2}+2 \rho / \sigma^{2}}$

$$
\begin{aligned}
A & =\left(\mathrm{V}^{*}-\mathrm{I}\right) V^{\beta 1}=\left(\beta_{1}-1\right)^{\beta 1-1} /\left[\beta_{1}{ }^{\beta 1} I^{\beta 1-1}\right] \\
\mathrm{V}^{*} & =\beta_{1} /\left(\beta_{1}-1\right) * I
\end{aligned}
$$

From the mathematical expression in (17), the value of option to invest, $F(V)$, yields two different upward trends of the value of the project. The first equation represents the value option to wait, denoted as the value of the project, $F(V){ }^{\mathrm{w}}$ with the positive slope $\mathrm{A}>0$ and with an exponent $\beta_{1}>1$. The second equation for the NPV of the CBTL plant gives the traditional NPV. With the inequalities on the right hand sides, this equation modifies the optimal investment rule: invest if the value of the project is greater than the trigger value $\mathrm{V}^{*}$, otherwise wait. So, if the value of the project is less or equal than the trigger value, $\mathrm{V} \leq \mathrm{V}^{*}$ the investment should be postponed. If the value of the project is greater than the trigger value, $\mathrm{V}>\mathrm{V}^{*}$, than the investor's optimal decision is to invest in the project .

The positive constant, $\beta_{1}$, depends on three variables: discount rate, $\rho$, dividend yield, $\delta$, and volatility, $\sigma$. The third term is the standard deviation of the present value of the net free cash flow. The positive slope, $A$, depends on the volatility of the project value and investment outlays. 
The threshold $\mathrm{V}^{*}$ serves as the critical point at which the investor decides whether to invest or wait until more information becomes available. Mathematically it depends on investments, $I$, and an expression $\beta_{1} /\left(\beta_{1}-1\right)>1$ with $\mathrm{V}^{*}>I$. The expression $\beta_{1} /\left(\beta_{1}-1\right)$ depends on uncertainty in the way that greater volatility results in a higher value option to invest. Contrary, a higher discount leads to a smaller constant $\beta_{1} /\left(\beta_{1}-1\right)$.

In order to calculate the value of investment option under uncertainty, the option of building a CBTL 50,000 bpd plant with $7.7 \mathrm{wt} \%$ biomass in the U.S. with the commercial operation in four years is evaluated. Section 2.3 provides the procedure and the results using DCF analysis, risk analysis and real options valuation for the CBTL plant.

\subsection{Coal and Biomass to Liquids Project Evaluation}

The CBTL project evaluation starts with a DCF model while using a comprehensive dataset of techno-economic parameters from NETL $(2009,2011)$ reports and CBTL investors' data sources. Assumptions have been made about project parameters related to the plant life, construction period, capacity factor, unit prices, escalation rate, cost of capital, tax rates, working capital etc. (Appendix A). The CBTL project evaluation is based on constant prices and unit costs as of 2010 obtained from the U.S. DOE EIA and NETL and escalated at $2 \%$ annually.

The DCF analysis for the CBTL project was performed using self-constructed MS Excel spreadsheets. The analysis of capital expenditure, depreciation, change in working capital and financing costs over the plant lifetime were derived using the NETL Power Systems Financial Model 6.6 (NETL, 2011). The probabilities for sensitive variables are based on historical data, followed by performing a Monte Carlo Simulation using the Risk Simulator (Mun, 2006). 


\subsubsection{DCF and Sensitivity Analysis}

The DCF analysis estimates the NPV of the CBTL project as the sum of present values of the expected free cash flows $(F C F F)$ during the project's lifetime as follows:

$$
F C F F=E B I T^{*}(1-\text { Tax Rate })+\text { Depreciation }- \text { Capital expenditures }-\Delta W C
$$

where EBIT is earnings before interest and taxes, and $\triangle W C$ is the change in working capital.

The FCFF from the CBTL plant reflects major economic flows: earnings and investments. The main components of earnings EBIT are operating revenues from selling the CBTL output, costs of input used in production and other expenses (i.e., operation and management $(\mathrm{O} \& \mathrm{M})$ costs, etc.) for each year of the project life. Plant inputs include coal, biomass, water, chemicals and slag. The output products include diesel, naphtha and sulfur. Operating revenues and expenses are determined by placing values on the production inputs and outputs from CBTL operations.

Table 2.1 shows capital expenditures which reflect the value of the CBTL plant's investments, $I$, expressed in constant dollars based on the NETL (2009) study.

Table 2.1

Capital Expenditures of CBTL $50 \mathrm{kbpd}, 7.7$ wt.\% Biomass

\begin{tabular}{lcc}
\hline Capital costs (in billion dollars) & Value & Percentage \\
\hline Coal \& biomass handling, preparation and feed & $\$ 0.70$ & $12 \%$ \\
Gasification & $\$ 1.35$ & $23 \%$ \\
Air separation, syngas cleaning \& shift & $\$ 0.67$ & $12 \%$ \\
Fischer-Tropsch (FT) synthesis & $\$ 0.66$ & $11 \%$ \\
Other & $\$ 0.79$ & $13 \%$ \\
Bare erected cost (based on NETL with escalation at 10\%) & $\$ 4.17$ & $71 \%$ \\
Total capital cost (BEC+EPC cost \& contingency at 31.4\% from BEC) & $\$ 5.48$ & $94 \%$ \\
Interest during construction (at 5.5\% for 48 month) & $\$ 0.36$ & $6 \%$ \\
Total capital expenditures & $\$ 5.85$ & $100 \%$ \\
\hline
\end{tabular}

Based on the NETL (2009) projected plant scenario: CBTL 50,000 bpd, 7.7 wt.\% biomass. 
From the table, capital expenditures comprise total capital cost (94\%), including engineering, procurement and construction (EPC) cost (77\%) and interest during construction (6\%). The EPC cost includes bare erected cost (BEC) and expenses on facilities and infrastructure. A contingency of $20 \%$ is added to the EPC cost to yield total capital cost. The total estimated capital investment for building the CBTL plant is about $\$ 5.9$ billion. Given that the CBTL facilities would represent a new generation of technology, the capital costs for such a large scale energy project can potentially increase significantly over the project time (Merrow, 2011).

Figure 2.1

Cash Flow from the CBTL Plant

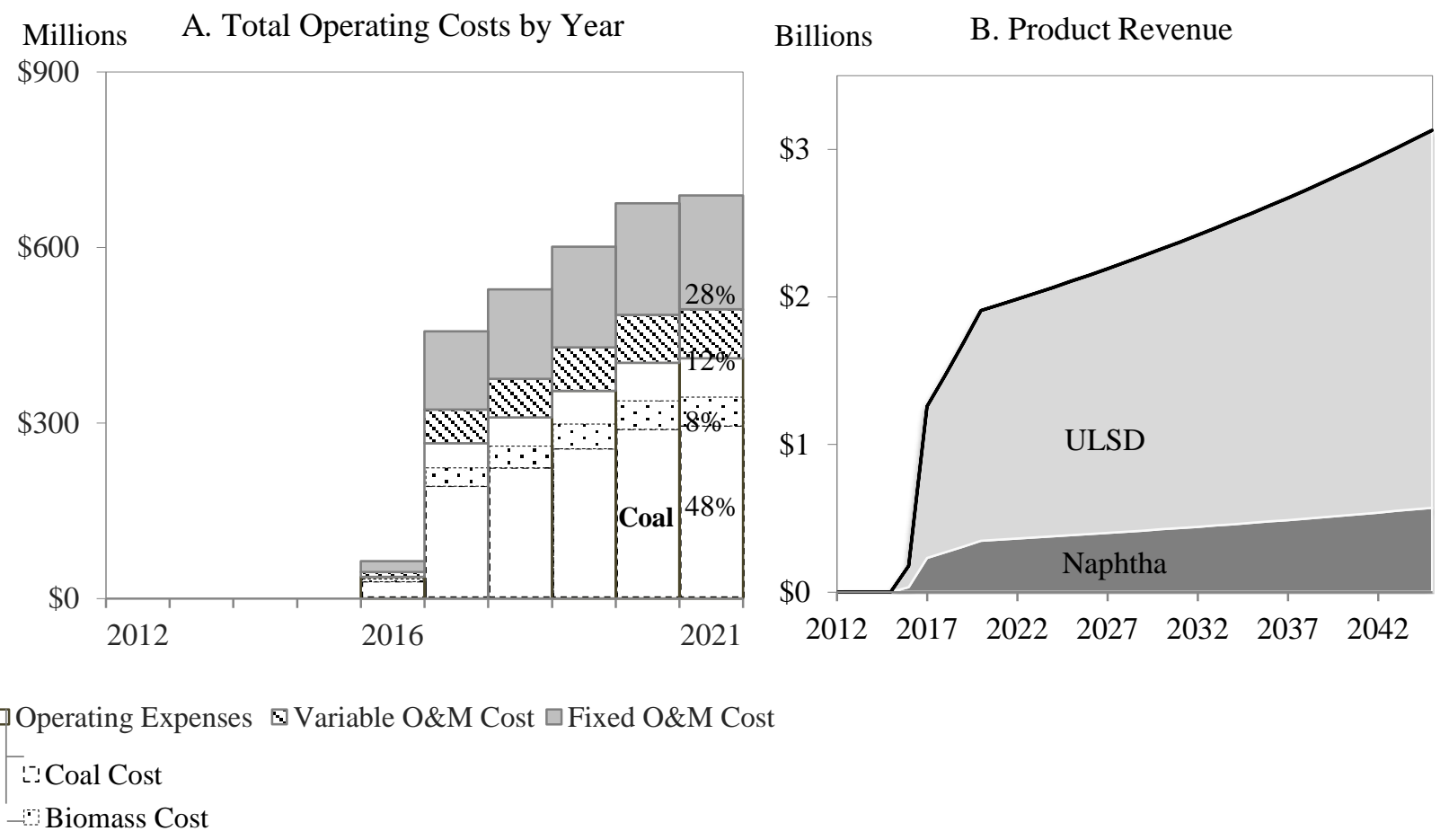


Panel A of Figure 2.1 shows that operating expenses are a major part of total operating costs (60\%), including the cost of coal (48\%) and biomass (8\%). The average total operating costs are estimated at $\$ 813$ million per year if operating at $89 \%$ of capacity. Panel B of Figure 2.1 shows that average operating revenues are about $\$ 1.9$ billion per year, $78 \%$ from ultra-low sulfur diesel (ULSD) and 22\% from naphtha.

Given capital expenditures, operating revenues and costs, the average $F C F F$ from operating the CBTL plant is estimated to be $\$ 193$ million per year. Discounted at 8\%, this cash flow yields a positive NPV of about $\$ 579$ million. Figure 2.2 illustrates the $F C F F$ and the NPV simulated profiles for the CBTL plant.

\section{Figure 2.2}

Free Cash Flow to the Firm and Net Present Value for the CBTL Plant
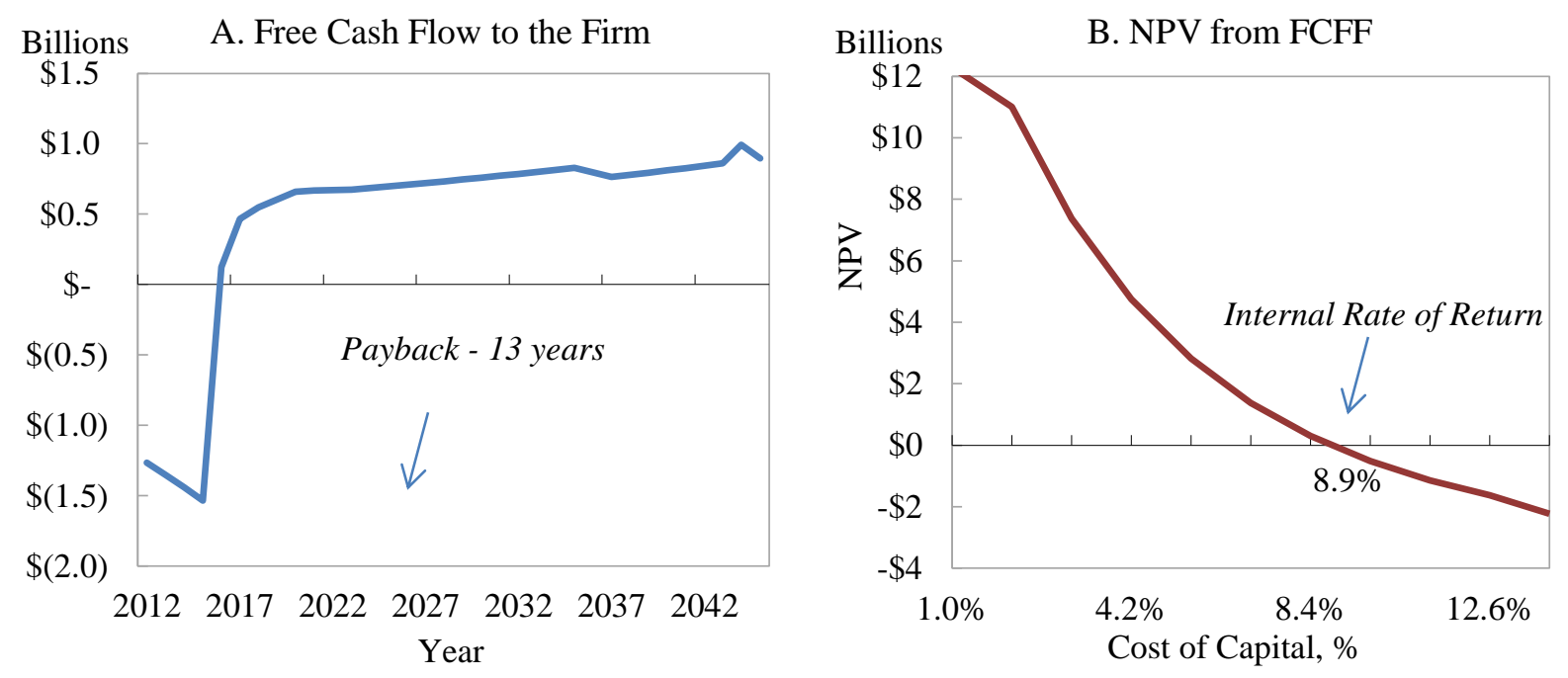

Panel A of Figure 2.2 indicates that the payback period is 13 years. Panel B of Figure 2.2 shows a relatively high sensitivity of NPV to the discount rate. The IRR, known as the expected economic rate of return, is $8.9 \%$. The probability index is 1.11 meaning that the investor can expect to earn about $\$ 1.1$ on every dollar invested in the CBTL plant. Overall, a 
positive NPV from the traditional DCF analysis suggests an acceptance of the CBTL project under stated assumptions.

Sensitivity analysis assesses the influence of the DCF variables on NPV. A sensitivity analysis for all economic variables is performed in the DCF to identify the critical variables and their effects on the NPV by changing variables ( $\pm 10 \%$ of the base value) in the DCF model.

Figure 2.3

Impact of major sensitive parameters $( \pm 10 \%)$ on NPV
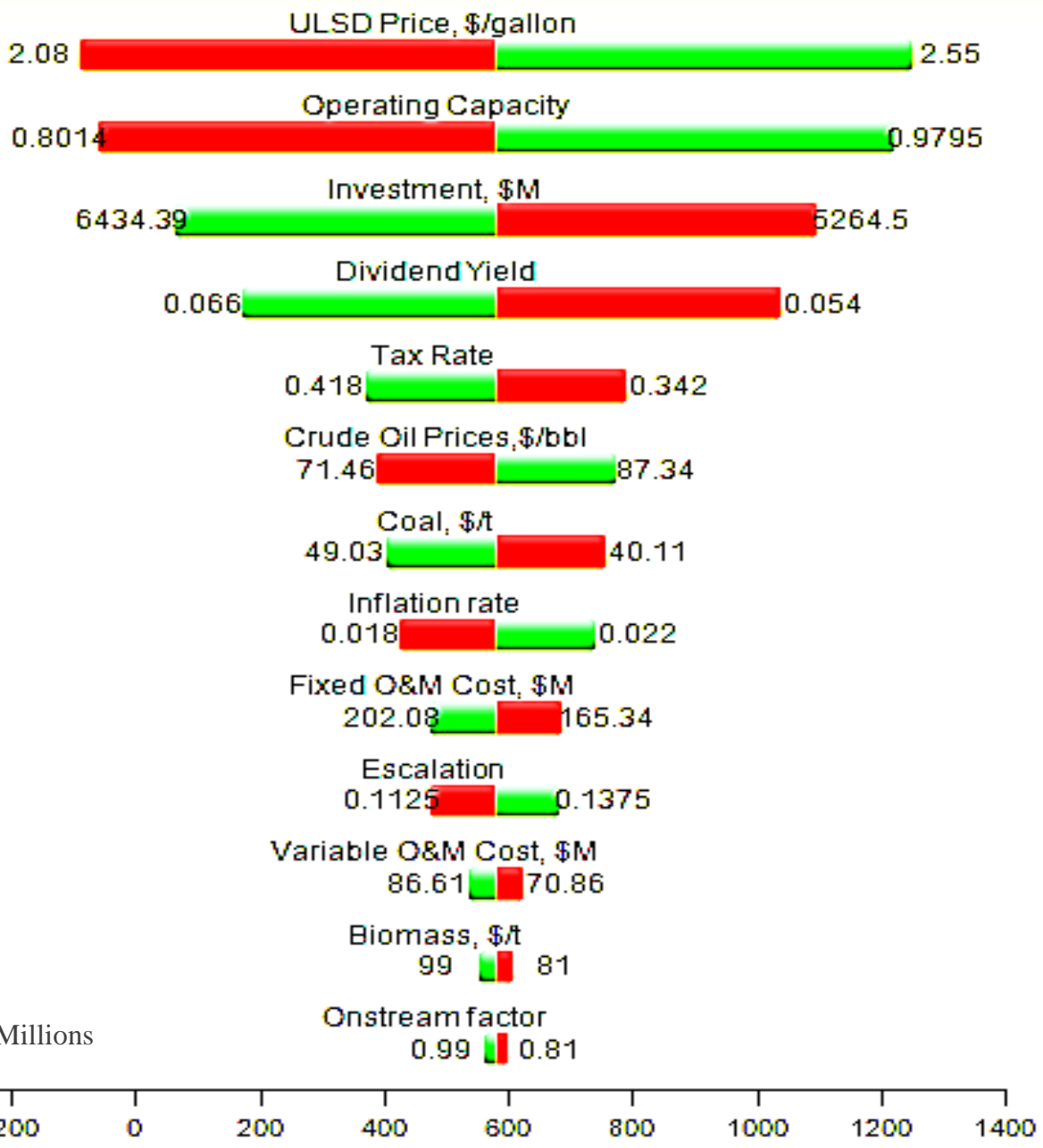

Figure 2.3 shows the effect of the primary sensitive variables in descending order for the change in NPV discounted at $8 \%$. The largest effects on the project NPV are attributed to the 
ULSD price, operating capacity, investments, dividend and other fuel prices. The bars on the right indicate a positive effect on the NPV, whereas the bars on the left show negative effects corresponding to an increase (green bar) or decrease (red bar) in the parameter. A $10 \%$ increase in capital expenditures reduces the project NPV by about $90 \%$. On the other hand, a $10 \%$ increase in the prices of output products increases twice the project NPV. The largest impacts of ULSD prices, operating capacity and capital expenditures on the NPV indicate at very large sensitivity of the NPV to those factors, which needs to be accounted in the economic analysis.

\subsubsection{Risk Assessment and Monte Carlo Simulation}

The risk assessment analysis examines the variability in the input variables for the most sensitive variables identified in the sensitivity analysis: fuel prices, operating capacity rate, investments and dividend rate. Historical data compiled by the EIA are used to estimate the extent of uncertainty for fuel prices and operating capacity. Where historical data are unavailable, a triangular distribution is employed. Less sensitive variables are not considered in this study, since they have a relatively small effect on the project NPV.

Table 2.2 shows selected variables and the estimates of the fitted distributions. The details on parameters estimation and distribution fitting are available in the conference proceedings accessible on-line (Kucher and Fletcher, 2011).

ULSD prices are available beginning in 2007. After performing distributional fitting of ULSD prices, the empirical distribution of lognormal 3 is selected for USLD prices with mean of $\$ 2.31$ and standard deviation of $30 \%$.

Crude oil prices reflect the value of the naphtha output. The distributional fitting of real prices of imported crude oil from 1949-2009 suggests a lognormal distribution with the standard 
deviation of annual crude oil prices of up to $45 \%$ from the mean. Similarly, a lognormal distribution is assigned to crude oil prices with a mean of $\$ 79.4$ per barrel based on the DCF analysis and a volatility of $45 \%$.

Table 2.2

Fitted Distribution Parameters for Input Variables

\begin{tabular}{llcc}
\hline Variable & Fitted Distribution & \multicolumn{2}{c}{ Distributional Assumptions } \\
\hline U.S. Ultra low sulfur diesel price, & Lognormal 3 & Mean & $\$ 2.31$ \\
\$/gallon & & St. Dev. & $30 \%$ \\
Coal price, \$/t & Lognormal & Mean & $\$ 44.6$ \\
& & St. Dev. & $35 \%$ \\
Crude oil price, \$/oil barrel (bbl.) & Lognormal 3 & Mean & $\$ 79.4$ \\
& & St. Dev. & $45 \%$ \\
Operating capacity rate & Gumbel Minimum & Alpha & 0.91 \\
& & Beta & 0.05 \\
Dividend rate & Triangular & Mean & 0.06 \\
& & Min & 0.05 \\
& & Max. & 0.07 \\
Capital expenditures, \$ billions & Triangular & Mean & $\$ 5.85$ \\
& & Min/Max. & $\pm 15 \%$ \\
\hline
\end{tabular}

Coal prices, as major input prices, significantly affect the NPV. The distributional fitting of real prices of bituminous coal over the 1949-2009 period yields a standard deviation of about $35 \%$. Similarly to crude oil prices, a lognormal distribution is employed with a mean of $\$ 44.60$ per short ton from the DCF analysis and a volatility of $35 \%$.

Because there are no commercial operating CBTL facilities, the U.S. petroleum refinery utilization rate is used as a proxy of operating rate for the CBTL project. The average refinery utilization rate over the period from 1949 to 2009 was $88.5 \%$, with a standard deviation of $6.3 \%$. Since the empirical distribution is negatively skewed, a Gumbel minimum distribution is fitted. 
CBTL capital expenditures are approximated with triangular distributions with a mean of $\$ 5.9$ billion and $\pm 15 \%$ change from the mean. The maximum investment is relevant to the NETL (2011) capital cost for the CTL plant, while minimum outlays could be due to technological improvement. The available estimates of capital investments for the projected CBTL facilities from the literature range from $\$ 1.1-\$ 1.4$ billion for a $10 \mathrm{k}$ bpd CBTL plant with $15 \%$ biomass by weight (Hileman et al., 2009) to $\$ 6.5$ billion for a 50k bpd CTL plant with CCS (NETL, 2011). The available estimates of capital expenditures for planned commercial CBTL projects vary from $\$ 4.5$ billion for a $30 \mathrm{kbpd}$ BCTL plant with CCS - Natchez Project (Rentech, 2008) to $\$ 5.5$ billion for a $53 \mathrm{kbpd}$ CBTL plant at Wellsville, Ohio (Baard Energy, 2007).

The dividend rate reflects the total rate of return on assets. Because this study considers a large-scale energy project, a dividend yield of $6 \%$ is assumed which also corresponds with the base value employed by NETL (2009). Note that this base level equals the average annual longterm return on common stock. As before, a triangular distribution with $\pm 15 \%$ change from the base is assumed to reflect uncertainty in the dividend rate.

Finally, this study specifies correlations among real prices of crude oil, diesel and coal over the 1979-2010 period. Fuel prices are highly positively correlated, with a correlation coefficient of 0.95 between crude oil and diesel prices. The correlation between diesel prices and coal prices is about 0.65 , and the correlation between oil prices and coal prices is 0.78 .

The distributional assumptions from Table 2.2 and fuel price correlations are used in a Monte Carlo simulation to derive volatility estimates of the CBTL payoff for real options valuation. Figure 2.4 shows the distribution of NPV and IRR values for the CBTL project. 
Figure 2.4

Net Present Value and Internal Rate of Return (4000 Iterations)

A. NPV, \$ millions

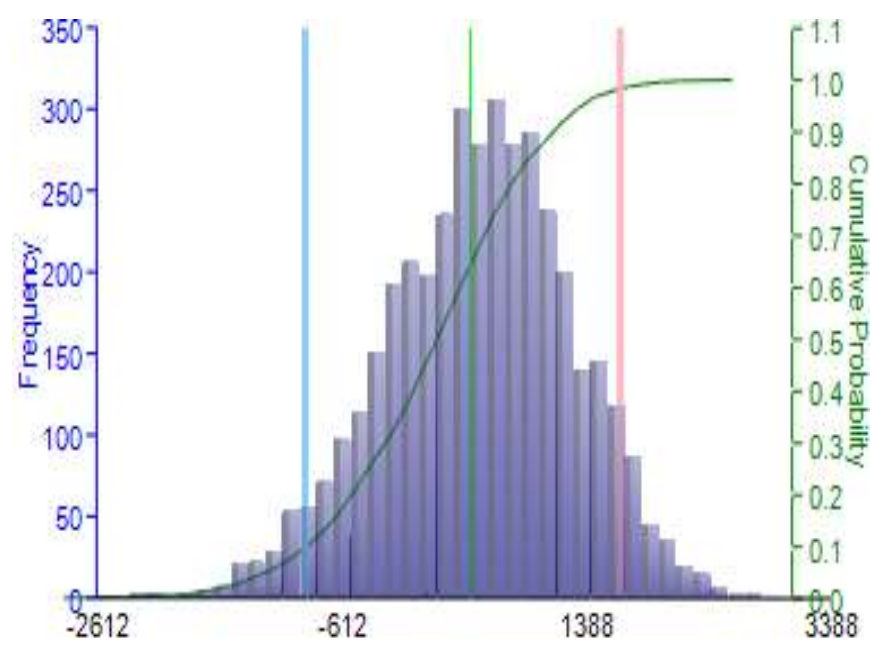

Type: Two-Tail, Lower: -907.21, Upper: 1670.87, Certainty: $90.0000 \%$
B. IRR

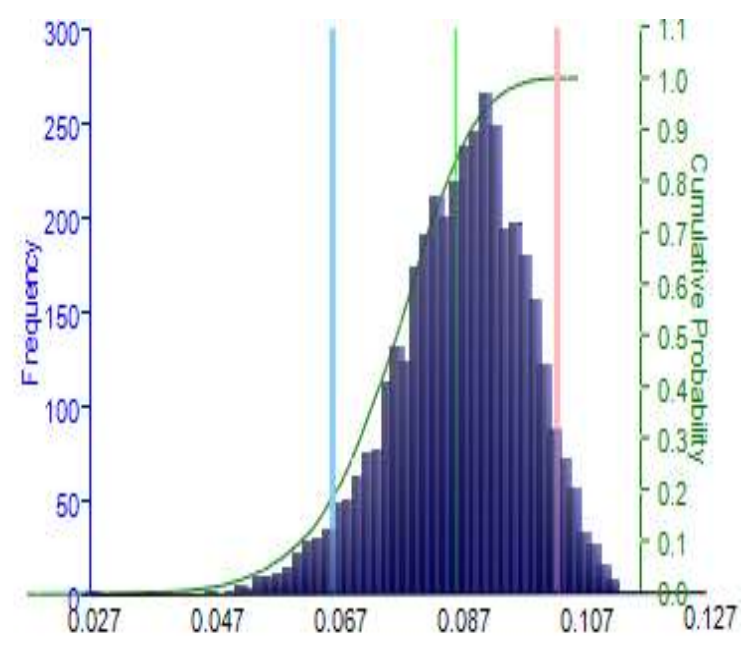

Type: Two-Tail, Lower. 0.07, Upper: 0.10, Certainty: $90.0000 \%$

The left panel of Figure 2.4 shows that the mean of the NPV is about $\$ 443.1$ million, $24 \%$ lower than the traditional NPV from the DCF. The right panel of figure 2.4 shows that the mean IRR is about $8.7 \%$, slightly lower than the IRR from the traditional DCF analysis. The $90 \%$ confidence interval for the NPV ranges from negative $\$ 0.6$ billion to $\$ 1.4$ billion. The probability that the CBTL project will a yield negative NPV is 0.23 .

Figure 2.5 presents the results of the Monte Carlo simulation of the free cash flow with corresponding descriptive statistics. The average present value of cash flow (FCF) is about $\$ 182.4$ million with a standard deviation of about $\$ 24$ million. The coefficient of variation, computed as (St.Dev.FCF/Mean FCF), is about 0.13 . This variation reflects the uncertainty in the variables. 
Figure 2.5

Present Value of Free Cash Flow (4000 Iterations)

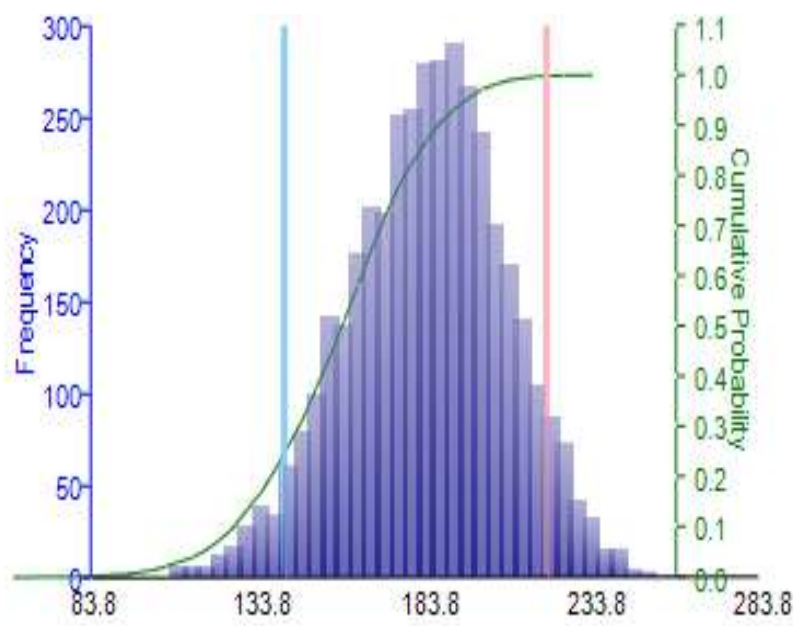

Series Statistics

Mean $\quad 182.41$

Median $\quad 183.71$

Standard Deviation $\quad 23.97$

Variance $\quad 574.41$

Coefficient of Variation $\quad 0.13$

Maximum 258.50

Minimum $\quad 81.08$

Skewness $\quad-0.26$

Kurtosis 0.15

Range $\quad 177.42$

Type: Two-Tail, Lower. 141.72, Upper. 220.21, Certainty: $90.0000 \%$

In summary, the simulation results show that ignoring uncertainty is likely to lead to overstating the NPV and free cash flows of the CBTL project. The lower mean of NPV obtained from the Monte Carlo simulation is still positive. The next section examines whether the project remains acceptable if one considers flexibility of investment decisions.

\subsubsection{Real Options Application}

The real options model is applied using the results from the DCF analysis and the Monte Carlo simulation to estimate the value of options to invest in the CBTL plant in the U.S. Table 2.3 shows input parameters for the real options model. Using a variance of $1.73 \%$, dividend rate of 0.06 and discount rate of 0.08 , provides the following parameter estimates: $\beta_{1}=2.456, A=$ $0.000000738005, V^{*}=\$ 8,770.2$ million. 
Table 2.3

Real Options Model Parameters for the CBTL Plant

\begin{tabular}{lr}
\hline Parameter & Base value \\
\hline$\rho$, discount rate & 0.08 \\
$\delta$, dividend rate & 0.06 \\
$I$, present value of capital expenditures, \$ millions & $\$ 5,199.5$ \\
$V$, present value of free cash flow, \$ millions & $\$ 5,778.5$ \\
NPV, \$ millions & $\$ 579.0$ \\
$\sigma$, volatility of present value of free cash flow, $\%$ & 13.14 \\
\hline
\end{tabular}

Figure 2.6 shows the value of options to invest in a CBTL plant.

Figure 2.6

Value of Investment Options for the CBTL plant in the U.S.

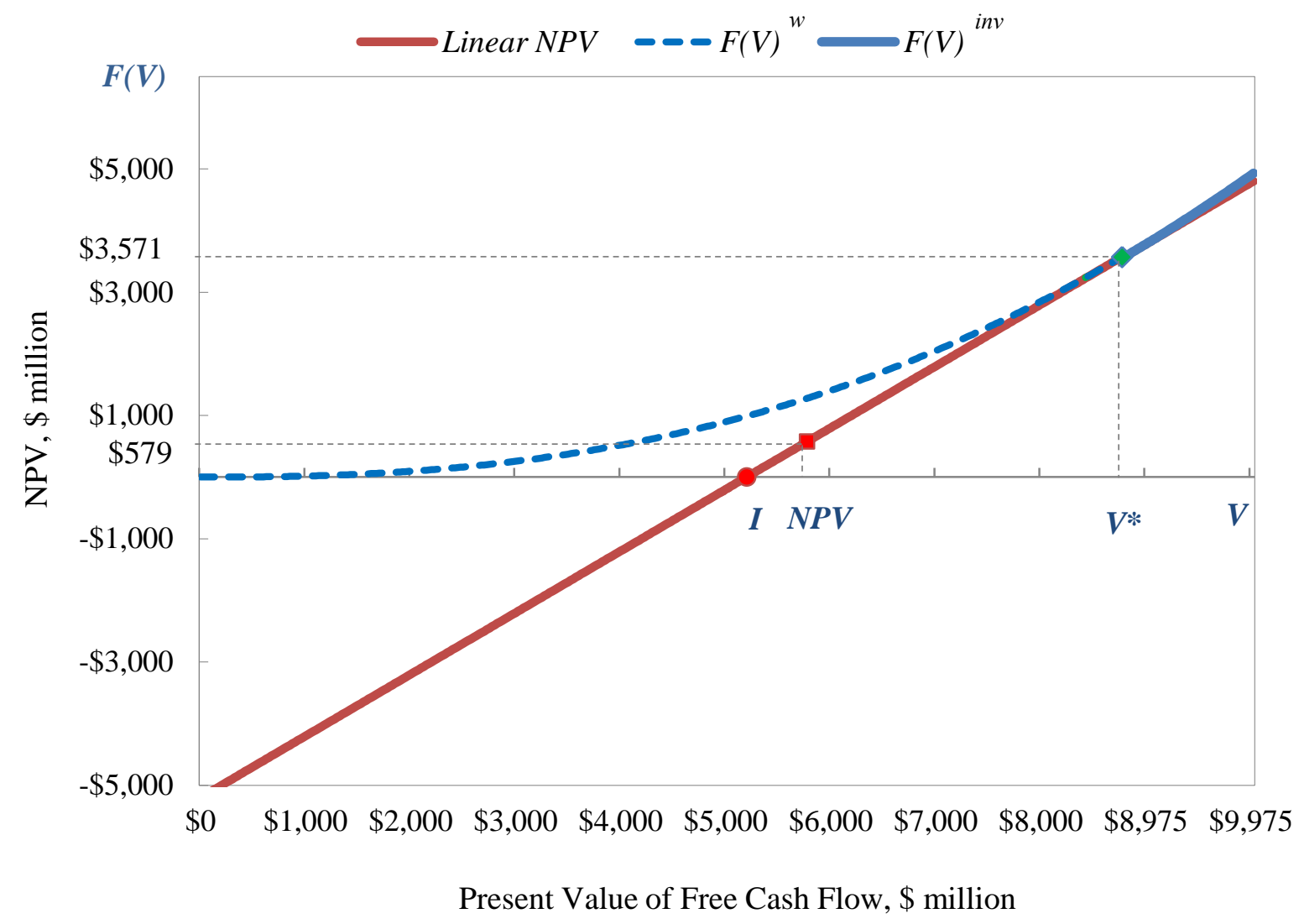


The vertical axis shows the expected payoff from investing in the CBTL plant, and the horizontal axis represents the present value of the free cash flow. The blue line is divided by the tangency point of trigger value $\mathrm{V}^{*}$ into two parts: the dotted line which shows the value option to wait, $F(V)^{w}$, and the continuous blue line which shows the value to invest, $F(V)^{i n v}$. The dark red line represents the NPV of the project, defined as $V-I$, where $V$ is the perpetual cash flow and $I$ is the fixed capital investment. The three dots on this line from bottom to top represent zero NPV, deterministic NPV from the DCF analysis and the value of investment options.

The value of the option to invest is about $\$ 3.6$ billion. This value exceeds the NPV from the DCF analysis by a factor of six. If the project NPV is below this optimal value, the investment in the new CBTL plant should be postponed. Correspondingly, the CBTL plant should be constructed if the PV of free cash exceeds the threshold $V^{*}$ of about $\$ 8.8$ billion.

\subsection{Conclusions}

CBTL technologies are viewed as a promising alternative to produce affordable transportation fuel from domestic feedstock with a compliant level of $\mathrm{CO}_{2}$ emissions. However, despite the technical feasibility of CBTL processes, there is little evidence of commercial viability for CBTL plants in the U.S. in the near-term given current uncertainties in fuel prices and costs. This analysis considers such uncertainty and shows that high capital expenditures of CBTL plants are the main barrier to construction of a large-scale CBTL plant in the U.S. Project payoff volatility increases the value of the option to delay construction of the CBTL plant.

The DCF analysis suggests that construction of a new CBTL plant with a capacity of 50,000 barrels per day using $7.7 \%$ biomass is expected to yield a payoff of about $10 \%$ of the total capital investments under current conditions. But does this payoff make CBTL feasible in the 
U.S. given the uncertainties in energy markets? Uncertainties regarding fuel prices and capital expenditures are estimated to lower the expected payoff from the project by $1 / 4^{\text {th }}$. Furthermore, with the flexibility of investment decisions, the project NPV needs to exceed the NPV from the DCF analysis by a factor of six in order to be an acceptable investment. The value of option to wait is estimated to be over $60 \%$ of the total capital expenditures for the CBTL plant. Despite a positive NPV, the real options analysis suggests deferring investment into CBTL plant until better economic conditions.

A precise evaluation of the economic feasibility of the CBTL project is a challenging task. These results should be interpreted with caution due to several limitations. This analysis is based on multiple technological and economic assumptions for a CBTL plant. The real options model relies on estimated volatility, as well as on fixed dividend yield and discount rate. While the analysis is affected by set of assumptions, the results point to a considerably higher level of option value to invest into a new CBTL plant than net present value.

The CBTL technology will need to be made substantially less costly, either through a reduction in capital expenditures or increased policy incentives such as low-carbon subsidies or carbon taxes. Advancing this technology to the level where it would be commercially viable in the near-term may help reduce capital expenditures of the CBTL plant. Other options might include adopting alternative plant configurations with better economies of scale, less expensive energy inputs, and creation of a better product mix. 


\section{Appendix A}

Parameters and Assumptions utilized in DCF analysis for CBTL $50 \mathrm{kbpd}$ with 7.7wt.\% biomass

\begin{tabular}{|c|c|c|c|}
\hline Parameter & Value & Unit Price & Assumption \\
\hline Life of project & 30 years & & The life of the project is 30 years (NETL, 2009). \\
\hline Construction period & 4 years & & Construction would be completed prior in four years. \\
\hline Base year & 2012 & & The base year for the CBTL plant construction is 2012 . \\
\hline Start-up year & 2016 & & The startup for the CBTL plant production is 2016 . \\
\hline Days of operation & 325 & & Operating period. \\
\hline Operating capacity & $89 \%$ & & Average capacity for petroleum refineries in the U.S. \\
\hline Onstream factor & $10-90 \%$ & & $\begin{array}{l}10 \% \text { of operating capacity in year one, } 70 \% \text { in year } \\
\text { two, } 80 \% \text { in year three, and } 90 \% \text { in year four. } \\
\text { The maximum output will be reached in the fifth year. }\end{array}$ \\
\hline \multicolumn{4}{|l|}{ Major Inputs } \\
\hline Coalfeed & 19948 tpd & $\$ 44.6$ & $\begin{array}{l}\text { The coal price is the delivered price of coal for electric } \\
\text { power in the U.S. in } 2010 \text { (2009 US\$ per short ton) } \\
\text { from the EIA "AEO 2011" Table "Coal Supply, } \\
\text { Disposition, and Prices, Reference Case" (EIA, 2011). }\end{array}$ \\
\hline Biomass feed & $1657 \mathrm{tpd}$ & $\$ 90.0$ & $\begin{array}{l}\text { The biomass feedstock cost is assumed to be roughly } \\
\text { twice the cost of coal. Duffy ( } 2007 \text { ) estimates the total } \\
\text { switchgrass cost from } \$ 80 \text { to } \$ 113.6 \text { per ton based on } \\
\text { various yield per acre in } 2007 \text {. }\end{array}$ \\
\hline Water & $11000 \mathrm{kgpd}$ & $\$ 1.08$ & Water cost per 1000 gallons (NETL, 2011). \\
\hline Chemicals & 30 tpd & $\$ 1000$ & Chemical cost per ton (NETL, 2011). \\
\hline Slag & 1909 tpd & $\$ 16.2$ & Disposal cost of slag per ton (NETL, 2011). \\
\hline \multicolumn{4}{|l|}{ Major Outputs } \\
\hline Diesel & $34292 \mathrm{bpd}$ & $\$ 97.2$ & $\begin{array}{l}\text { The ULSD price is } \$ 2.31 \text { per gallon based on N } 2 \\
\text { diesel retail sales by refiners in } 2010 \text { (EIA, 2010). I } \\
\text { multiply this price by } 42 \text { to obtain the price per barrel. }\end{array}$ \\
\hline Naphtha & $15708 \mathrm{bpd}$ & $\$ 61.1$ & $\begin{array}{l}\text { Naphtha is valued at } 77 \% \text { of the spot price of WTI } \\
\text { crude oil at } \$ 79.4 \text { per barrel in } 2010 \text { (NETL, 2007). }\end{array}$ \\
\hline Sulfur & 500 tpd & $\$ 36.3$ & $\begin{array}{l}\text { The unit price is } \$ 36.29 \text { per ton in } 2007 \text { from the U.S. } \\
\text { Geological Survey. }\end{array}$ \\
\hline \multicolumn{4}{|l|}{ Financial Parameter } \\
\hline Discount & $8 \%$ & & The discount of $8 \%$ exceeds $7 \%$ from NETL (2009). \\
\hline Dividend & $6 \%$ & & The dividend of $6 \%$ is assumed as part of the discount. \\
\hline Inflation & $2 \%$ & & $\begin{array}{l}\text { The annual inflation is } 2 \% \text {. Note, GDP price index is } \\
1.8 \% \text {, while CPI for energy commodities is } 2.9 \% \text { for } \\
2009-2035 \text { (U.S. EIA, 2011). }\end{array}$ \\
\hline Interest & $5.5 \%$ & & Interest during construction cost is assumed to be $5.5 \%$. \\
\hline Working capital & $7 \%$ & & Initial working capital set at $7 \%$ of first year revenue. \\
\hline Depreciation period & 20 years & & $\begin{array}{l}\text { Depreciation of capital expenditures is calculated over } \\
20 \text { years. }\end{array}$ \\
\hline
\end{tabular}




\section{Chapter 3}

\section{SPATIAL DEPENDENCE IN WHOLESALE GASOLINE MARKETS ACROSS THE UNITED STATES ${ }^{2}$}

\subsection{Introduction}

Gasoline prices are spatially dependent across states. Spatial dependence arises from a spatial interaction of geographic, economic and policy related factors in the gasoline markets determined by location, fundamentals and regulations. This study examines the spatial dependence in monthly wholesale gasoline markets across the 48 contiguous U.S. states over the period 1995-2006. Spatial effects are accounted for by modeling the spatially dependent wholesale gasoline prices ${ }^{3}$ conditional on exogenous gasoline market determinants across states. Specifically, I employ a spatial panel fixed effects approach to examine an impact of major gasoline content regulation, required by the Clean Air Act, on state wholesale gasoline price variables along with proxy variables for the gasoline inventories and refinery outages.

For the last two decades, researchers have intensively modeled the fundamental factors affecting the price for gasoline in the U.S. market (e.g. Borenstein and Shepard, 1996; Vita, 2000; Chouinard and Perloff, 2007). Gasoline supply-demand studies have always paid particular attention to the structural components of gasoline prices. At the same time, conventional panel fixed or random effect models rely on the hypotheses that elasticities are the same for all regions (Pirotte and Madre, 2009). The developed models have ignored the spatial

\footnotetext{
${ }^{2}$ I thank Donald Lacombe for help with spatial econometric applications, comments and suggestions. I thank Tancred Lidderdale and Win Gardner for suggestions on gasoline content regulation.

${ }^{3}$ The price charged for gasoline by the refiner or jobber (distributor supplier) to the retail gasoline station and large user (Karrenbrock, 1991).
} 
effects (or spatial interaction) that could result from the spatial dependence of gasoline prices across individuals and their location over time. If gasoline prices are spatially correlated among competitors across geographic space, as well as in a more general market space, then it is necessary to account for the spatial effects in gasoline markets.

Spatial effects play an important role in gasoline price determination. For example, when consumers purchase gasoline they consider these prices to be the outcome of a competitive market. When a local supply shock occurs (e.g. refinery outage), gasoline prices at the wholesale and retail levels are likely to change in the immediate vicinity area as well as in nearby areas. Thus, gasoline pricing is also influenced through spatial spillovers in the gasoline markets. On a regional level, gasoline prices might also be mutually dependent due to similar fuel supply marginal costs in the area. Moreover, location-specific factors generally reflect a common set of values held by producers and consumers which influence gasoline prices. Other spatially related characteristics could be transportation cost, distributions cost and the cost associated with pipelines, nearby terminals and other petroleum infrastructure. Therefore, it seems important to account for spatial effects in gasoline markets.

By employing spatial panel econometric techniques, this study accounts for spatial dependence in wholesale gasoline price variables and unobserved cross-section and time-period fixed effects. Under spatial dependence, I reexamine the impact of the gasoline content regulation on the stationary wholesale gasoline margin and wholesale gasoline price change. In addition, this study addresses the marginal effects associated with the inventory and refinery outages. Unlike other gasoline studies, I identify spatial spillovers in wholesale gasoline markets represented by direct and indirect price effects both in-state and out-of-state ${ }^{4}$. Estimates of the

\footnotetext{
${ }^{4}$ Direct and indirect effects are proposed by LeSage and Pace (2009), and developed by Elhorst (2010).
} 
direct and indirect effects of gasoline market determinants provide a richer information set for developing cross-section comparisons of parameter estimates.

This study makes several contributions to the literature. The most important contribution is the demonstration of spatial dependence within wholesale gasoline markets. I find that monthly gasoline prices are spatially dependent across contiguous states with a highly positive and statistically significant spatial autocorrelation of about 0.75 . Wholesale prices tend to be correlated across states with spatial differentiation across petroleum districts: gasoline is cheaper on the Gulf Coast, expensive on the West Coast and it priced at about the national average in the Midwest. I also observe spatial dependence in gasoline price determinants that arise from the spatial arrangement of gasoline markets.

Second, this study finds that proliferation of gasoline content regulation is likely to increase the wholesale gasoline margin in a state if reformulated gasoline (RFG) and oxygenated gasoline (OXY) are sold within the state. The regression results suggest that once the RFG and OXY programs have been implemented, the extension of the gasoline sales in the state under RFG and OXY fuel requirements have very little effect on state wholesale gasoline prices. This study also finds negative and statistically significant direct and indirect effects of inventories on wholesale gasoline margin and prices. The direct inventory effect in the state is about twice less than indirect effect from other states, suggesting that wholesale gasoline pricing is largely affected through inventories in other states. Finally, I find that the direct price effect associated with refinery outages is positive and significant. This result suggests that a reduction in refinery utilization rate below 85 percent positively impact prices within the state.

The following sections provide a review of the relevant literature; describe a reducedform price model; describe the data and key variables; outline the spatial panel econometric 
approach, and discuss empirical results from the regression analysis. The last section discusses the conclusions derived from the analysis.

\subsection{Related Literature}

Recent econometric studies attempt to explain fluctuations in gasoline prices by modeling changes in gasoline market determinants. The common model for regional price analysis is the linear panel data model in which the dependent variable, gasoline prices (usually in log form) is estimated as a function of the explanatory gasoline market variables assumed to be exogenous, i.e., independent of the error term. Researchers commonly ignore spatial effects in the panel models, omitting the presence of spatial effects on gasoline prices across different jurisdictions. An important strand of the literature investigates the effect of the fundamentals on gasoline prices. Borenstein and Shepard (1996) find evidence of tacitly collusive behavior in gasoline retail market. They estimate the price equation with a complex lag structure using Ordinary Least Squares (OLS) and Two-Stage Least Squares (2-SLS) regression analysis of monthly retail and terminal (wholesale) gasoline prices, crude oil prices and gasoline sales in 43 U.S. cities during the 1986-1991 period. Vita (2000) finds that the "divorcement" regulation increases gasoline prices, on average, by about 2.6 cents per gallon using a reduced form price equation estimated using a Feasible Generalized Least Squares procedure and cross-sectional monthly variables for the period January 1995 - December 1997.

Chouinard and Perloff (2007) determine the effects of various fundamental variables on the variation of the retail and wholesale gasoline price levels (in log form) across the 48 contiguous U.S. states for the period January 1989 - July 1997. They employ a reduced-form price model to a panel of crude oil prices, taxes and mergers along with other demand and supply 
shifters. Doyle and Samphantharak (2008) find significant short run effects of a gasoline tax moratorium on daily gasoline prices in Illinois and Indiana in 2000 by using OLS and a difference-in-differences approach to the reduced form price equation. Lewis (2009) finds that spikes in wholesale prices of gasoline associated with a hurricane event have long lasting effects on retail gasoline prices using an OLS regression of the retail prices over the months conditional on variation in the wholesale costs after hurricanes and the retail margins across cities. Klier and Linn (2009) focus on vehicle sales response to gasoline prices and gasoline taxes using a reduced form linear equations model. Burke and Nishitateno (2013) estimate low long-run price elasticity of gasoline demand using IV estimation to a panel of 132 countries during 1995-2008.

Other papers examine the impact of gasoline content regulations on gasoline prices. Muehlegger (2006) estimates the price effect of ethanol-blended RFG and California reformulated gasoline regulation conditional on refinery outage in California, Chicago and Milwaukee of about 4 cents per gallon. Brown et al. (2007) estimate marginal effects of Reformulated Gasoline (RFG), the Oxygenated Gasoline (OXY) and Reid Vapor Pressure (RVP) programs on the wholesale price, of about 3 cents per gallon using weekly panel data for treatment cities for the 1994-1998 period. They use a treatment and control approach to the panel of the wholesale price levels for unbranded gasoline in each regulated city as the function of the unbranded gasoline price levels in the neighboring unregulated cities, dummy variables for the type of fuel content regulation and the number of gasoline suppliers in the treatment cities.

Chakravorty et al. (2008) find that the wholesale gasoline price would increase by about 16 percent if a state with no regulation would impose the regulation to the whole state. They model the price effects using Three-Stage Least Squares (3-SLS) for the full six-equation model with annual data across the 48 contiguous U.S. states from 1995-2002. 
While the above studies use sound methodological approaches to estimate the economic effects on gasoline prices based on commonly accepted assumptions, the researchers ignore spatial effects in gasoline markets. The present study extends the previous panel data analyses by studying the spatial effects between observations which might take the form of a spatial autoregressive process or spatial error correction in gasoline markets. Even though the panel fixed effect model accommodates spatial heterogeneity to a certain degree by using dummy variables for each spatial unit, the problem remains as to whether the spatial dependence can or cannot be captured completely by the intercepts (Elhorst, 2010). In the presence of spatial autocorrelation between the observations, OLS estimates could systematically underestimate the effects due to the inefficiency, inconsistency and biasedness (Anselin et al., 2008; LeSage and Pace 2009; Elhorst, 2010).

\subsection{Model and Data}

Heterogeneous gasoline prices are determined by gasoline markets through the interaction of supply and demand. Assume that spatial dependence in gasoline markets is influenced by spatial autocorrelation in the dependent variable, between determinants or in the error term which exhibit effects on the gasoline prices from neighboring observations. Figure 3.1 shows that wholesale gasoline prices differ across states. The difference between the lowest wholesale gasoline price in Louisiana and the highest gasoline price in Idaho is, on average, about $\$ 0.21$ per gallon as of 2010 . 
Figure 3.1

Regular Wholesale Gasoline Prices by State, 2010

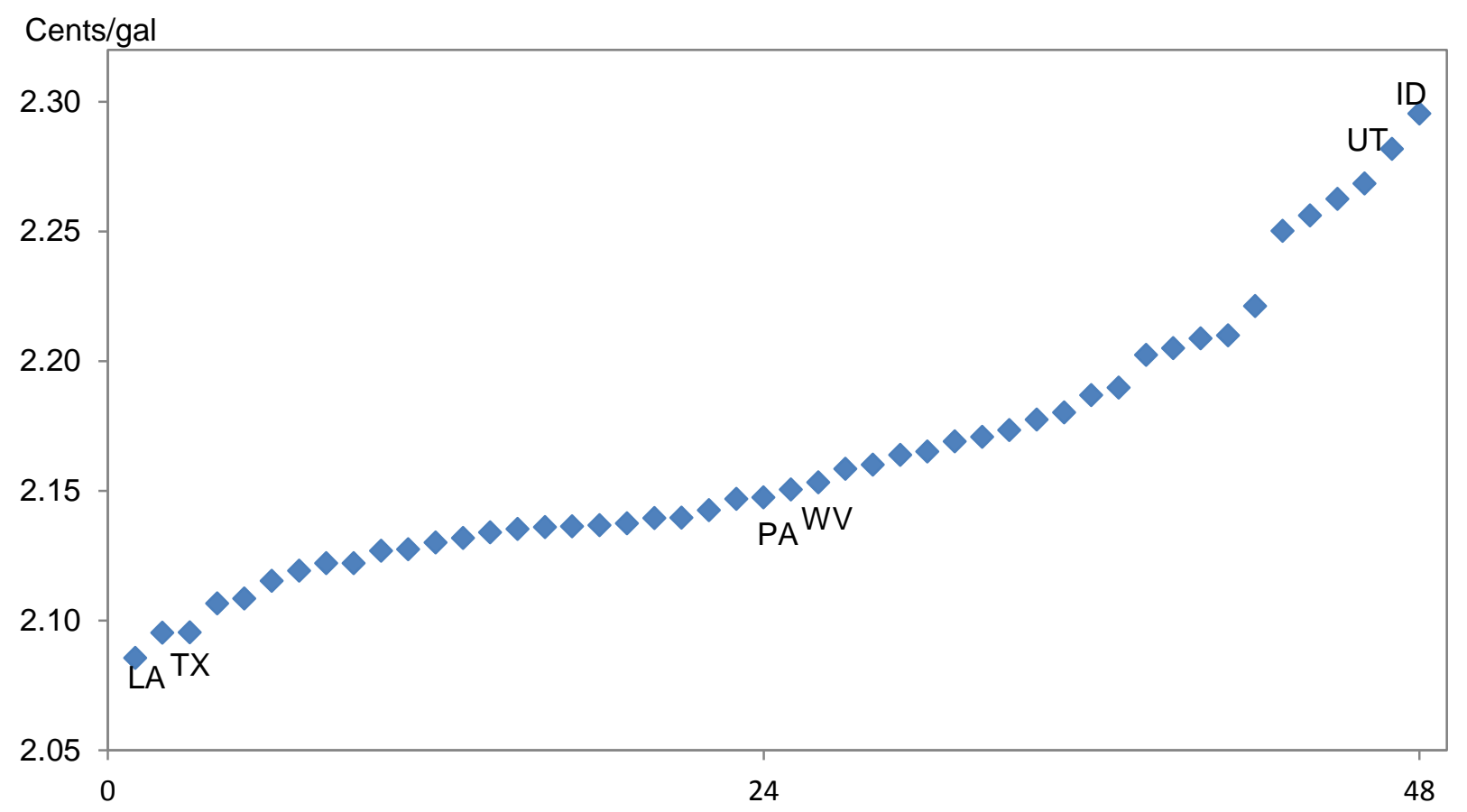

Figure 3.2 displays an apparent spatial pattern of average wholesale gasoline prices:

gasoline is cheaper in neighboring states on the Gulf Coast with the largest refinery capacity and expensive in the neighboring states on the West Coast with large refinery capacity in California. 
Figure 3.2

Regular Wholesale Gasoline Price Pattern across States, $2010^{5}$

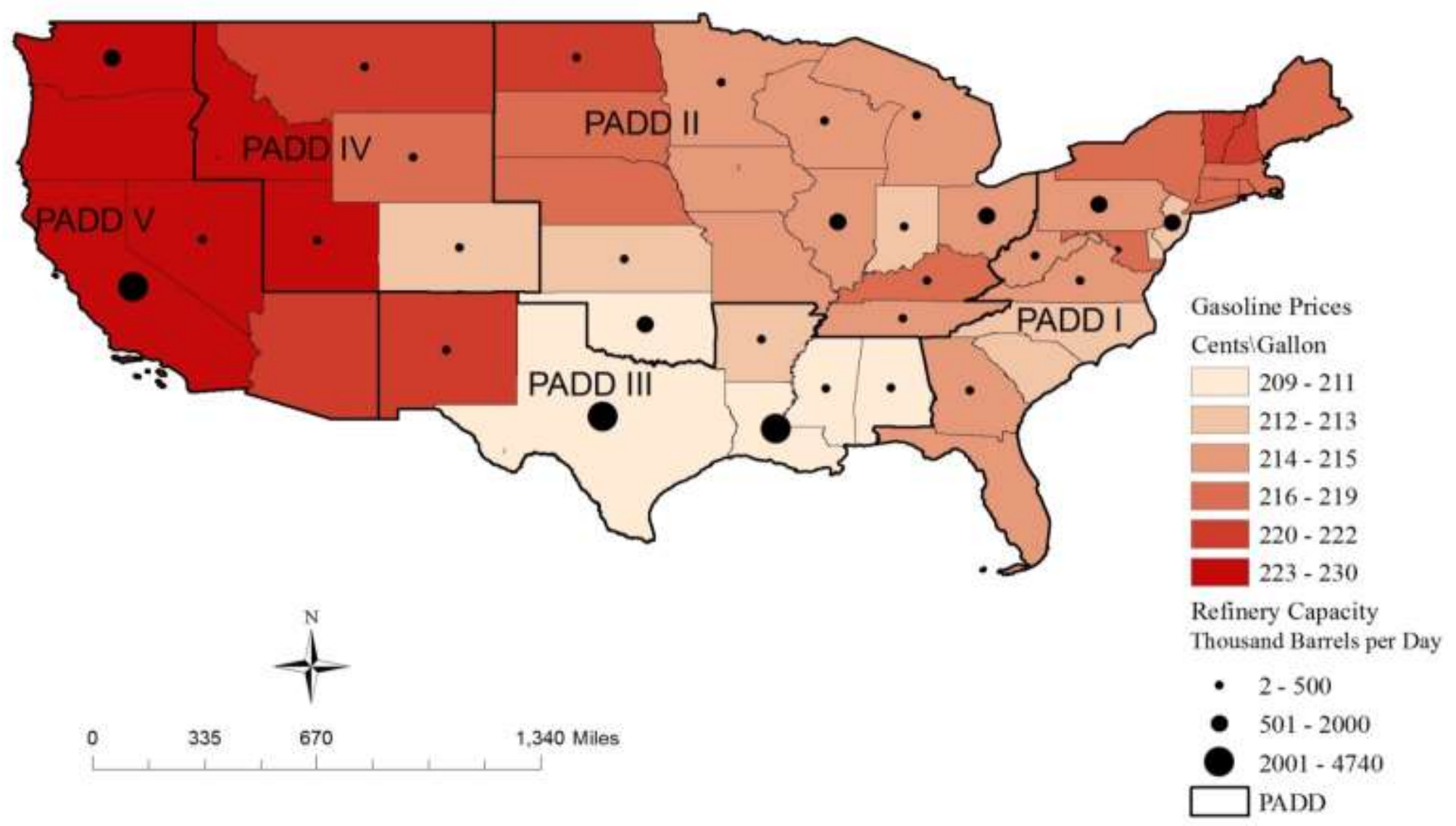

\footnotetext{
${ }^{5}$ I thank Nazia Arbab for the assistance with this figure.
} 
An analysis of Figure 3.3 indicates that monthly average wholesale gasoline prices have similar patterns across the five Petroleum Administration for Defense Districts (PADD) over time. As noted, wholesale gasoline prices tend to be highest on the West Coast (PADD 5), lowest in the Gulf Coast (PADD 3) and about at the national average in the Midwest (PADD 2).

Figure 3.3

Regular Gasoline Wholesale/Resale Price for All Sellers, 1995-2006

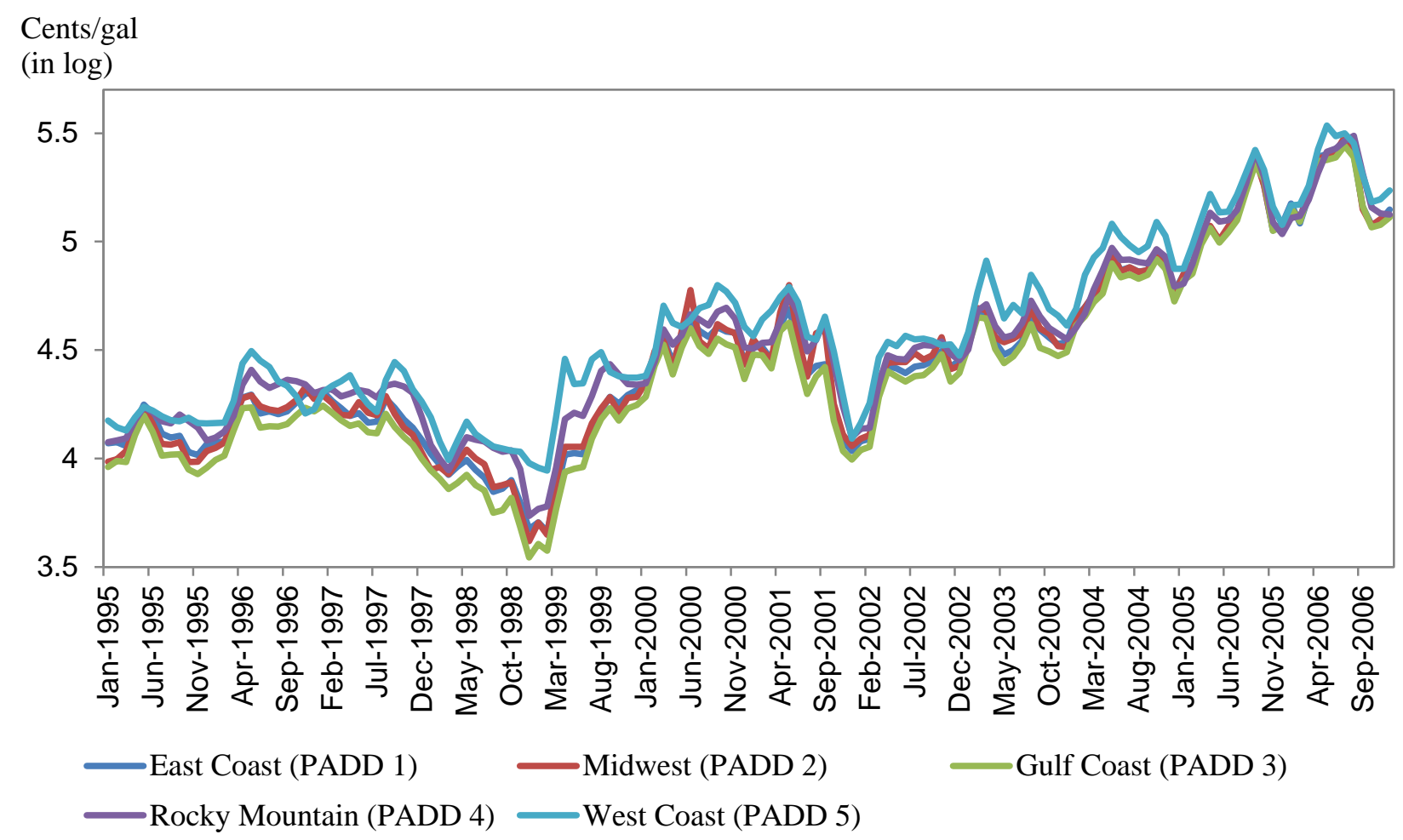

An analysis of the date behind Figure 3.3 shows that the peak prices occur in the late spring, summer and the early fall in response to high demand during driving season. Fuel supply disruptions and refinery outages also influence prices. For instance, the last price jumps of 2005 and 2006 are associated with two hurricanes, Katrina and Rita in August and September of 2005, 
and with limitations of gasoline supply after Methyl Tertiary Butyl Ether (MTBE) removal in May of $2006^{6}$.

\subsubsection{A Reduced-Form Price Model}

Measuring gasoline price effects through classical structural supply and demand models is impractical due to the lack of substantial variation in fundamental variables (Chouinard and Perloff, 2007). Thus, I employ a reduced-form price model that has been widely utilized (e.g., Vita, 2000; Chouinard and Perloff, 2007; Chakravorty et al., 2008).

Let the market price for gasoline in spatial unit $i$ at time $t$ be given by $P_{i t}$. Let $X_{i t}$ represent the exogenous demand-supply shifters and regulation effects. Because the demand and supply shifts over time due to changes in petroleum prices and other characteristics in petroleum markets, the market price, $P_{i t}$, adjusts to equate supply and demand over time, such that the observed price is directly related to the gasoline price determinants, as:

$$
P_{i t}=f\left(X_{i t}\right) \quad(i=1,2 \ldots N ; t=1,2 \ldots, T)
$$

In general, the wholesale gasoline price represents costs to produce gasoline by refineries. Thus, hypotheses regarding the wholesale gasoline price refer to changes in the cost shifters. In the reduced form model, such shifters typically include the crude oil price, storage cost, and other variables. I account for the balance of supply-demand shifters by using gasoline inventory levels as a proxy for storage cost. In addition, I account for refinery outages which cause supply disturbances through reductions in gasoline production. Refinery outages have a major impact on

\footnotetext{
${ }^{6} \mathrm{MTBE}$ is a compound of methanol and isobutylene. It was used as a fuel additive in gasoline from $1992-2006$. MTBE can no longer be used in gasoline in the U.S. due to liability concerns.
} 
regional gasoline production and, therefore, directly affect wholesale gasoline prices in the state and neighboring states.

For the regulation effects in wholesale gasoline markets, I consider gasoline content regulations including the Reformulated Gasoline (RFG) Program and the Oxygenated Gasoline (OXY) Program. These programs require the use of reformulated and oxygenated gasoline ${ }^{7}$ in designated state $\operatorname{areas}^{8}$. Reformulated gasoline was required to be used in ozone nonattainment areas beginning in 1995, while oxygenated gasoline has been required in carbon monoxide nonattainment areas since 1992 . As of 2006, RFG gasoline was sold in 20 states throughout the year, while the oxygenated gasoline was sold in 7 states during winter months. Sales of reformulated gasoline constitutes, on average, about $30 \%$ of total motor gasoline sales, while oxygenated gasoline makes up about $3 \%$ of total sales.

Many states and local jurisdictions have voluntarily enrolled in clean fuel programs to reduce emissions of smog-forming and toxic pollutants such as benzene and carbon monoxide. Since some state areas have enrolled in the RFG and OXY programs while other jurisdictions have withdrawn from the programs since 1995, state sales of the reformulated and oxygenated gasoline vary over time. This outcome might cause spatial and temporal variations in the production cost of gasoline. Therefore, the price implications for these gasoline programs depend on the time periods in which the RFG and OXY programs have been in effect, and the state designated areas enrolled in these programs. Depending on the time period and segmentation of

\footnotetext{
${ }^{7}$ The gasoline content regulation standards are mandated by the EPA and regional regulators. The minimum standards require that RFG must contain $2.0 \%$ oxygen by weight. The OXY must contain at least $2.7 \%$ oxygen, typically achieved by addition of $7.5 \%$ ethanol in the control areas with exception of California which currently has a waiver to meet $1.8 \%$ to $2.2 \%$ oxygen [EPA].

${ }^{8}$ The list of areas under RFG and OXY programs is available at: http://www.epa.gov/otaq/gasoline.htm
} 
the state designated areas, the gasoline content regulations have been typically shown to increase gasoline prices.

Apart from fundamental shifters and regulation, the wholesale price determination is also influenced by spatial price interaction among market areas. I account for the spatial interaction in the empirical analysis by modeling the spatial dependence within wholesale gasoline markets.

\subsubsection{Data and Key Variables}

Monthly panel data for wholesale gasoline prices, crude oil prices (refiner acquisition cost), sales of reformulated and oxygenated gasoline, gasoline inventories and refinery utilization rates were collected and sorted by states and by month using data obtained from the website of the U.S. Energy Information Administration". The sample includes data on the 48 contiguous states for the January 1995 through December 2006 period. The end date is constrained by the availability of the data covering reformulated and oxygenated gasoline sales.

Wholesale gasoline price reflects the marginal cost of gasoline supply by refineries prior to blending. I use average monthly U.S. regular motor gasoline wholesale/resale ${ }^{10}$ price (in cents per gallon) by state excluding federal, state or local excise or sales taxes. The largest part of the wholesale gasoline price is the cost of crude oil. For the price of crude oil I use the weighted average monthly refiner acquisition cost of the composite (domestic and imported) crude oil (in cents per gallon) within the PADD ${ }^{11}$. The acquisition cost is derived by dividing the sum of the total purchasing (acquisition) costs of all refineries by the total volume of all refiners' purchases.

\footnotetext{
${ }^{9}$ The petroleum data are available at: http://www.eia.gov/petroleum/data.cfm

${ }^{10}$ Resale sales are sales of gasoline to purchasers who are other-than-ultimate consumers.

${ }^{11}$ The data for the composite acquisition cost of crude oil by PADD before 2004 is not available. Instead, the national composite refiner acquisition cost in the U.S. is used before 2004.
} 
The wholesale gasoline price and crude oil price are adjusted for inflation using Consumer Price Index (in real 2007\$).

To measure the price effect of the gasoline content regulation, this study uses the prime supplier sales volumes of reformulated regular gasoline and oxygenated regular gasoline sold into local markets of final consumption by state (in thousands of gallons per day) $)^{12}$. Previously, Chakravorty and Nauges (2005) and Chakravorty et al. (2008) used the proportion of a state's population that resides within areas covered by environmental programs. I take advantage of the spatial and temporal variation of the monthly sales of the reformulated gasoline in each state by estimating the market shares of reformulated gasoline as a proportion of reformulated and oxygenated gasoline to the total gasoline sales in each state. Those market shares are direct proxies for the cost effect resulting from proliferation of environmental regulation in the state. The larger the market shares under the RFG and OXY programs, the bigger the regulated market for clean gasoline and, hence, the higher the wholesale gasoline price.

To measure the price effect of the inventory, we use inventory level data for finished motor gasoline stock of conventional gasoline, oxygenated and reformulated gasoline from refinery, bulk terminal, and natural gas plant stocks (in thousands of barrels) by state. The normalized detrended inventory (in log form) is used following Gorton et al. (2012) as, $\operatorname{In} v_{i t}=\ln \left(I_{i t} / I_{i t}^{*}\right)$, where $I_{i t}$ is the gasoline inventory in state $i$ at the end of the month $t$ and $I_{i t}^{*}$ is the trend in the gasoline inventory estimated with the Hodrick-Prescott filter.

Finally, to measure the price effect from refinery outages, I use data on the operable utilization rate of atmospheric crude oil distillation units (in percent), derived by dividing the gross input to distillation units by the operable calendar day refining capacity of the units. Using

12 The U.S. EIA no longer publishes data for sales of oxygenated gasoline separately from data covering reformulated gasoline. Oxygenated gasoline data were published through the end of 2006. 
this utilization rate we compile a dummy variable with a value of one if the monthly refinery operable utilization rate in each state is below $85 \%$ and zero otherwise. Summary statistics of the variables are reported in Table 3.1.

\section{Table 3.1}

Summary Statistics

\begin{tabular}{|c|c|c|c|c|c|c|c|c|}
\hline \multirow[t]{2}{*}{ Variables } & \multirow[t]{2}{*}{ Mean } & \multirow[t]{2}{*}{ S.D. } & \multirow[t]{2}{*}{ Skewness } & \multirow[t]{2}{*}{ Kurtosis } & \multirow[t]{2}{*}{ Obs. } & \multicolumn{3}{|c|}{ Panel Unit Root Tests } \\
\hline & & & & & & LLC & IPS & ADF-Fisher \\
\hline Wholesale Price of & 4.7 & 0.3 & 0.4 & 2.8 & 6912 & 5.3 & 3.9 & 28.3 \\
\hline \multicolumn{9}{|l|}{ Gasoline (log) } \\
\hline Price of Crude Oil (log) & 4.3 & 0.4 & 0.2 & 2.7 & 6912 & 5.2 & 6.0 & 17.2 \\
\hline Wholesale gasoline & 0.38 & 0.11 & 0.68 & 3.58 & 6912 & $-2.9 *$ & $-14.5^{*}$ & $427.2^{*}$ \\
\hline margin $(\log )$ & & & & & & & & \\
\hline$\Delta$ Wholesale Price of & 0.005 & 0.089 & -0.24 & 4.04 & 6864 & $-11.9 *$ & $-44.4^{*}$ & $1946.2 *$ \\
\hline \multicolumn{9}{|l|}{ Gasoline (log) } \\
\hline RFG Index & 0.20 & 0.34 & 1.47 & 3.66 & 6912 & $-2.0 * *$ & $-2.0 * *$ & $28.6^{*}$ \\
\hline OXY Index & 0.04 & 0.14 & 0.27 & 1.91 & 6912 & $-1.4 * * *$ & -16.6 & $212.6^{*}$ \\
\hline Log Normalized & -0.02 & 0.24 & -4.38 & 55.13 & 6834 & $-10.0^{*}$ & $-28.3^{*}$ & $1033.6^{*}$ \\
\hline Inventory & & & & & & & & \\
\hline
\end{tabular}

The sample period is from January 1995 through December 2006. Wholesale gasoline margin is computed as the difference between the wholesale gasoline price and crude oil price in natural logarithm. The null hypothesis for Panel Unit Root Tests: Unit root. The lag orders are automatically selected along with the Andrews or Newey-West method for bandwidth selection. *, ** denote significance at $1 \%, 5 \%$, $10 \%$ level respectively. Fisher statistics is based on Chi -square distribution.

Each data series is tested for the presence of an unit root using the panel tests of Levin, Lin and Chu (LLC), Im, Pesaran and Shin (IPS), and Fisher. The statistics of LLC, IPS and Fisher tests are shown in the last three columns of Table 3.1. The statistics of panel unit root tests for gasoline and crude oil price levels in natural logarithm deviate systematically from the long run mean of their time series over the sample period.

The correct estimation procedure requires dealing with stationary determinants. I focus on price stationary variables, the wholesale gasoline margin and the wholesale gasoline price 
change. The wholesale gasoline margin is computed as the difference between the wholesale gasoline price (in log form) and the crude oil price (in log form) for each state over each month. Because the margin directly depends on the wholesale gasoline price, the inference on its relation with other determinants directly correspond with the wholesale gasoline price. The wholesale gasoline margin also measures the economic performance in the refining industry. The wholesale gasoline price change is computed as the first difference of monthly wholesale gasoline prices (in $\log$ form). Both measures are stationary at the $1 \%$ level of statistical significance.

Table 3.1 shows that wholesale gasoline margins and wholesale gasoline price changes are moderately volatile, with standard deviations ranging from $3 \%$ to $11 \%$. The RFG and OXY indexes vary from 0 to 1 with the mean of 0.2 and 0.04 respectively across states. The normalized inventory variable is stationary at the $1 \%$ significance level with zero mean and standard deviation of 0.24 . The next section addresses the specific empirical price model extended to allow for the presence of spatial effects in gasoline markets.

\subsubsection{The Empirical Model}

I depart from a panel fixed effects model for the reduced-form gasoline price equation after Chakravorty et al. (2008) as follows:

$$
y_{i t}=X_{i t}^{\prime} \beta+\alpha_{i}+\lambda_{t}+u_{i t} \quad(i=1,2 \ldots N ; t=1,2 \ldots, T)
$$

where $y_{i t}$ is a vector of observations on the dependent variable (e.g. gasoline prices), $X_{i t}$ is the matrix of the exogenous variables (e.g. supply-demand shifters, regulation impact), $\beta$ is a vector of regression coefficients, $a_{i}$ are state-specific fixed effects (intercepts) that vary 
across states, $\lambda_{t}$ are yearly-time fixed effects (intercepts) that affect all states simultaneously and $u_{i t}$ is an idiosyncratic error terms for each individual at time $t$ with zero mean.

In order to account for the possibility of spatial effects in the gasoline markets, a panel fixed effects model can be extended into a general spatial panel fixed effects model, as follows:

$$
\begin{aligned}
& y_{i t}=X_{i t}^{\prime} \beta+\alpha_{i}+\lambda_{t}+\delta \sum_{j=1}^{N} W_{i j} y_{j t}+\sum_{j=1}^{N} W_{i j} X_{i j t} \gamma+u_{i t} \quad(i, j=1, \ldots, N ; i \neq j) \\
& u_{i t}=\rho \sum_{j=1}^{N} W_{i j} u_{i t}+\varepsilon_{i t}
\end{aligned}
$$

where $\delta, \rho$ are spatial autoregressive parameters, $W_{i j}$ is a nonstochastic and positive spatial weights matrix of constants with zero diagonal elements which describe the spatial arrangement of units between locations of cross-section $i$ and $j$, and $\gamma$ is a vector of regression coefficients on the spatially-weighted $X_{i t}$ variables, and other variables are as previously defined.

Kalendoski and Lacombe (2012) point out that by restricting the spatial autoregressive parameters $\delta, \rho$ and coefficients $\gamma$ on the spatially-weighted variables, the general spatial panel fixed effects model can be transformed into a family of spatial panel fixed effects models, including spatial autoregressive (SAR) model when both $\rho=0$ and $\gamma=0$, a spatial error (SEM) model when both $\delta=0$ and $\gamma=0$, and a spatial Durbin model (SDM) when $\rho=0$. A justification for using the SAR, SEM and SDM panel models is provided by Anselin (1988), Anselin et al. (2008) and Elhorst (2010), among others. Anselin et al. (2008) discuss spatial panel econometric models with both fixed and random spatial individual effects. Elhorst (2010) utilizes spatial panel data models which include panel spatial SAR, SEM and SDM.

To better account for the spatial effects through proper spatial arrangements in wholesale gasoline markets, I use a five nearest neighbor's weights matrix in which each row elements sum 
equals to one. The choice of the weight matrix is determined by regional distribution of the petroleum regions ${ }^{13}$. Each regions contains infrastructure integrated by location, transportation and markets to meet petroleum supply and demand. Regarding the fact that neighboring subregions of PADD 1 and the regions of PADD3, PADD4, and PADD5 include on average five states, I assume that a five-nearest-neighbors weight matrix will closely represent geographic aggregations of the 48 contiguous states within PADD districts.

If wholesale gasoline prices are spatially dependent across states, the panel SAR model will reflect the spatial autocorrelation in the wholesale gasoline prices. If observed gasoline prices are affected by omitted variables spatially correlated in gasoline markets, the panel SEM model results might reflect spatial autocorrelation in the error term. Such unobservable locationspecific factors can reflect transportation or pipeline infrastructure distribution costs. If spatially dependent gasoline prices are influenced by spatial interaction of gasoline market determinants, the panel SDM model will capture the spatial autocorrelation in dependent variables and spatial autocorrelation in spatially weighted explanatory variables.

Each of the spatial panel models may include cross-sectional and time-period fixed effects. The intuition behind fixed effects is that the wholesale gasoline prices can be influenced by unobservable state fixed effects which vary across states but remain constant for each state over time. For example, a substantial portion of petroleum distribution infrastructure across states is fixed and does not vary over time. The inferences of time-period fixed effects reflect the average time effects of unobservable influences across all states. In gasoline markets, the time-

\footnotetext{
${ }^{13}$ Historically, the U.S. territory is divided into five U.S. PADDs: PADD1 - East Coast, PADD2 - Midwest, PADD3 - Gulf Coast, PADD4- the Rockies, and PADD5-West Coast (geographic distribution is also shown at Figure 2.2). PADD1 is further divided in sub-regions: with PADD1A as New England, PADD1B as the Central Atlantic States and PADD1C comprising the Lower Atlantic States.
} 
invariant effects may be reasonable under timely fixed changes in taxes, petroleum and transportation infrastructure, and gasoline regulation.

I estimate panel regressions for the wholesale gasoline margin and the wholesale gasoline price changes in two steps. First, I perform diagnostic tests for the model selection and second, estimate the selected models. For diagnostic tests, I perform several Lagrange Multiplier (LM) tests, the Hausman Testand Likelihood Ratio (LR) tests under maximum likelihood estimation. After determination of the spatial effects, the spatial LM tests allows selection of the appropriate SAR or SEM models for the empirical analysis by comparing of the significance of the spatial lag or spatial error term. The Hausman test is performed to determine relevance of the fixed effects model versus random effects model. Based on the results of the Hausman test, our empirical analysis narrows to the specification of the spatial panel fixed effects model. Next, the Likelihood ratio (LR) test is carried out to investigate the significance of cross-section and timeperiod fixed effects. Finally, the extended LR test is performed to test for the possibility of the SDM model (Elhorst, 2010). The null hypothesis $\mathrm{H}_{0}: \gamma=0$ examines whether the spatially weighted explanatory variables are spatially correlated. A rejection of this hypothesis suggests that the SDM model is appropriate for thedata generating process. Detailed discussion of specification testing along with the routine procedure in Matlab for spatial panel models can be found in Elhorst (2010 a,b) and Lacombe (2010).

\subsection{Results}

Table 3.2 presents results from regression analysis (panel A) and diagnostic tests (panel B) for the wholesale gasoline margin regressed on proxies for the gasoline content regulation, the gasoline inventory and dummy variable for refinery outages. 
Table 3.2

Regression Results for the Wholesale Gasoline Margin (in Log)

\begin{tabular}{|c|c|c|c|c|c|c|}
\hline & \multicolumn{3}{|c|}{ Panel Fixed Effects Estimates } & \multirow{2}{*}{\multicolumn{3}{|c|}{$\begin{array}{c}\text { Spatial Panel Fixed Effects Estimates } \\
\text { SDM Two-Way }\end{array}$}} \\
\hline & \multirow[t]{2}{*}{ Cross-section } & \multirow[t]{2}{*}{ Time-Period } & \multirow[t]{2}{*}{ Two-Way } & & & \\
\hline & & & & Direct & Indirect & Total \\
\hline \multicolumn{7}{|l|}{ Panel A. $(N=6912)$} \\
\hline OXY index & $\begin{array}{l}\mathbf{- 0 . 0 9} * * * \\
(0.03)\end{array}$ & $\begin{array}{l}\mathbf{0 . 1 4} * * * \\
(0.009)\end{array}$ & $\begin{array}{l}\mathbf{0 . 0 2} * * * \\
(0.001)\end{array}$ & $\begin{array}{l}\mathbf{0 . 0 3 5} * * * \\
(0.006)\end{array}$ & $\begin{array}{l}-\mathbf{0 . 0 6 *} \\
(0.03)\end{array}$ & $\begin{array}{l}-0.02 \\
(0.003)\end{array}$ \\
\hline RFG index & $\begin{array}{l}\mathbf{- 0 . 0 5 * * * *} \\
(0.01)\end{array}$ & $\begin{array}{l}\mathbf{0 . 0 2} * * * \\
(0.003)\end{array}$ & $\begin{array}{l}0.001 \\
(0.004)\end{array}$ & $\begin{array}{l}\mathbf{0 . 0 0 6 *} \\
(0.004)\end{array}$ & $\begin{array}{l}0.02 \\
(0.003)\end{array}$ & $\begin{array}{l}0.03 \\
(0.03)\end{array}$ \\
\hline $\begin{array}{l}\text { Log Normalized } \\
\text { Inventory }\end{array}$ & $\begin{array}{l}-\mathbf{- 0 . 0 2 *} \\
(0.01)\end{array}$ & $\begin{array}{l}-\mathbf{0 . 0 1} * * * \\
(0.004)\end{array}$ & $\begin{array}{l}\mathbf{- 0 . 0 0 5 *} \\
(0.02)\end{array}$ & $\begin{array}{l}-\mathbf{0 . 0 2} * * * \\
(0.002)\end{array}$ & $\begin{array}{l}-\mathbf{0 . 0 5} * * * \\
(0.01)\end{array}$ & $\begin{array}{l}-\mathbf{0 . 0 6} * * * * \\
(0.01)\end{array}$ \\
\hline $\begin{array}{l}\text { Refinery Outage } \\
\text { Dummy }\end{array}$ & $\begin{array}{l}-\mathbf{0 . 0 2 *} \\
(0.01)\end{array}$ & $\begin{array}{l}-0.008 \\
(0.005)\end{array}$ & $\begin{array}{l}\text { 0.008**** } \\
(0.04)\end{array}$ & $\begin{array}{l}\mathbf{0 . 0 0 7} * * \\
(0.002)\end{array}$ & $\begin{array}{l}0.01 \\
(0.008)\end{array}$ & $\begin{array}{l}\mathbf{0 . 0 2} * \\
(0.009)\end{array}$ \\
\hline$\delta$ & & & & & & $\begin{array}{l}\mathbf{0 . 7 8} * * * \\
(0.007)\end{array}$ \\
\hline $\begin{array}{l}\text { Adj. } R^{2} \\
\text { Corr }^{2}\end{array}$ & 0.19 & 0.68 & 0.84 & & & $\begin{array}{l}0.92 \\
0.01\end{array}$ \\
\hline \multicolumn{7}{|l|}{ Panel B. Diagnostic Tests } \\
\hline LM Lag & $219.1 * * *$ & $382.2 * * *$ & $7.6^{* * * *}$ & & & \\
\hline LM Error & 0.3 & 0.06 & $18.0 * * *$ & & & \\
\hline Robust LM Spatial Lag & & & & & & $2465.6 * * *$ \\
\hline Robust LM Spatial Error & & & & & & $351.5 * * *$ \\
\hline LR Spatial Lag & & & & & & $29.5 * * *$ \\
\hline LR Spatial Error & & & & & & $22.0 * * *$ \\
\hline
\end{tabular}

The table shows the estimated effects of the wholesale gasoline margin to content gasoline regulation, the gasoline inventory and inventory outages. The sample period is from January 1996 to December 2006. The response coefficients are estimated using panel fixed effects model and spatial panel fixed effects model. The coefficients of the panel fixed effects dummies are not reported. Standard errors are shown in parentheses. ***,*** indicate statistical significance at $10 \%, 5 \%$, and $1 \%$ levels, respectively. 
The standard LM tests statistics indicate the presence of spatially lagged dependent variables and spatially autocorrelated error terms (LM: 7.6 and 18.0, p-value $<0.01$ ), with inclusion of spatial and time-period fixed effects. Based on robust LM tests statistics values, I reject the null hypothesis of no spatially lagged dependent variables and no spatially autocorrelated error terms at a one percent statistical significance level for two-way fixed effects panel model (LM: 2465.6 and 351.5, p-value<0.01). The LR tests statistics on joint significance of the cross-section fixed effects (LR: 4620.73, df 48, $p$-value<0.01) and time-period fixed effects (LR: 1120.35, df 144, p-value<0.01) reject the null hypothesis of joint insignificance for these effects at a one percent level. Therefore, both state- and month-fixed effects are included in the models. Finally, the LR test statistics (LR: 29.49, p-value<0.01) leads to a rejection of the null hypothesis that $\gamma=0$. This result implies that the SDM cannot be simplified to the SAR model. Similarly, the Wald test (W: 28.84, p-value<0.01) leads a rejection of the null hypothesis $\gamma=0$ at a one percent statistical significance level, pointing to the selection of the spatial Durbin model.

For comparison, I report the estimation results from the non-spatial panel fixed effects models and SDM panel two-way fixed effects model. In the non-spatial panel fixed effects regressions, the coefficients on the gasoline content regulation variables vary in terms of sign, significance and magnitude. Specifically, estimates of OXY and RFG indexes in the crosssection fixed effects regression are negative and statistically significant at $1 \%$ level. These coefficients are positive in time-period- and two way fixed effects models. Similarly, the dummy variable measuring the refinery outage has a negative and significant coefficient in cross-section fixed effects models, a positive and insignificant coefficient in time-period fixed effects 
regression, and a positive and significant estimate in two-way fixed effects models. Thus, nonspatial panel fixed effects coefficients are non-robust.

The SDM results indicate that there is a relatively large level of spatial autocorrelation in the wholesale gasoline margin variable, with the $\delta$ parameter equal to 0.78 , statistically significant at $1 \%$ level. This result supports our hypothesis of spatial dependence in wholesale gasoline markets. Without accounting for spatial autocorrelation the standard panel estimates are likely to be inconsistent.

In the presence of spatial autocorrelation, the parameter estimates in SDM panel fixed effects model are separated into direct and indirect effects or spillover effects rising from feedback effects within state (direct effect) and from neighboring states (indirect effects) ${ }^{14}$. The direct effects of the OXY and RFG indexes are 0.035 and 0.006. In line with the evidence, this means that an increase in the market share under OXY and RFG program from 0 to 1 will increase the wholesale gasoline margin on average by about $1 \%$ in a state ${ }^{15}$. Because I focus on the wholesale gasoline margin, coefficients cannot be compared with the estimates in Chakravorty et al., (2008). In addition, this study finds that the spillover effect estimate for the OXY index is -0.06 , marginally significant at $10 \%$ level with a p-value of 0.083 . It suggests that wholesale gasoline margins in adjacent states are likely to decrease by about $1 \%$ with production of oxygenated gasoline in a neighboring state.

The direct and indirect effects of gasoline inventories are negative and statistically significant at the $1 \%$ level. The corresponding estimates for gasoline inventories are about -0.02 and -0.05 , respectively. The direct and spillover effects' interpretation is that a $10 \%$ increase in

\footnotetext{
${ }^{14}$ Direct effect is an impact of changes in independent variable on the dependent variable at a location. Indirect effect is an effect of changes in independent variable in other locations on the dependent variable in their own location. Total effect is the sum of the direct and indirect effects (LeSage and Pace, 2009).

${ }^{15}$ In case of OXY index: $\mathrm{e}^{0.035}=1.036$ and $\mathrm{e}^{0.006}=1.006$ for the RFG index.
} 
the gasoline inventory in a state will decrease the wholesale gasoline margin on average by about $0.2 \%$ within the state, and by about $0.5 \%$ from the change in the gasoline inventory in neighboring states. These findings are particular relevant for those states which depend upon other states for their gasoline supply, including those states which have no petroleum refineries. Taking into account that over ninety percent of gasoline consumed in the U.S. is produced in 139 refineries in 28 states, and supplies primarily depend on the established petroleum infrastructure, the spillover effects might have economically larger impact on the wholesale gasoline market in surrounding states. Furthermore, the point estimate for the total effect of the gasoline inventory on wholesale gasoline margin is -0.06 , statistically significant at $1 \%$ level. Combining direct and spillover effects, the total effect shows that on average a decline in the gasoline inventory by $10 \%$ causes wholesale gasoline margin to increase by $0.6 \%$.

The remaining estimates of the effects of refinery outage dummy are positive when spatial autocorrelation is taken into account. The direct effect estimate is about 0.007 , statistically significant at $1 \%$ level. The total effect estimate is about 0.02 , statistically significant at $10 \%$ level of significance. This suggests that, if refinery utilization rate decreases below $85 \%$, the wholesale gasoline margin will increase on average by about $0.02 \%$. A refinery outage impact on the state's gasoline market has a relatively small positive effect on the wholesale gasoline margin throughout the states but this monthly effect is rather limited. Because the wholesale gasoline price is the main determinant of the wholesale gasoline margin, the gasoline inventory and refinery outages directly affect the wholesale gasoline prices. A more general discussion is presented below in the wholesale gasoline price change estimation.

In terms of goodness of fit, the $\mathrm{R}^{2}$ is about $92 \%$ which is largely explained by the crosssection and time-period fixed effects. The squared correlation coefficient between actual and 
fitted values is 0.01 . In comparison with overall model fit of SDM two-way fixed effects, the spatial autoregressive parameter on dependent variable and coefficients on the spatially-weighted variables explain approximately $8 \%$. Thus, the fixed effects explain about $83 \%$ of the overall fit.

Panel A of Table 3.3 presents results for wholesale gasoline price changes. The diagnostic tests results for the model selection are reported in Panel B of Table 3.3.

Table 3.3

Regression Results for the Wholesale Gasoline Price Change (in Log)

\begin{tabular}{|c|c|c|c|}
\hline \multirow[b]{3}{*}{ Panel A (6912) } & \multicolumn{3}{|c|}{ Spatial Autoregressive Panel Time Fixed Effects Estimates } \\
\hline & Direct & Indirect & Total \\
\hline & & & \\
\hline OXY index & $\begin{array}{l}\mathbf{0 . 0 0 5 *} \\
(0.003)\end{array}$ & $\begin{array}{l}\mathbf{0 . 0 1 1} * \\
(0.007)\end{array}$ & $\begin{array}{l}\text { 0.016* } \\
(0.009)\end{array}$ \\
\hline RFG index & $\begin{array}{l}0.0005 \\
(0.001)\end{array}$ & $\begin{array}{l}0.0011 \\
(0.002)\end{array}$ & $\begin{array}{l}0.0015 \\
(0.003)\end{array}$ \\
\hline $\begin{array}{l}\text { Log Normalized } \\
\text { Inventory }\end{array}$ & $\begin{array}{l}\mathbf{- 0 . 0 0 3 *} \\
(0.001)\end{array}$ & $\begin{array}{l}\mathbf{- 0 . 0 0 7 *} \\
(0.003)\end{array}$ & $\begin{array}{r}\mathbf{- 0 . 0 1 0 *} \\
(0.005)\end{array}$ \\
\hline $\begin{array}{l}\text { Refinery Outage } \\
\text { Dummy }\end{array}$ & $\begin{array}{l}0.001 \\
(0.001)\end{array}$ & $\begin{array}{l}0.002 \\
(0.003)\end{array}$ & $\begin{array}{r}0.003 \\
(0.004)\end{array}$ \\
\hline$\delta$ & & & $\begin{array}{l}\mathbf{0 . 7 5}^{* * * *} \\
(0.008)\end{array}$ \\
\hline $\begin{array}{l}\text { Adj. } \mathrm{R}^{2} \\
\text { Corr }^{2}\end{array}$ & & & $\begin{array}{r}0.92 \\
0.001\end{array}$ \\
\hline Panel B. Diagnostic Tests & & & \\
\hline Robust LM Spatial Lag & & & $10.77 * * *$ \\
\hline Robust LM Spatial Error & & & 1.34 \\
\hline LR Spatial Fixed Effect & & & $\begin{array}{l}5.85 \\
48 \text { d.f. }\end{array}$ \\
\hline LR Time Fixed Effect & & & $\begin{array}{l}\text { 12540.5*** } \\
144 \text { d.f }\end{array}$ \\
\hline LR Spatial Lag & & & 4.71 \\
\hline
\end{tabular}

The table shows the estimated effects of the wholesale gasoline price change (in log) to the proxies for the content gasoline regulation, the gasoline inventory and inventory outages. The response coefficients are estimated using SAR panel time- fixed effects model. The coefficients of the panel time-fixed effects dummies are not reported. Standard errors are shown in parentheses. *,**, *** indicate statistical significance at $10 \%, 5 \%$, and $1 \%$ levels, respectively. 
As before, the LM test results suggest that the spatial model is a more appropriate specification as is the non-spatial model. The robust LM test rejects the null hypothesis of no spatial lag in the panel two-way fixed effects model (LM: 10.77, $p$-value<0.01). The LR test result rejects the null hypothesis that the time period fixed effects are jointly insignificant (LR: 12540.52 d.f. 144, $p$-value<0.01). However, the test fails to reject the null hypothesis that the cross-section fixed effects are jointly insignificant (LR: 5.85, d.f. 48, p < 0.01). This evidence justifies the SAR time-period fixed effects model for the empirical estimation. Furthermore, the results of Wald test (W: 4.47, p-value 0.35 ) and LR test (LR: 4.71, p-value 0.32 ) indicates that the null hypothesis that $\gamma=0$ cannot be rejected. Therefore, the SDM should be simplified to the SAR model.

The results from the SAR model support a high level of spatial autocorrelation in the wholesale gasoline price change, with $\delta$ parameter equals 0.752 , statistically significant at $1 \%$ level. In other words, the spatial autocorrelation parameter indicates at the presence of spatial dependence in wholesale gasoline price changes across states. This is a noteworthy result because it suggests that spatial effects are present in dynamic wholesale gasoline markets and therefore should be considered in the gasoline price analysis. In other words, changes in wholesale gasoline prices in the state depend on changes in wholesale gasoline prices in neighboring states.

SAR panel fixed estimates for the wholesale gasoline price changes suggest that the gasoline content regulation doesn't play a significant role in gasoline price change within the state (direct effect) and outside from neighboring states (indirect effect). The total effect for OXY index is about 0.016 , statistical significance at $8.5 \%$ level. The regression results for reformulated gasoline effects show no statistically significant impact of RFG index on wholesale 
gasoline price change. This suggests that the requirement to produce reformulated gasoline has relatively low impact on the gasoline price change in the state with other things equal.

The estimation results indicate a negative and statistically significant relationship between the gasoline inventory and wholesale gasoline price change. A $10 \%$ decrease in the gasoline inventory increases the difference in wholesale gasoline price by about $0.1 \%$. The indirect effect of the gasoline inventory on wholesale gasoline price change is relatively large, suggesting that spillovers may greatly affect the wholesale gasoline markets from neighboring states. At the same time, there is no evidence that the wholesale gasoline price change increase with the decline in the refinery utilization rate. Because of the limitations of the data, our empirical analysis indicates that, on average, there is no statistically significant impact of a dummy proxy for refinery outage on the wholesale gasoline price change.

\subsection{Conclusions}

This study examines the presence of spatial effects in wholesale gasoline markets. Using a panel of monthly data on wholesale gasoline margin and price changes, I find the presence of spatial dependence and spatial spillovers in the monthly wholesale gasoline markets across the 48 contiguous states over the $1995-2006$ period. The spatial effects contain important information on wholesale gasoline price determination in state gasoline markets.

In the presence of spatial dependence, I find that wholesale gasoline margins increase by about $1 \%$ on average if a regulated area under the RFG and OXY programs were extended to the whole state. The magnitude of the effect of the OXY and RFG programs implies that they have little impact on statewide wholesale gasoline price changes. The evidence for gasoline inventories is particularly strong because both wholesale gasoline margins and price changes 
respond to gasoline inventories directly and indirectly in predicted directions - wholesale margin and prices tend to increase when the gasoline inventory declines within state and in neighboring states. Recognizing this, large gasoline suppliers and retailers might consider the gasoline inventory moves in their own state as well as neighboring states. 


\section{Chapter 4}

\section{ENERGY PRICES, INVENTORY AND THE BUSINESS CYCLE ${ }^{16}$}

\subsection{Introduction}

This study examines the variation of spot and futures prices of energy commodities over the business cycle. The theory of storage originated by Working $(1933,1949)$ links the difference between futures and spot prices, also called the basis, with costs and benefits of carrying inventory. According to the modern view of the theory of storage, when commodity inventory is low and the marginal benefit of holding inventory (known as convenience yield) is high, the basis tends to be negative, i.e. the futures price is below the spot price. This market condition is known as backwardation. ${ }^{17}$ In contrast, when inventory rises and the convenience yield falls, the basis tends to be positive, i.e. the futures price is above the spot price. This condition is called contango. ${ }^{18}$

Understanding the relation between spot and futures prices of energy commodities is crucial to economic agents in energy markets. For example, if the crude oil market is in backwardation, oil companies are likely to increase production (Litzenberger and Rabinowitz, 1995). A shift to contango increases the benefits of holding inventory. Furthermore, when the crude oil market is in backwardation, commodity futures investors and speculators with long futures positions earn positive returns from rolling over their positions. This so-called "roll return" becomes negative when prices exhibit contango. Therefore, it is important to understand what determines the basis and expected returns of energy commodities.

\footnotetext{
${ }^{16}$ This essay is based on the conference proceedings accessible on-line (Kucher and Kurov, 2012).

${ }^{17}$ Backwardation is consistent with the theory of normal backwardation, which states that futures price of commodity should be below expected spot price by the amount of normal backwardation (Keynes, 1930).

${ }^{18}$ Contango in energy commodities markets is also consistent with the theory of Hotelling (1931), which states that the net price of exhaustible resources rises over time at the rate of interest under certainty.
} 
This study investigates the effect of the state of the national economy on the interestadjusted basis (the basis net of the interest rate) for energy commodities. Several studies examine the link between the basis and business conditions. Fama and French (1988) find negative interest-adjusted basis for metals around business cycle peaks, suggesting that metal prices are affected by general business conditions through variation in their inventories. Gorton et al. (2013) find that commodity basis depend on inventory levels. Kilian and Murphy (2011) find that global business cycle demand shocks strongly affect inventory and real price of crude oil. Hong and Yogo (2012) find that open interest in commodity futures and changes in macroeconomic activity predict commodity returns.

This study extends the analysis of Fama and French $(1987,1988)$ by directly looking at the effect of inventory levels on the interest-adjusted basis of energy commodities over the business cycle. Moreover, this study examines the effects of the state of the national economy on interest-adjusted basis and expected returns, also incorporating determinants predicted by the theory of storage.

Our paper makes several contributions to the literature. First, the study finds that the state of the national economy has a significant effect on interest-adjusted basis and expected returns of energy commodities. Consistent with the theory of storage, interest-adjusted basis for all energy commodities except natural gas are negative around business cycle peaks. This study also shows that the energy interest-adjusted basis tend to be positive in recessions. Expected spot returns of energy commodities over a three-month horizon are positive around business cycle peaks and negative during recessions. Regression results show that the interest-adjusted basis for petroleum commodities decrease and expected returns increase when national economic conditions are strong. Conversely, the basis increase and expected returns fall during recessions. 
Second, this is the only study to directly examine the variation of spot and futures prices for five energy commodities in periods when the inventory is low or high. Prior studies (e.g. Serletis and Hulleman, 1994; Serletis and Shahmoradi, 2006; Stronzik et al., 2009) analyze crude oil and natural gas markets using an indirect test proposed by Fama and French (1988). This indirect test relies on using the sign of the interest-adjusted basis as a proxy for inventory. In contrast, this study uses a direct measure of inventory based on the reported U.S. physical stock $^{19}$. This study further examines the effects of inventory on interest-adjusted basis under low and high levels of inventory. Previous research (e.g., Gorton et al., 2013) examined the inventory effects without conditioning on low and high inventory levels. This research finds positive and statistically significant effects of inventory on interest-adjusted basis at low inventory levels, but small and statistically insignificant effects at high inventory levels. The conditional return volatility negatively affects the basis when inventory is low. Since this study uses weekly data, our test is more powerful than the analysis of Gorton et al. (2013) based on monthly data. Finally, results show that energy commodity basis positively predict expected returns.

\subsection{The Futures and Spot Price Relationship}

The basis is typically defined as the difference between commodity futures price, $F_{t, T}$, at time $t$ for delivery of the commodity at $T$ and the spot price, $S_{t}$. The theory of storage predicts that the basis depends on the foregone interest, $S_{t} r_{t, T}$, the marginal cost of storage, $W_{t, T}$, and the convenience yield, $C_{t, T}$. Fama and French (1988) state this relation as follows:

\footnotetext{
${ }^{19}$ Energy commodities are consumed and produced internationally. However, global inventory data are not available. We use weekly U.S. stocks data across five commodities, which are accurate and available since 1987. U.S. energy inventory strongly affect national benchmark prices for five energy commodities, which are produced, consumed, and traded in the United States. The correlation between monthly U.S. petroleum stocks and the OECD petroleum stocks (excluding the U.S.) for 1990-2011 is about 0.58 .
} 


$$
F_{t, T}-S_{t}=S_{t} r_{t, T}+W_{t, T}-C_{t, T}
$$

Dividing by the spot price and subtracting the interest rate, the interest-adjusted basis is expressed as a percentage of the spot price:

$$
\left(F_{t, T}-S_{t}\right) / S_{t}-r_{t, T}=\left(W_{t, T}-C_{t, T}\right) / S_{t}
$$

Equation (2) relates the interest-adjusted basis to the relative convenience yield and the physical storage cost. Because supply and demand factors change, the interest-adjusted basis also varies, moving between positive and negative territory depending on the magnitude of the net marginal convenience yield, $W_{t, T}-C_{t, T}$ (Pindyck, 2001). According to the theory of storage, the marginal convenience yield declines - and the basis increases - with increases in inventory.

The basis is expressed as the sum of the expected change in the spot price and the risk premium, defined as the difference between the futures and a forecast of the future spot price:

$$
F_{t, T}-S_{t}=E_{t}\left[S_{T}-S_{t}\right]+F_{t, T}-E_{t}\left[S_{T}\right]
$$

Dividing by the spot price gives the following equation:

$$
\text { Basis }_{t}=\left(F_{t, T}-S_{t}\right) / S_{t}=\left(E_{t}\left[S_{T}\right]-\left[S_{t}\right]\right) / S_{t}+\left(F_{t, T}-E_{t}\left[S_{T}\right]\right) / S_{t}
$$

Equation (4) expresses the basis in terms of the expected spot returns and the risk premium. According to the theory of normal backwardation, producers hedge their risk exposure by selling futures at prices that are below the expected spot prices. Speculators, who hold long futures positions, earn a positive risk premium. An alternative view is that variation in expected returns and the premium is determined by changes in costs and benefits of carrying inventory.

\subsubsection{Hypothesis}

The theory of storage predicts that demand and supply shocks affect futures and spot prices through changes in the inventory. Fama and French (1988) argue that the effect of demand 
shocks on the interest-adjusted basis is determined by the inventory level. At low inventory levels, often observed at business cycle peaks, demand shocks have a large effect on the spot price, leading to negative interest-adjusted basis. In contrast, at high inventory levels, the inventory response dampens the effect of demand shocks.

The state of the economy should also affect the basis and expected returns of energy commodities. This effect may operate through several channels. Permanent demand and supply shocks for energy are often induced by changes in macroeconomic activity. For example, business activity in energy-intensive sectors depends on the state of the economy. Furthermore, energy inventories and futures prices are likely to respond to changes in expectations of future economic conditions (e.g., Kilian and Murphy, 2012).

When the economy grows, spot and futures prices of energy tend to increase due to growing demand. Positive demand shocks near business cycle peaks decrease inventories and generate negative interest-adjusted basis, as the theory of storage predicts. Expectations of future economic growth leads to higher expected future spot prices and increasing expected returns. When the economy is in recession, energy prices decline due to a fall in demand. Negative demand shocks increase inventories and generate a positive interest-adjusted basis. Because the inventory acts as a buffer absorbing demand and supply shocks, the current spot prices fall less than the expected future spot prices. This effect is reinforced by negative economic expectations. Therefore, expected returns tend to be negative in recessions. We propose the hypothesis: Hypothesis. The state of the economy influences interest-adjusted basis and expected returns of energy commodities. Interest-adjusted basis tends to be negative and the expected returns are positive near a business cycle peak. The basis becomes positive and the expected returns fall in a recession. 


\subsection{Data and Key Variables}

Daily and weekly spot and three-month futures prices are used for crude oil, gasoline, and heating oil for the period from 1987 to 2011. Prices for natural gas begin in 1997 and prices for propane are available from 1994 to 2009 . The futures prices for energy commodities are from the New York Mercantile Exchange. Available spot and three-month futures prices are matched up on the same day. Available weekly inventory data are also used for the same five energy commodities. Missing observations are excluded from the sample to have a continuous series.

Table 4.1

Energy commodity futures and inventory

\begin{tabular}{|c|c|c|c|}
\hline Commodity & Description & Units & Start \\
\hline \multicolumn{4}{|c|}{ A. Futures Prices } \\
\hline Crude Oil & $\begin{array}{l}\text { Light-Sweet Cushing, Oklahoma, } \\
\text { West Texas Intermediate }\end{array}$ & \$/Barrel & $1 / 02 / 1987$ \\
\hline Gasoline & Regular, New York Harbor & \$/Gallon & $1 / 02 / 1987$ \\
\hline Heating Oil & No. 2 fuel oil, New York Harbor & \$/Gallon & $1 / 02 / 1987$ \\
\hline Natural Gas & Henry Hub Gulf Coast & \$/Million BTU & $1 / 07 / 1997$ \\
\hline Propane & Mont Belvieu, Texas & \$/Gallon & 2/08/1994 \\
\hline \multicolumn{4}{|l|}{ B. Inventory } \\
\hline Crude Oil & $\begin{array}{l}\text { U.S. Ending Stocks excluding SPR } \\
\text { of Crude Oil }\end{array}$ & Thousand Barrels & $1 / 01 / 1987$ \\
\hline Gasoline & $\begin{array}{l}\text { U.S. Ending Stocks of Total } \\
\text { Gasoline }\end{array}$ & Thousand Barrels & $1 / 04 / 1990$ \\
\hline Heating Oil & $\begin{array}{l}\text { Weekly U.S. Ending Stocks of } \\
\text { Distillate Fuel Oil }\end{array}$ & Thousand Barrels & $1 / 01 / 1987$ \\
\hline Natural Gas & $\begin{array}{l}\text { Lower } 48 \text { States Natural Gas } \\
\text { Working Underground Storage }\end{array}$ & Billion Cubic Feet & $12 / 30 / 1993$ \\
\hline Propane & $\begin{array}{l}\text { U.S. Ending Stocks of Propane and } \\
\text { Propylene }\end{array}$ & Thousand Barrels & $3 / 04 / 1993$ \\
\hline
\end{tabular}

Three month futures prices and inventory data are from Energy Information Administration of the U.S. Department of Energy. The futures contracts are traded on the New York Mercantile Exchange. 
Table 4.1 lists the description of futures prices and the inventory data for five energy commodities. The data for energy prices and inventories are obtained from the website of the U.S. Department of Energy. Three-month Treasury constant maturity rates are used from the FRED database of the Federal Reserve Bank of St. Louis.

Daily and weekly three-month interest-adjusted basis are computed in percentage for commodities after Fama and French (1988) as:

$$
\left(F_{t, T}-S_{t}\right) / S_{t}-r_{t, T}
$$

where $S_{t}$ is the spot price at time $t, F_{t, T}$ is the three month futures price at $t$ for delivery of a commodity at the end of the third month, and $r_{t, T}$ is the three month interest rate yield on Treasury bills.

Daily spot realized returns over a three-month horizon are computed in percentage as:

$$
\left(S_{T}-S_{t}\right) / S_{t}
$$

where $S_{T}$ is the spot price to be realized in three months and other variables are as previously defined.

In order to determine low and high inventory levels, the long-term averages of the physical stock are calculated for each energy commodity for each week of the year using the prior five years of weekly estimates. Thus, the physical stock below (above) the five-year averages for each week determines the low (high) inventory levels.

For regression tests, log normalized detrended inventory data are computed following Gorton et al. (2012) as $\ln \left(\mathrm{I}_{\mathrm{t}} / \mathrm{I}_{\mathrm{t}}^{*}\right)$, where $\mathrm{I}_{\mathrm{t}}$ is the inventory at the end of the week $\mathrm{t}$ and $\mathrm{I}_{\mathrm{t}}^{*}$ is the trend in inventory estimated with the Hodrick-Prescott filter. Gorton et al. (2012) indicate that the Hodrick-Prescott filter method and other methods of calculating normalized inventory levels yield similar estimates of a unit-free measure of the inventory that has no trend. 
Table 4.2 presents descriptive statistics for interest-adjusted basis, returns, conditional return volatilities estimated with $\operatorname{GARCH}(1,1)$ model, and detrended inventories for five energy commodities. Panel A of the table shows that the daily three-month interest-adjusted basis are moderately volatile, with standard deviations ranging from $4 \%$ to $8 \%$ for petroleum products and of about $15 \%$ for natural gas. The basis of crude oil, heating oil, natural gas and propane are positively correlated. Panel B of Table 4.2 shows that returns over a three-month horizon are at least twice as volatile as the basis and are more correlated across energy commodities. Similar to interest-adjusted basis, energy returns have low skewness and moderate kurtosis.

Panel C of Table 4.2 shows that the detrended normalized inventory has a distribution close to normal. Inventories for crude oil, heating oil, propane, and natural gas are positively correlated and negatively correlated with the gasoline inventory. The conditional standard deviation of daily spot returns shown in Panel D of Table 4.2 is moderately volatile, positively skewed, and less correlated across the five energy commodities. Natural gas return volatility has the highest standard deviation and is uncorrelated with the conditional volatilities of petroleum commodities. Overall, the statistics for the basis, returns and conditional return volatility for natural gas and gasoline differ from those for other energy commodities. Such differences arise from different supply and demand fundamentals, seasonalities in consumption and production, and different storage technologies. 
Table 4.2

Statistics for Interest-Adjusted Basis, Inventory and Return Volatility

\begin{tabular}{|c|c|c|c|c|c|c|c|c|c|c|}
\hline & Mean & S.D. & Skewness & Kurtosis & Obs. & & & orrelation wit & & \\
\hline & & & & & & Crude Oil & Gasoline & Heating Oil & Natural Gas & Propane \\
\hline A. Interest-Ad & sis, \% & & & & & & & & & \\
\hline Crude Oil & -0.34 & 4.36 & 0.86 & 12.63 & 6275 & 1 & 0.30 & 0.50 & 0.16 & 0.40 \\
\hline Gasoline & 1.06 & 7.90 & -0.07 & 3.86 & 6275 & 0.30 & 1 & 0.01 & -0.14 & -0.08 \\
\hline Heating Oil & 0.32 & 6.56 & -2.33 & 12.30 & 6275 & 0.50 & 0.01 & 1 & 0.42 & 0.72 \\
\hline Natural Gas & 7.31 & 14.89 & 2.63 & 17.17 & 3742 & 0.16 & -0.14 & 0.42 & 1 & 0.38 \\
\hline Propane & -1.25 & 6.31 & -2.71 & 12.31 & 3909 & 0.40 & -0.08 & 0.72 & 0.38 & 1 \\
\hline B. Log Norma & entory & & & & & & & & & \\
\hline Crude Oil & -0.0006 & 0.03 & -0.40 & 2.80 & 1305 & 1.00 & -0.21 & 0.73 & 0.75 & 0.75 \\
\hline Gasoline & -0.0008 & 0.04 & 0.10 & 3.23 & 1148 & -0.21 & 1.00 & -0.23 & -0.46 & -0.51 \\
\hline Heating Oil & -0.005 & 0.10 & -0.45 & 2.59 & 1305 & 0.73 & -0.23 & 1.00 & 0.84 & 0.80 \\
\hline Natural Gas & -0.06 & 0.34 & -0.64 & 2.13 & 940 & 0.75 & -0.46 & 0.84 & 1.00 & 0.98 \\
\hline Propane & -0.05 & 0.32 & -0.57 & 2.63 & 482 & 0.75 & -0.51 & 0.80 & 0.98 & 1.00 \\
\hline C. Spot Retur & onal Volat & ty, \% & & & & & & & & \\
\hline Crude Oil & 0.24 & 0.10 & 2.77 & 15.85 & 1305 & 1.00 & 0.50 & 0.13 & 0.04 & 0.19 \\
\hline Gasoline & 0.26 & 0.08 & 2.63 & 16.45 & 1305 & 0.50 & 1.00 & 0.09 & 0.05 & 0.10 \\
\hline Heating Oil & 0.23 & 0.11 & 6.05 & 62.93 & 1305 & 0.13 & 0.09 & 1.00 & 0.03 & 0.22 \\
\hline Natural Gas & 0.42 & 0.23 & 3.73 & 27.99 & 782 & 0.04 & 0.05 & 0.03 & 1.00 & 0.63 \\
\hline Propane & 0.21 & 0.14 & 4.39 & 32.46 & 1017 & 0.19 & 0.10 & 0.22 & 0.63 & 1.00 \\
\hline
\end{tabular}

The statistics are for the daily three-month interest-adjusted basis (Panel A), weekly log normalized inventory (Panel B), and weekly conditional volatility of spot returns (Panel C). The sample period is 1987-2011 for crude oil and heating oil; 1990-2011 for gasoline; 1997-2011 for natural gas; and February 11, 1994 to September 18, 2009 for propane. 
This study uses two proxies for national economic conditions. The first proxy is the ADS business conditions index designed by Aruoba et al. (2009) and published by the Federal Reserve Bank of Philadelphia. The second proxy is the Chicago Fed National Activity Index (CFNAI). The CFNAI is a principal component of 85 economic indicators. Similar to Basistha and Kurov (2008), the three-month moving average of the CFNAI is used. The historical values of the CFNAI are obtained from the website of the Federal Reserve Bank of Chicago. This study also uses two proxies for U.S. recessions including the National Bureau of Economic Research (NBER) recession dummy and the real time probability of recession index constructed by Chauvet and Piger (2008) at monthly intervals using a Markov switching model. ${ }^{20}$ The NBER recession timing is based on information that is unavailable to market participants in real time. In contrast, the recession probability index indicates the probability that the U.S. economy is in recession in real time.

\footnotetext{
${ }^{20}$ We thank Marcelle Chauvet for making the recession probability index data available to us.
} 
Figure 4.1

\section{Business Cycle Measures}

The Aruoba-Diebold-Scotti (ADS) Business Conditions Index and three-month moving average of the Chicago Fed National Activity Index (CFNAI) on the left axis, and the Probability of Recession index on the right axis. Shaded areas are NBER recessions.

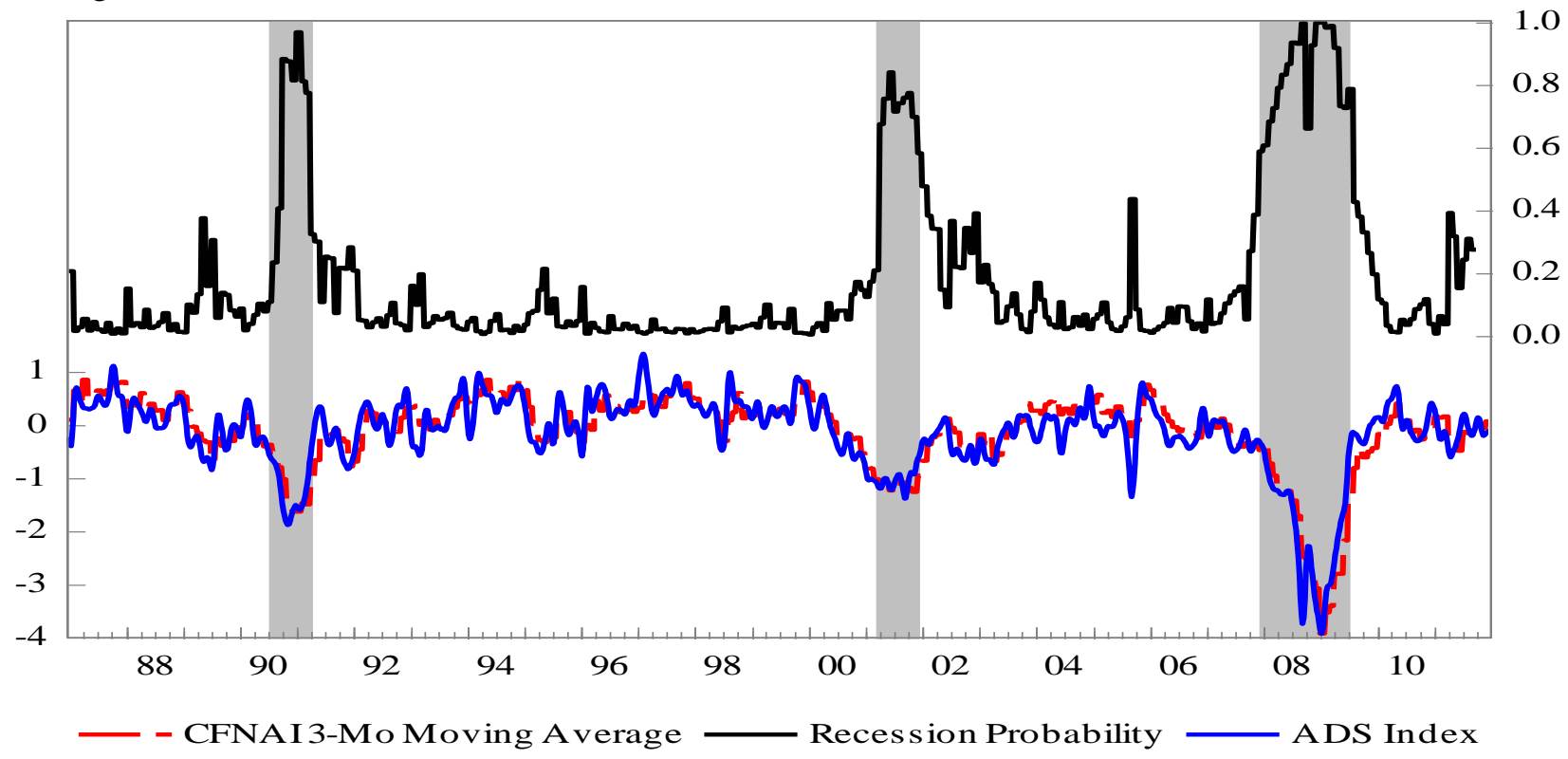

Figure 4.1 shows time variation of the macroeconomic activity and business cycle proxies. Positive values of the ADS index and of the three-month moving average of the CFNAI imply better-than-average economic conditions, and negative values imply worse-than-average economic conditions. The ADS and the three-month moving average of the CFNAI positively correlate with each other and negatively correlate with the recession probability index. Large declines in the national economic conditions proxies coincide with NBER recessions.

\subsection{Empirical Methodology}

The study employs two complementary approaches. First, statistics for energy interestadjusted basis and returns at low and high inventory levels and in different stages of the business cycle are compared. Second, regression analysis is used to examine the effect of the state of the 
economy on interest-adjusted basis and returns, while controlling for other determinants predicted by theory. Regression tests are modified after Fama and French (1987) by adding proxies for the state of the economy and other determinants of the basis and expected returns.

The interest-adjusted basis is regressed on proxies for the state of the economy, $E M_{t}, \log$ normalized detrended inventory, $\operatorname{In} v_{t}$, conditional standard deviation of spot returns, $\sigma_{t}$, and monthly seasonal dummies, $d_{m}$ :

$$
\left(\mathrm{F}_{\mathrm{t}, \mathrm{T}}-\mathrm{S}_{\mathrm{t}}\right) / \mathrm{S}_{\mathrm{t}}-r_{t, T}=\alpha+\beta_{1} E M_{t}+\beta_{2} \operatorname{Inv}_{t}+\beta_{3} \sigma_{t}+\sum \delta_{m} d_{m}+\varepsilon_{t}
$$

The proxies for the state of the economy include two measures of business conditions and two recession proxies. The hypothesis is that the estimate of $\beta_{1}$ is expected to be negative when the business conditions proxies are used and positive when recession proxies are used. Inventory, $\operatorname{In} v_{t}$, is a proxy for the convenience yield. This variable is used by Gorton et al. (2013) in a similar context. According to the theory of storage, the relation between the basis and inventories should be positive at low inventory levels and close to zero at high inventory levels. To explore these predictions about inventories and variation of futures and spot prices, a linear regression is estimated for the interest-adjusted basis under low and high inventory levels. The conditional standard deviation of spot returns is included to capture the relation between price volatility and the basis suggested by Pindyck (2001). When price volatility increases, the convenience yield and demand for storage should increase, leading to a decline in the basis. The model also includes seasonal dummies as in Fama and French (1987). Energy inventories typically increase during summer and decline in winter. Thus, the impact of seasonal dummies on energy basis is expected to be positive during summer and negative during winter. 
The basis can be decomposed into the expected change in spot prices and the risk premium, as in equation (4). The expected spot price at expiration is unobservable and has to be replaced with the realized spot price, $S_{T}$. The following regressions are estimated:

$$
\begin{gathered}
\left(S_{T}-S_{t}\right) / S_{t}=\alpha+\beta_{1} \text { Basis }_{t}+\beta_{2} E M_{t}+u_{t} \\
\left(F_{t, T}-S_{T}\right) / S_{t}=\delta+\gamma_{1} \text { Basis }_{t}+\gamma_{2} E M_{t}+v_{t}
\end{gathered}
$$

The summation of equations (8) and (9) sum both coefficients on basis to 1.0 since the right hand sides sum to basis. ${ }^{21}$ Thus, the basis variation can explain the variation in expected returns, the risk premium, or their mix. Adding proxies for the economic conditions can explain whether the state of the economy predicts the future spot prices. Positive relationships are expected between the state of the economy and expected spot returns.

\subsection{Results}

\subsubsection{The Theory of Storage and Evidence on Futures and Spot Prices}

The theory of storage predicts a non-linear relation between the interest-adjusted basis and the inventory. Figure 4.2 shows that the interest-adjusted basis for heating oil is negative at low inventory levels. As the inventory increases, the basis increases at a gradually decreasing rate. Figure 4.2 also shows that equal changes in the inventory lead to much larger changes in the basis when the inventory is low than when the inventory is high.

\footnotetext{
${ }^{21}$ Fama and French (1987) find that $\beta_{1}$ and $\gamma_{1}$ are positive, indicating that the basis is related to expected returns or time-varying futures risk premiums. However, their sample did not include energy commodities.
} 
Figure 4.2

Interest-Adjusted Basis as a Function of Inventory

Scatter plot of three-month interest-adjusted basis of New York Harbor No. 2 heating oil and weekly U.S. ending stock of distillate fuel oil.

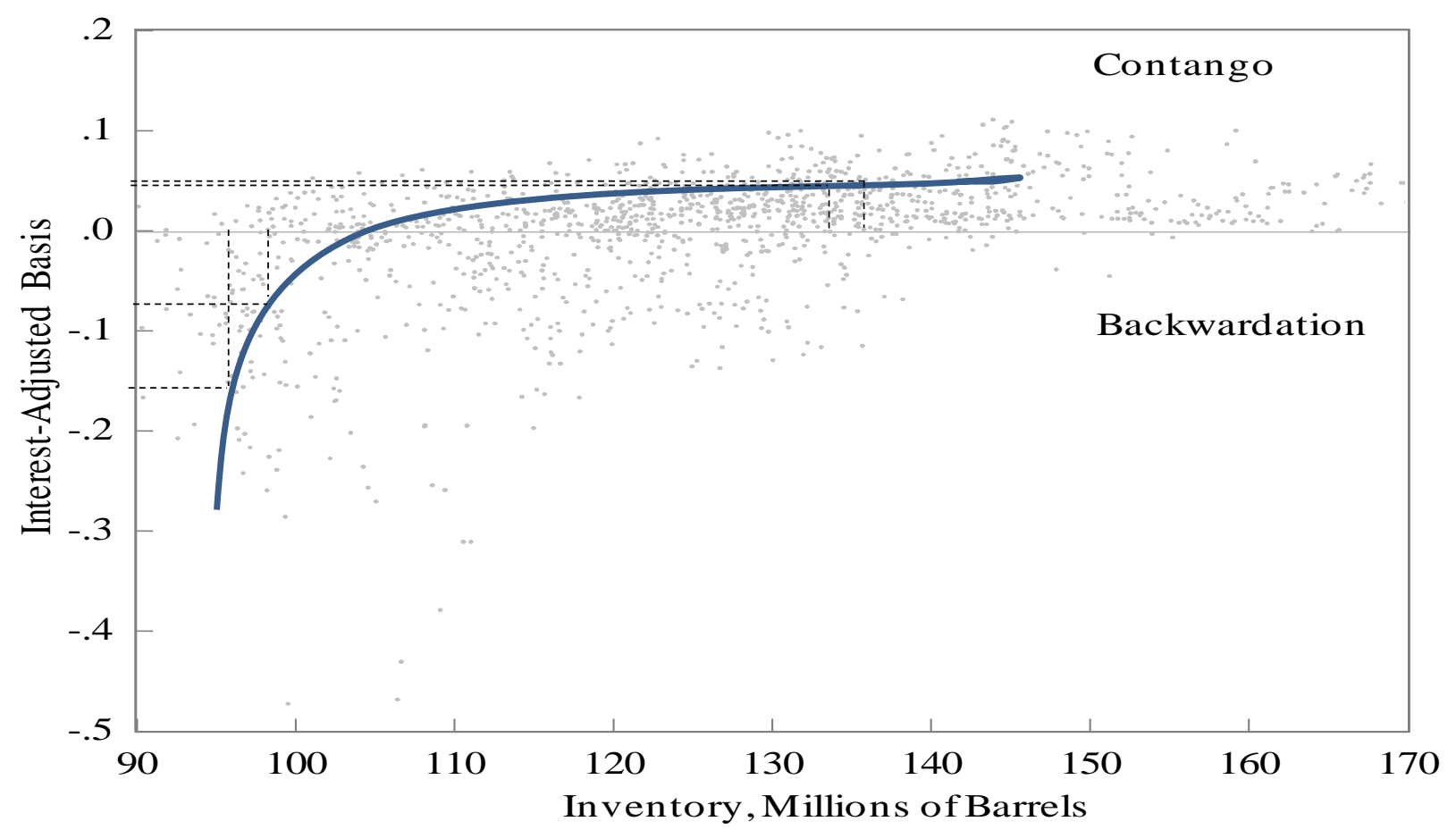

The theory of storage predicts that demand and supply shocks have a larger effect on interest-adjusted basis at low inventory levels than at high inventory levels. As a result, basis volatility should increase when inventory is low. Fama and French (1988) perform an indirect test of this hypothesis for metals by using interest-adjusted basis as a proxy for the inventory.

Table 4.3 reports variation in the interest-adjusted basis for energy commodities (panels A and B) and the variability of energy futures and spot returns (panels C and D). In the first three columns, the sample for daily data is partitioned based on the level of the basis (indirect test). 
Table 4.3

Comparative Statistics for Relative Variation of Futures and Spot Prices

\begin{tabular}{|c|c|c|c|c|c|c|}
\hline & \multicolumn{3}{|c|}{ Daily Observations } & \multicolumn{3}{|c|}{ Weekly Observations } \\
\hline & Positive & Negative & All & High & Low & All \\
\hline \multicolumn{7}{|c|}{ A. Standard Deviation of Changes for Interest-Adjusted Basis (\%) } \\
\hline Crude Oil & 1.47 & 1.25 & 1.34 & 2.11 & 1.61 & 1.87 \\
\hline Gasoline & 1.61 & 1.69 & 1.66 & 2.60 & 3.27 & 3.01 \\
\hline Heating Oil & 0.98 & 1.82 & 1.36 & 1.52 & 2.90 & 2.25 \\
\hline Natural Gas & 6.10 & 4.41 & 5.79 & 7.54 & 4.59 & 6.78 \\
\hline Propane & 1.28 & 2.10 & 1.79 & 2.46 & 3.56 & 2.48 \\
\hline \multicolumn{7}{|c|}{ B. Averages for Interest-Adjusted Basis (\%) } \\
\hline Crude Oil & 2.60 & -3.88 & -1.32 & 0.86 & -3.47 & -1.34 \\
\hline Gasoline & 6.09 & -6.21 & 0.06 & 3.84 & -1.50 & 0.79 \\
\hline Heating Oil & 2.92 & -6.65 & -0.67 & 1.97 & -3.31 & -0.44 \\
\hline Natural Gas & 10.37 & -5.28 & 6.51 & 8.95 & 0.73 & 6.45 \\
\hline Propane & 1.65 & -5.46 & -2.16 & -2.50 & -5.68 & -2.28 \\
\hline \multicolumn{7}{|c|}{ C. Ratios of Standard Deviation of Futures Returns to Standard Deviation of Spot Returns } \\
\hline Crude Oil & 0.83 & 0.77 & 0.79 & 0.81 & 0.83 & 0.82 \\
\hline Gasoline & 0.80 & 0.70 & 0.76 & 0.81 & 0.70 & 0.74 \\
\hline Heating Oil & 0.88 & 0.66 & 0.76 & 0.87 & 0.66 & 0.76 \\
\hline Natural Gas & 0.65 & 0.55 & 0.63 & 0.70 & 0.57 & 0.66 \\
\hline Propane & 0.93 & 0.67 & 0.75 & 0.67 & 0.63 & 0.77 \\
\hline \multicolumn{7}{|c|}{ D. Conditional Correlation between Spot and Futures Returns } \\
\hline Crude Oil & 0.90 & 0.86 & 0.87 & 0.93 & 0.92 & 0.93 \\
\hline Gasoline & 0.78 & 0.76 & 0.77 & 0.81 & 0.75 & 0.77 \\
\hline Heating Oil & 0.89 & 0.80 & 0.85 & 0.89 & 0.83 & 0.86 \\
\hline Natural Gas & 0.27 & 0.27 & 0.27 & 0.68 & 0.72 & 0.69 \\
\hline Propane & 0.88 & 0.84 & 0.86 & 0.88 & 0.83 & 0.86 \\
\hline
\end{tabular}

Statistics are for daily observations when the interest-adjusted basis is positive (Positive) and negative (Negative). Statistics are for weekly observations at high inventory (High) and at low inventory (Low). Statistics are for all observations (All). Spot and futures returns are computed as percentage changes in spot prices and three-month futures prices. The sample period is 1987-2011 for crude oil and heating oil; 1990-2011 for gasoline; 1997-2011 for natural gas; February 8, 1994 to September 18, 2009 for propane.

In the last three columns, the sample of weekly observations is partitioned based on the level of the inventory which allows for a direct test of the prediction of the theory of storage ${ }^{22}$.

Panel A of Table 4.3 shows that, consistent with the theory of storage, the standard deviations of daily changes for heating oil and propane are about twice as high when interestadjusted basis is negative as when the basis is positive. Similarly, the standard deviation of

\footnotetext{
${ }^{22}$ Weekly estimates for the sample partitions based on the sign of the interest-adjusted basis and on inventory levels are of the similar magnitude.
} 
weekly changes in the basis for heating oil, propane and gasoline is larger when inventories are low compared to when inventories are high. However, both daily and weekly changes in the interest-adjusted basis for crude oil and natural gas tend to be larger when the basis is positive and inventories high. This prediction contradicts the theory of storage. I suggest that changes in crude oil and natural gas prices tend to be permanent under low and high inventories due to permanent demand and supply shocks in those markets.

In general, Panel B of Table 4.3 supports the predictions of the theory of storage about the positive (negative) interest-adjusted basis under high (low) inventory levels. For all energy commodities but natural gas, the average absolute value of the interest-adjusted basis is larger when the basis is negative than when the basis is positive. The interest-adjusted bases are negative when inventories are low, while the bases tend to be positive when inventories are high.

Panel C of Table 4.3 shows that, consistent with the Samuelson hypothesis, energy spot prices vary more than futures prices. The ratio of the standard deviations of futures returns to the standard deviation of spot returns is larger when interest-adjusted basis is positive or when inventories are high. These results are consistent with the prediction of the theory of storage discussed by Fama and French (1988).

Panel D of Table 4.3 shows that the conditional correlations between spot and futures returns, estimated with the dynamic conditional correlation mean reverting model, are larger when the basis is positive or when inventories are high ${ }^{23}$. At the same time, the correlations are of similar magnitude for some of the commodities. For example, the conditional correlation between spot and futures returns for natural gas and crude oil is similar when interest-adjusted basis is positive and negative and when inventories are high and low. This suggests that demand

\footnotetext{
${ }^{23}$ Daily return correlations are lower than weekly correlations, implying that daily returns are noisier than weekly
} returns. 
and supply shocks have a similar effect on spot and futures prices at different inventory levels in oil and gas markets. This findings support the results in panels A and B of Table 4.3.

Figure4.3 illustrates the behavior of the dynamic conditional correlation of daily spot and futures returns and interest-adjusted basis for crude oil. The figure shows that this correlation often drops below 0.6 from its average level of about 0.9. At the beginning of the sample period, the declines in correlation coincide with declines in interest-adjusted basis. Beginning in 1998, the declines in the conditional correlation occur simultaneously with both peaks and troughs in interest-adjusted basis. From 2008 onwards, peaks in the basis coincide with declines in the return correlation. This pattern is not consistent with the theory of storage, but it can be explained by general business conditions.

Figure 4.3

Return Correlation and Interest-Adjusted Basis

Conditional correlation between daily spot and three-month futures returns on the right axis and threemonth interest-adjusted basis for WTI crude oil on the left axis. Shaded areas are NBER recessions.

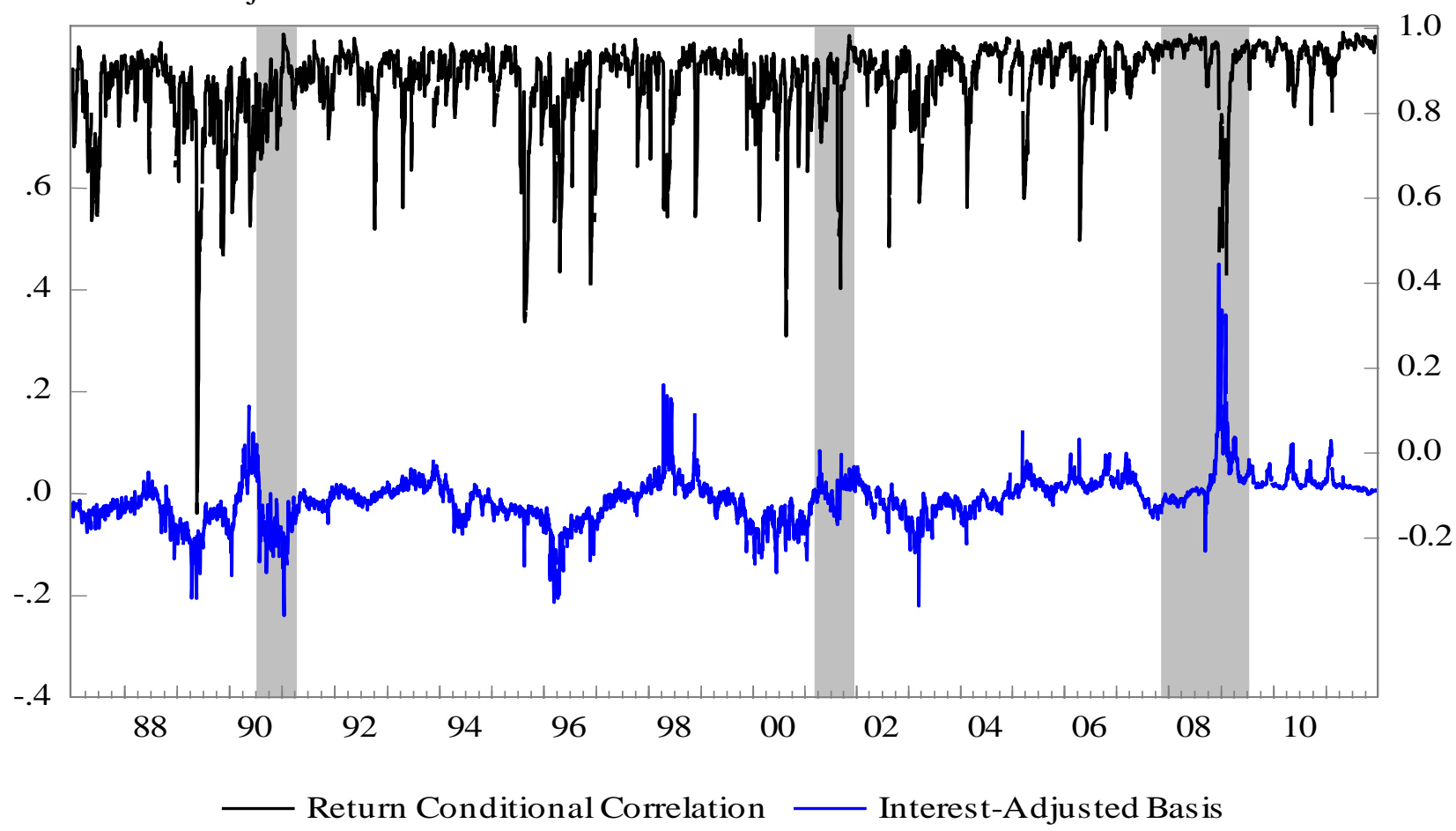




\subsubsection{Evidence on Futures and Spot Prices over the Business Cycle}

The theory of storage predicts that demand shocks around business cycle peaks decrease inventories, which causes spot prices to increase more than futures prices. Fama and French (1988) find that interest-adjusted basis for metals are negative around business cycle peaks. Let describe relative spot prices and interest-adjusted basis for energy commodities around business cycle peaks and during recessions.

Table 4.4 shows a sharp increase in the relative spot energy prices around the NBER business cycle peaks and a strong decline in the relative prices during recessions. As expected, energy prices rise in good economic times, reaching their maximum around the business cycle peak or at the beginning of a recession and fall in periods of economic decline. Consider the increase in energy prices around the NBER business cycle peaks of July 1990, March 2001 and December 2007. Based on the monthly maximum price levels, the increase in energy prices from their levels of about two years before the business cycle peak ranges from about $70 \%$ to $190 \%$. Prices fall considerably in late recessions, presumably due to a decrease in demand. During the recessions of 1990-91 and 2001, energy prices fell by over 40\% from their previous highs, and the decline sometimes continued after the recession was over. During the recent recession, spot energy prices declined by over two-thirds from their 2008 highs. 
Table 4.4

Relative Spot Prices around Business Cycle Peaks and Recessions

\begin{tabular}{|c|c|c|c|c|c|c|c|}
\hline & $\begin{array}{c}\text { Before } \\
\text { Peak }\end{array}$ & $\begin{array}{c}\text { Around } \\
\text { Peak }\end{array}$ & Peak & \multicolumn{3}{|c|}{ Recession } & $\begin{array}{c}\text { After } \\
\text { Trough }\end{array}$ \\
\hline \multicolumn{8}{|l|}{ A.1990-91 } \\
\hline & Jan-88 & Jan-90 & Jul-90 & Maximum (Mo.) & Minimur & (Mo.) & Jan-92 \\
\hline Crude Oil & 1 & 1.33 & 1.08 & $2.10 \quad($ Oct-90) & 1.16 & (Mar-91) & 1.10 \\
\hline Gasoline & 1 & 1.42 & 1.44 & (Sep-90) & 1.47 & (Feb-91) & 1.18 \\
\hline Heating Oil & 1 & 1.37 & 1.03 & (Oct-90) & 1.19 & (Mar-91) & 1.00 \\
\hline \multicolumn{8}{|l|}{ B.2000-01 } \\
\hline & Jan-98 & Jan-00 & Mar 01 & Maximum (Mo.) & Minimur & (Mo.) & Jan-02 \\
\hline Crude Oil & 1 & 1.63 & 1.63 & 1.71 (May-01) & 1.17 & (Nov-01) & 1.18 \\
\hline Gasoline & 1 & 1.47 & 1.64 & (Apr-01) & 1.08 & (Nov-01) & 1.14 \\
\hline Heating Oil & 1 & 1.96 & 1.59 & (Apr-01) & 1.18 & (Nov-01) & 1.15 \\
\hline Natural Gas & 1 & 1.16 & 2.50 & (Mar-01) & 1.12 & (Nov-01) & 1.11 \\
\hline Propane & 1 & 1.84 & 1.85 & (Mar-01) & 1.10 & (Nov-01) & 0.96 \\
\hline \multicolumn{8}{|l|}{ C. $2007-09$} \\
\hline & Jan-05 & Jan-07 & Dec-07 & Maximum (Mo.) & Minimur & (Mo.) & Jan-10 \\
\hline Crude Oil & 1 & 1.16 & 1.96 & 2.86 (Jun-08) & 0.83 & (Feb-09) & 1.67 \\
\hline Gasoline & 1 & 1.15 & 1.88 & (Jun-08) & 0.77 & (Dec-08) & 1.64 \\
\hline Heating Oil & 1 & 1.16 & 1.96 & (Jun-08) & 0.97 & (Mar-09) & 1.55 \\
\hline Natural Gas & 1 & 1.07 & 1.16 & (Jun-08) & 0.62 & (Jun-09) & 0.95 \\
\hline Propane & 1 & 1.21 & 2.07 & (Jul-08) & 0.83 & (Dec-08) & 1.78 \\
\hline
\end{tabular}

The spot price for each commodity in Panels A, B, and C is divided by the spot price of January 1988, January 1998, and January 2005, respectively. The maximum price ratio in Panels A, B and C is the highest ratio around business cycle peaks and in recessions. The minimum price ratio is the lowest ratio during recessions. The business cycle peaks and recessions are dated by the NBER. The dates Before Peak and Around Peak are one month prior to about two years and five months before the NBER peaks, respectively. The dates After Trough are one month after the end of recession.

Panel A of Table 4.5 demonstrates that three-month interest-adjusted basis except natural gas are negative around business cycle peaks, when spot prices increase as shown in Table 4.4.

These results support the prediction of the theory of storage that demand shocks around business cycle peaks reduce inventories and generate negative basis. Conversely, the bases for all energy commodities except heating oil are positive during recessions, when spot prices decline. A possible explanation is that excess supply shocks in recessions are absorbed by the inventory, generating positive interest-adjusted basis in recessions. 
Table 4.5

Averages and Standard Deviations of Interest-Adjusted Basis and Returns over the Business Cycle (Daily Data)

\begin{tabular}{|c|c|c|c|c|c|c|}
\hline & \multicolumn{2}{|c|}{ Around Peaks } & \multicolumn{2}{|c|}{ Recessions } & \multicolumn{2}{|c|}{$\begin{array}{l}\text { Excluding Dates Around } \\
\text { Peaks and Recessions }\end{array}$} \\
\hline & Mean & S.D. & Mean & S.D. & Mean & S.D. \\
\hline \multicolumn{7}{|c|}{ A. 3-Mo Basis } \\
\hline Crude Oil & -2.44 & 4.90 & 0.14 & 7.23 & -1.46 & 3.96 \\
\hline Gasoline & -3.55 & 7.42 & 0.01 & 8.72 & 0.30 & 7.91 \\
\hline Heating Oil & -5.12 & 7.42 & -0.99 & 6.88 & -0.29 & 6.48 \\
\hline Natural Gas & 4.50 & 16.15 & 6.39 & 10.57 & 6.85 & 15.57 \\
\hline Propane & -5.31 & 9.88 & 0.51 & 3.09 & -2.39 & 6.31 \\
\hline \multicolumn{7}{|c|}{ B. 3-Mo Returns } \\
\hline Crude Oil & 11.48 & 34.27 & -1.25 & 32.49 & 3.74 & 13.56 \\
\hline Gasoline & 9.00 & 19.75 & -2.17 & 28.46 & 4.19 & 16.69 \\
\hline Heating Oil & 8.73 & 30.04 & -3.99 & 27.20 & 4.54 & 16.11 \\
\hline Natural Gas & 7.83 & 35.29 & -13.40 & 24.55 & 6.47 & 26.51 \\
\hline Propane & 2.44 & 20.44 & -7.87 & 23.85 & 5.01 & 17.57 \\
\hline
\end{tabular}

Statistics are for daily three-month interest-adjusted basis in Panel A and spot returns over a threemonth horizon in Panel B for days around business cycle peaks (Around Peaks): 1/01/19906/30/1990, 9/01/2000-2/28/2001, 6/01/2007-11/30/2007 and during recessions (Recessions): 7/01/1990-3/31/1991, 2/01/2001-11/28/2001, 12/01/2007-6/30/2009. Business cycle peaks and recessions are dated by the NBER. The periods Around Peaks are six-month periods prior to the NBER business cycle peaks.

Panel B of Table 4.5 shows that the energy returns over a three-month horizon are procyclical: they are positive around business cycle peaks and negative during recessions. The average returns around business cycle peaks range from $2.4 \%$ for propane to $11.5 \%$ for natural gas. In recessions, the average energy commodity returns range from $-1.3 \%$ for crude oil to $3.4 \%$ for natural gas. For all commodities, the standard deviations of the basis and returns tend to be larger around business cycle peaks and during recessions than in other periods, implying that volatility in energy markets is driven by supply and demand shocks.

\subsubsection{Spot and Futures Price Variation, Inventory and the State of the Economy}

I estimate regressions for interest-adjusted basis and expected returns shown in equations (7) and (8) using daily and weekly data, so that the regression coefficients can be compared, and 
robustness of results can be verified. The first five columns of Table 4.6 report daily regression results for interest-adjusted basis with the $\mathrm{ADS}$ index ${ }^{24}$. The last five columns report the daily results with the NBER recession dummy. These regressions do not include an inventory variable.

Columns 1, 3, and 4 of Table 4.6 show that the interest-adjusted basis for crude oil, heating oil, and propane are related to national economy proxies. Specifically, these basis have a strong negative relation with the economic conditions proxies and positive relation with the recession proxies. For example, in the daily regression, the coefficient estimate of the ADS business conditions index for crude oil is about -1.6 . For heating oil, this coefficient estimate is about -0.9 . These negative coefficients show that interest-adjusted basis of energy commodities are countercyclical. The coefficient estimates of the NBER recession dummy are positive and significant for the same three commodities. Based on these estimates, interest-adjusted basis increases by about $2 \%$ on average for crude oil and heating oil and by about $4 \%$ on average for propane when the U.S. economy is in recession ${ }^{25}$. In comparison of the regression fit for energy commodities, the $\mathrm{R}^{2}$ is the lowest in the daily regression for crude oil. The substantially lower goodness of fit for the crude oil regression could be explained by substantially lower seasonality in the crude oil market in comparison with other fuel markets.

\footnotetext{
${ }^{24}$ The weekly results with the three-month moving average of the CFNAI and with the probability of recession are accessible on-line (Kucher and Kurov, 2012).

${ }^{25}$ The coefficient estimates for the state of the economy in the weekly regression tend to be larger than those in the daily regression. However, the standard errors of these coefficients are also larger in the weekly results, implying less precision in weekly estimates.
} 
Table 4.6

Regression Results for Interest-Adjusted Basis (Daily Data)

\begin{tabular}{|c|c|c|c|c|c|c|c|c|c|c|}
\hline & \multicolumn{5}{|c|}{ With Economic conditions Proxy } & \multicolumn{5}{|c|}{ With Recession Proxy } \\
\hline & Crude Oil & Gasoline & Heating Oil & Propane & Natural Gas & Crude Oil & Gasoline & Heating Oil & Propane & Natural Gas \\
\hline ADS Index $\left(\beta_{1}\right)$ & $\begin{array}{c}\mathbf{- 1 . 6 1} * * * \\
(0.40)\end{array}$ & $\begin{array}{l}0.13 \\
\quad(0.39)\end{array}$ & $\begin{array}{c}-\mathbf{0 . 9 5} * * * \\
(0.32)\end{array}$ & $\begin{array}{c}-\mathbf{1 . 5 1} * * * \\
\quad(0.25)\end{array}$ & $\begin{array}{l}0.27 \\
\quad(0.53)\end{array}$ & - & & & & \\
\hline $\operatorname{NBER}$ Recession $\left(\beta_{1}\right)$ & - & & & & & $\begin{array}{l}\mathbf{1 . 8 5} * * * \\
(0.68)\end{array}$ & $\begin{array}{l}0.32 \\
(0.72)\end{array}$ & $\begin{array}{l}\mathbf{1 . 9 4 * *} \\
(0.79)\end{array}$ & $\begin{array}{l}\mathbf{4 . 1 3} * * * * \\
(0.57)\end{array}$ & $\begin{array}{l}0.94 \\
(1.15)\end{array}$ \\
\hline $\begin{array}{l}\text { Returns Volatility, } \% \\
\left(\beta_{3}\right)\end{array}$ & $\begin{array}{l}\mathbf{- 0 . 4 5 *} \\
(0.27)\end{array}$ & $\begin{array}{l}-0.17 \\
(0.38)\end{array}$ & $\begin{array}{l}\mathbf{- 2 . 1 4} * * * \\
(0.39)\end{array}$ & $\begin{array}{l}-\mathbf{1 . 4 3 * * * *} \\
(0.26)\end{array}$ & $\begin{array}{l}1.00 \\
(0.69)\end{array}$ & $\begin{array}{l}-0.12 \\
(0.33)\end{array}$ & $\begin{array}{l}-0.28 \\
(0.34)\end{array}$ & $\begin{array}{l}-2.13 * * * \\
(0.38)\end{array}$ & $\begin{array}{l}\mathbf{- 1 . 4 0 * * * *} \\
(0.26)\end{array}$ & $\begin{array}{l}1.00 \\
(0.69)\end{array}$ \\
\hline $\begin{array}{l}\text { Constant } \\
\text { Dummies: }\end{array}$ & $\begin{array}{l}0.29 \\
(0.85)\end{array}$ & $\begin{array}{l}\text { 4.28**** } \\
(0.47)\end{array}$ & $\begin{array}{l}3.45 * * * \\
(1.25)\end{array}$ & $\begin{array}{l}0.11 \\
(1.87)\end{array}$ & $\begin{array}{l}-1.16 \\
(2.18)\end{array}$ & $\begin{array}{l}-0.61 \\
(0.92)\end{array}$ & $\begin{array}{l}\mathbf{4 . 5 4} * * * \\
(1.14)\end{array}$ & $\begin{array}{l}\text { 3.31**** } \\
(1.24)\end{array}$ & $\begin{array}{l}-3.05 * * * \\
(1.14)\end{array}$ & $\begin{array}{l}-4.12 \\
(4.25)\end{array}$ \\
\hline January & $\begin{array}{l}-1.43 \\
(0.93)\end{array}$ & $\begin{array}{l}3.92 * * * \\
(1.06)\end{array}$ & $\begin{array}{l}\mathbf{- 2 . 9 6 * * * *} \\
(1.19)\end{array}$ & $\begin{array}{c}-3.44 * * \\
(1.67)\end{array}$ & $\begin{array}{c}\mathbf{- 8 . 8 5 * * *} \\
(2.34)\end{array}$ & $\begin{array}{l}-1.18 \\
(0.99)\end{array}$ & $\begin{array}{l}3.89 * * * \\
(1.06)\end{array}$ & $\begin{array}{l}-2.78 * * * \\
(1.08)\end{array}$ & $\begin{array}{c}-3.54 * * \\
(1.67)\end{array}$ & $\begin{array}{c}\mathbf{- 6 . 0 9} * * * \\
(2.35)\end{array}$ \\
\hline February & $\begin{array}{l}-0.79 \\
(0.96)\end{array}$ & $\begin{array}{l}\mathbf{4 . 1 6} * * * * \\
(1.20)\end{array}$ & $\begin{array}{l}\mathbf{- 3 . 3 9} * * \\
(1.41)\end{array}$ & $\begin{array}{l}-1.36 \\
(1.63)\end{array}$ & $\begin{array}{c}\mathbf{- 5 . 1 9} * * * \\
(1.56)\end{array}$ & $\begin{array}{l}-0.62 \\
(1.01)\end{array}$ & $\begin{array}{l}\text { 4.11**** } \\
(1.20)\end{array}$ & $\begin{array}{l}-3.33 * * \\
(1.33)\end{array}$ & $\begin{array}{l}-1.52 \\
(1.61)\end{array}$ & $\begin{array}{c}-2.44 \\
(2.61)\end{array}$ \\
\hline March & $\begin{array}{l}-1.05 \\
(0.86)\end{array}$ & $\begin{array}{l}1.04 \\
(1.10)\end{array}$ & $\begin{array}{l}-3.57 * * * \\
(1.26)\end{array}$ & $\begin{array}{c}\text { 3.04** } \\
(1.26)\end{array}$ & $\begin{array}{l}-2.83 \\
(2.63)\end{array}$ & $\begin{array}{l}-0.90 \\
(0.88)\end{array}$ & $\begin{array}{l}1.01 \\
(1.10)\end{array}$ & $\begin{array}{l}-3.47 * * * \\
(1.15)\end{array}$ & $\begin{array}{c}\text { 2.93** } \\
(1.31)\end{array}$ & $\begin{array}{c}2.75 \\
(2.63)\end{array}$ \\
\hline April & $\begin{array}{l}-0.74 \\
(0.95)\end{array}$ & $\begin{array}{l}\mathbf{- 2 . 8 8 * * * *} \\
(1.07)\end{array}$ & $\begin{array}{l}-2.30 * \\
(1.22)\end{array}$ & $\begin{array}{c}4.69 * * * \\
(1.09)\end{array}$ & $\begin{array}{c}1.23 \\
(0.89)\end{array}$ & $\begin{array}{l}-0.61 \\
(0.97)\end{array}$ & $\begin{array}{l}-2.91 * * * \\
(1.07)\end{array}$ & $\begin{array}{l}-\mathbf{2 . 2 4} * * \\
(1.10)\end{array}$ & $\begin{array}{c}4.51 * * * \\
(1.12)\end{array}$ & $\begin{array}{l}\text { 3.92* } \\
(2.37)\end{array}$ \\
\hline May & $\begin{array}{l}-0.31 \\
(0.89)\end{array}$ & $\begin{array}{l}\mathbf{- 5 . 0 8 * * *} \\
(1.11)\end{array}$ & $\begin{array}{l}0.41 \\
(1.07)\end{array}$ & $\begin{array}{c}5.36 * * * \\
(1.07)\end{array}$ & $\begin{array}{c}\text { 1.75** } \\
(0.87)\end{array}$ & $\begin{array}{l}-0.20 \\
(0.90)\end{array}$ & $\begin{array}{l}\mathbf{- 5 . 1 4} * * * \\
(1.12)\end{array}$ & $\begin{array}{l}0.55 \\
(0.95)\end{array}$ & $\begin{array}{c}5.08 * * * \\
(1.09)\end{array}$ & $\begin{array}{l}\mathbf{4 . 4 5 *} \\
(2.46)\end{array}$ \\
\hline June & $\begin{array}{l}-0.44 \\
(0.90)\end{array}$ & $\begin{array}{l}-4.80 * * * \\
(1.16)\end{array}$ & $\begin{array}{l}\text { 3.02**** } \\
(0.99)\end{array}$ & $\begin{array}{c}\mathbf{6 . 0 2} * * * \\
(1.09)\end{array}$ & $\begin{array}{c}0.90 \\
(0.99)\end{array}$ & $\begin{array}{l}-0.23 \\
(0.90)\end{array}$ & $\begin{array}{l}-4.87 * * * \\
(1.17)\end{array}$ & $\begin{array}{l}3.94 * * * \\
(0.95)\end{array}$ & $\begin{array}{c}5.78 * * * \\
(1.12)\end{array}$ & $\begin{array}{c}3.58 \\
(2.41)\end{array}$ \\
\hline July & $\begin{array}{l}-0.75 \\
(0.79)\end{array}$ & $\begin{array}{l}\mathbf{- 8 . 0 9} * * * * \\
(1.09)\end{array}$ & $\begin{array}{l}\text { 3.73**** } \\
(1.03)\end{array}$ & $\begin{array}{c}\mathbf{6 . 4 0} * * * \\
(1.10)\end{array}$ & $\begin{array}{c}1.03 \\
(1.14)\end{array}$ & $\begin{array}{l}-0.41 \\
(0.79)\end{array}$ & $\begin{array}{l}\mathbf{- 8 . 1 5 * * *} \\
(1.10)\end{array}$ & $\begin{array}{l}\mathbf{4 . 3 4} * * * \\
(0.95)\end{array}$ & $\begin{array}{c}6.42 * * * \\
(1.10)\end{array}$ & $\begin{array}{c}3.78 \\
(2.41)\end{array}$ \\
\hline August & $\begin{array}{l}-1.22 \\
(0.77)\end{array}$ & $\begin{array}{l}\mathbf{- 1 0 . 5 2} * * * * \\
(1.10)\end{array}$ & $\begin{array}{l}\text { 4.02**** } \\
(1.03)\end{array}$ & $\begin{array}{c}5.90 * * * \\
(1.06)\end{array}$ & $\begin{array}{c}9.73 * * * \\
(2.10)\end{array}$ & $\begin{array}{l}-1.11 \\
(0.79)\end{array}$ & $\begin{array}{l}\mathbf{- 1 0 . 5 7 * * *} \\
(1.09)\end{array}$ & $\begin{array}{l}\text { 4.36**** } \\
(0.96)\end{array}$ & $\begin{array}{c}\mathbf{5 . 8 5} * * * \\
(1.08)\end{array}$ & $\begin{array}{c}12.47 * * * \\
(2.92)\end{array}$ \\
\hline September & $\begin{array}{l}-\mathbf{1 . 4 6} * \\
(0.79)\end{array}$ & $\begin{array}{l}\mathbf{- 8 . 9 3 * * * *} \\
(1.23)\end{array}$ & $\begin{array}{l}\text { 4.09**** } \\
(1.04)\end{array}$ & $\begin{array}{c}5.44 * * * \\
(1.06)\end{array}$ & $\begin{array}{c}\mathbf{2 0 . 5 6} * * * \\
(3.70)\end{array}$ & $\begin{array}{l}-1.06 \\
(0.78)\end{array}$ & $\begin{array}{l}\mathbf{- 8 . 9 6} * * * \\
(1.24)\end{array}$ & $\begin{array}{l}\text { 3.63**** } \\
(0.95)\end{array}$ & $\begin{array}{c}5.56 * * * \\
(1.06)\end{array}$ & $\begin{array}{c}23.28 * * * \\
(4.05)\end{array}$ \\
\hline October & $\begin{array}{l}-1.22 \\
(0.77)\end{array}$ & $\begin{array}{l}-7.18 * * * * \\
(1.18)\end{array}$ & $\begin{array}{l}3.48 * * * \\
(1.04)\end{array}$ & $\begin{array}{c}\mathbf{5 . 8 4} * * * \\
(1.07)\end{array}$ & $\begin{array}{c}16.86 * * * \\
(3.16)\end{array}$ & $\begin{array}{l}-0.82 \\
(0.81)\end{array}$ & $\begin{array}{l}-7.23 * * * \\
(1.19)\end{array}$ & $\begin{array}{l}2.17 * * * \\
(0.94)\end{array}$ & $\begin{array}{c}5.85 * * * \\
(1.08)\end{array}$ & $\begin{array}{c}19.59 * * * \\
(3.19)\end{array}$ \\
\hline November & $\begin{array}{l}-0.86 \\
(0.80)\end{array}$ & $\begin{array}{l}\mathbf{- 5 . 4 6 * * *} \\
(1.26)\end{array}$ & $\begin{array}{l}2.07 * * \\
(1.06)\end{array}$ & $\begin{array}{c}\text { 2.70** } \\
(1.13)\end{array}$ & $\begin{array}{c}9.32 * * * \\
(2.99)\end{array}$ & $\begin{array}{l}-0.82 \\
(0.81)\end{array}$ & $\begin{array}{l}\mathbf{- 5 . 4 9 * * * *} \\
(1.26)\end{array}$ & $\begin{array}{l}2.07 * * \\
(1.06)\end{array}$ & $\begin{array}{c}2.45 * * \\
(1.16)\end{array}$ & $\begin{array}{c}\text { 12.10** } \\
(2.61)\end{array}$ \\
\hline $\mathrm{N}$ & 6166 & 6166 & 6166 & 3907 & 3629 & 6166 & 6166 & 6166 & 3907 & 3629 \\
\hline $\mathrm{R}^{2}$ & 0.06 & 0.33 & 0.38 & 0.48 & 0.33 & 0.02 & 0.34 & 0.39 & 0.49 & 0.33 \\
\hline
\end{tabular}

The table shows estimates for the regression: $\left(\mathrm{F}_{\mathrm{t}, \mathrm{T}}-\mathrm{S}_{\mathrm{t}}\right) / \mathrm{S}_{\mathrm{t}}-r_{t, T}=\alpha_{t}+\beta_{1} E M_{t}+\beta_{3} \sigma_{t}+\sum \delta_{m} d_{m}+\varepsilon_{t}$. The regression is estimated using OLS with HAC standard errors. The sample period is 1/02/1987-7/29/2011 for crude oil, heating oil and gasoline; 1/09/1997-9/22/2005 for natural gas; 2/08/1994-9/18/2009 for propane. *,**,*** indicate significance at 10\%, 5\% and 1\% level. Standard errors are in parentheses. 
The volatility of spot returns is negatively related to the interest-adjusted basis for all energy commodities, although this coefficient estimate is statistically significant only for heating oil and propane. For example, based on the daily regression, a $1 \%$ increase in the conditional volatility of returns decreases the interest-adjusted basis by over $2 \%$ for heating oil and by almost $2 \%$ for propane. These results are consistent with the hypothesis of Pindyck (2001) that the convenience yield increases and the basis declines when price volatility increases.

The coefficient estimates of monthly seasonal dummies are mostly significant in both daily and weekly regressions for all energy commodities except crude oil. For heating oil, propane, and natural gas, the coefficients of the dummies for summer and fall months are typically positive and those for winter months are negative. Since the demand for heating oil, propane, and natural gas is very high during the heating season and the inventory accumulation occurs during summer, this evidence is consistent with the theory of storage. On the other hand, for gasoline, the seasonal dummy coefficients are positive for winter months and negative for summer and fall months. Demand for gasoline increases during the summer driving season and declines in winter. The absence of seasonal pattern in the crude oil basis is likely to be due to a lack of seasonality in the demand for crude oil.

Table 4.7 presents weekly regression results with the log detrended inventory variable at times of low and high levels of the inventory. Consistent with the theory of storage, the results show a large positive and significant effect of log normalized inventory on interest-adjusted basis when inventories are low for all energy commodities except natural gas. In contrast, at high inventory levels, the response of interest-adjusted basis is smaller and statistically insignificant, implying that the relation between the inventory and the basis is almost flat when the inventory is high. For example, the inventory coefficient estimates for crude oil and gasoline are over four 
times as large when inventories are low as when they are high. The coefficient of log normalized inventory in the low-inventory subsample ranges from 0.12 for propane to 0.69 for gasoline. This implies that a $1 \%$ increase in inventories increases the basis by about $0.12 \%$ for propane and by about $0.69 \%$ for gasoline when the corresponding inventory is low. For natural gas, the inventory coefficients are not statistically significant, implying a weak relation between the inventory and the basis.

Table 4.7 also demonstrates that price volatility affects the interest-adjusted basis for energy commodities when inventories are low. The coefficient estimates for the response of interest-adjusted basis to return volatility are negative and statistically significant when inventories are low. This result implies that interest-adjusted basis of energy commodities decrease when volatility increases, because higher volatility increases the demand for storage, leading to higher convenience yield. At the same time, the volatility coefficient estimates for natural gas and gasoline are positive and significant when the inventory is high. This positive effect of volatility on the basis may be due to market expectations (Pindyck, 2001).

The effect of the state of the economy proxies is statistically significant for crude oil, heating oil, propane and natural gas at low inventory levels. Interest-adjusted basis tends to decline in periods of economic growth. The coefficients of the three-month moving average of the CFNAI are consistently negative for all commodities except gasoline, ranging from about -0.6 for heating oil to about -2.1 for propane when the inventory is low. Conversely, the coefficient estimates for the probability of recession are positive, ranging from about 2.1 for heating oil to 4.8 for crude oil. These results support the hypothesis that interest-adjusted basis is likely to be positive in recessions. 
Table 4.7

Regression Results for Interest-Adjusted Basis (Weekly Data)

\begin{tabular}{|c|c|c|c|c|c|c|c|c|c|c|}
\hline \multirow[b]{2}{*}{ Inventory: } & \multicolumn{2}{|c|}{ Crude Oil } & \multicolumn{2}{|c|}{ Gasoline } & \multicolumn{2}{|c|}{ Heating Oil } & \multicolumn{2}{|c|}{ Propane } & \multicolumn{2}{|c|}{ Natural Gas } \\
\hline & Low & High & Low & High & Low & High & Low & High & Low & High \\
\hline \multicolumn{11}{|l|}{ A. With CFNA Index } \\
\hline CFNA Index $\left(\beta_{1}\right)$ & $\begin{array}{c}-\mathbf{1 . 5 2} * * * \\
(0.44)\end{array}$ & $\begin{array}{c}\mathbf{- 1 . 4 8} * * \\
(0.64)\end{array}$ & $\begin{array}{c}0.25 \\
(0.68)\end{array}$ & $\begin{array}{c}0.45 \\
(0.28)\end{array}$ & $\begin{array}{c}\mathbf{- 0 . 5 5} * \\
(0.33)\end{array}$ & $\begin{array}{c}\mathbf{- 0 . 3 0} * \\
(0.15)\end{array}$ & $\begin{array}{c}-\mathbf{2 . 0 6} * * * \\
(0.44)\end{array}$ & $\begin{array}{c}\mathbf{- 1 . 4 2 * *} \\
(0.56)\end{array}$ & $\begin{array}{c}\mathbf{- 1 . 0 8} * * \\
(0.48)\end{array}$ & $\begin{array}{l}-0.92 \\
(0.62)\end{array}$ \\
\hline Log Normalized Inventory $\left(\beta_{2}\right)$ & $\begin{array}{c}\mathbf{0 . 3 6} * * * \\
(0.11)\end{array}$ & $\begin{array}{c}0.09 \\
(0.16)\end{array}$ & $\begin{array}{c}\mathbf{0 . 6 9} * * * \\
(0.18)\end{array}$ & $\begin{array}{c}0.17 \\
(0.17)\end{array}$ & $\begin{array}{c}\mathbf{0 . 2 2} * * * \\
(0.04)\end{array}$ & $\begin{array}{c}\mathbf{0 . 0 7} * * \\
(0.01)\end{array}$ & $\begin{array}{c}\mathbf{0 . 1 5} * * * \\
(0.05)\end{array}$ & $\begin{array}{l}-0.01 \\
(0.03)\end{array}$ & $\begin{array}{l}-0.02 \\
(0.04)\end{array}$ & $\begin{array}{l}-0.07 \\
(0.07)\end{array}$ \\
\hline Returns Volatility, $\%\left(\beta_{3}\right)$ & $\begin{array}{c}\mathbf{- 1 . 6 5} * * * \\
(0.25)\end{array}$ & $\begin{array}{c}0.41 \\
(0.61)\end{array}$ & $\begin{array}{c}\mathbf{- 1 . 0 2} * * \\
(0.45)\end{array}$ & $\begin{array}{l}2.25 * \\
(0.75)\end{array}$ & $\begin{array}{c}\mathbf{- 1 . 9 6} * * * * \\
(0.32)\end{array}$ & $\begin{array}{l}-0.09 \\
(0.22)\end{array}$ & $\begin{array}{c}\mathbf{- 0 . 8 6} * * * \\
(0.28)\end{array}$ & $\begin{array}{l}-1.02 \\
(0.96)\end{array}$ & $\begin{array}{c}\mathbf{- 1 . 3 2} * * * \\
(0.25)\end{array}$ & $\begin{array}{c}3.46 * * * \\
(0.64)\end{array}$ \\
\hline Constant & $\begin{array}{c}0.46 \\
(0.90)\end{array}$ & $\begin{array}{c}0.31 \\
(1.61)\end{array}$ & $\begin{array}{c}7.13 * * * \\
(1.37)\end{array}$ & $\begin{array}{c}1.47 \\
(2.88)\end{array}$ & $\begin{array}{c}-\mathbf{2 . 4 0} * * \\
(1.24)\end{array}$ & $\begin{array}{c}\mathbf{3 . 5 5} * * * \\
(0.65)\end{array}$ & $\begin{array}{c}\mathbf{- 9 . 1 6} * * * \\
(1.86)\end{array}$ & $\begin{array}{l}-1.77 \\
(2.17)\end{array}$ & $\begin{array}{c}6.09 \\
(2.13)\end{array}$ & $\begin{array}{r}-11.31 \\
(4.95)\end{array}$ \\
\hline $\begin{array}{l}\mathrm{N} \\
\mathrm{R}^{2}\end{array}$ & $\begin{array}{c}662 \\
0.31\end{array}$ & $\begin{array}{c}621 \\
0.19\end{array}$ & $\begin{array}{c}655 \\
0.44\end{array}$ & $\begin{array}{c}470 \\
0.56\end{array}$ & $\begin{array}{c}708 \\
0.66\end{array}$ & $\begin{array}{l}575 \\
0.36\end{array}$ & $\begin{array}{c}173 \\
0.87\end{array}$ & $\begin{array}{c}147 \\
0.56\end{array}$ & $\begin{array}{l}229 \\
0.74\end{array}$ & $\begin{array}{l}530 \\
0.58\end{array}$ \\
\hline B. With Probability of Recession & & & & & & & & & & \\
\hline Probability of Recession $\left(\beta_{1}\right)$ & $\begin{array}{c}\mathbf{4 . 8 2} * * * * \\
(0.89)\end{array}$ & $\begin{array}{c}0.50 \\
(1.85)\end{array}$ & $\begin{array}{l}-1.56 \\
(2.35)\end{array}$ & $\begin{array}{l}-1.09 \\
(1.34)\end{array}$ & $\begin{array}{c}\mathbf{2 . 1 0} * * * \\
(0.76)\end{array}$ & $\begin{array}{c}-0.57 \\
(0.58)\end{array}$ & $\begin{array}{c}\mathbf{3 . 6 7} *_{\mathbf{v}} \\
(1.15)\end{array}$ & $\begin{array}{c}\mathbf{4 . 4 5} * * \\
(1.76)\end{array}$ & $\begin{array}{c}\text { 3.27**** } \\
(1.09)\end{array}$ & $\begin{array}{l}\text { 3.99* } \\
(2.39)\end{array}$ \\
\hline Log Normalized Inventory $\left(\beta_{2}\right)$ & $\begin{array}{c}\mathbf{0 . 3 1} * * * \\
(0.11)\end{array}$ & $\begin{array}{c}0.05 \\
(0.17)\end{array}$ & $\begin{array}{c}\mathbf{0 . 6 8} * * * \\
(0.19)\end{array}$ & $\begin{array}{c}0.18 \\
(0.17)\end{array}$ & $\begin{array}{c}\mathbf{0 . 2 1} * * * \\
(0.04)\end{array}$ & $\begin{array}{c}\mathbf{0 . 0 7} * * \\
(0.03)\end{array}$ & $\begin{array}{c}\mathbf{0 . 1 2} * * * * \\
(0.04)\end{array}$ & $\begin{array}{c}0.01 \\
(0.03)\end{array}$ & $\begin{array}{c}-0.04 \\
(0.04)\end{array}$ & $\begin{array}{c}-0.09 \\
(0.07)\end{array}$ \\
\hline Returns Volatility, $\%\left(\beta_{3}\right)$ & $\begin{array}{c}-1.74 * * * \\
(0.24)\end{array}$ & $\begin{array}{c}1.07 \\
(0.60)\end{array}$ & $\begin{array}{c}\mathbf{- 0 . 9 2} * * \\
(0.47)\end{array}$ & $\begin{array}{l}\text { 2.23* } \\
(0.71)\end{array}$ & $\begin{array}{c}\mathbf{- 1 . 9 9} * * * \\
(0.32)\end{array}$ & $\begin{array}{c}0.37 \\
(0.24)\end{array}$ & $\begin{array}{c}\mathbf{- 0 . 7 7} * * \\
(0.30)\end{array}$ & $\begin{array}{c}-0.52 \\
(0.83)\end{array}$ & $\begin{array}{c}-\mathbf{1 . 3 7} * * * \\
(0.24)\end{array}$ & $\begin{array}{c}3.44 * * * \\
(0.64)\end{array}$ \\
\hline Constant & $\begin{array}{c}-0.16 \\
(0.80)\end{array}$ & $\begin{array}{l}-1.39 \\
(1.55)\end{array}$ & $\begin{array}{c}7.13 \\
(1.36)\end{array}$ & $\begin{array}{c}1.67 \\
(2.80)\end{array}$ & $\begin{array}{c}-\mathbf{2 . 6 8} * * \\
(1.21)\end{array}$ & $\begin{array}{c}\text { 2.99**** } \\
(0.65)\end{array}$ & $\begin{array}{c}\text { 6.31** } \\
(3.18)\end{array}$ & $\begin{array}{c}0.21 \\
(0.53)\end{array}$ & $\begin{array}{l}-8.01 \\
(3.54)\end{array}$ & $\begin{array}{r}-14.73 \\
(3.12)\end{array}$ \\
\hline $\begin{array}{l}\mathrm{N} \\
\mathrm{R}^{2}\end{array}$ & $\begin{array}{c}662 \\
0.35 \\
\end{array}$ & $\begin{array}{l}621 \\
0.14 \\
\end{array}$ & $\begin{array}{l}655 \\
0.44 \\
\end{array}$ & $\begin{array}{c}470 \\
0.56 \\
\end{array}$ & $\begin{array}{l}708 \\
0.66 \\
\end{array}$ & $\begin{array}{l}575 \\
0.35 \\
\end{array}$ & $\begin{array}{l}173 \\
0.85 \\
\end{array}$ & $\begin{array}{l}147 \\
0.51 \\
\end{array}$ & $\begin{array}{c}229 \\
0.74 \\
\end{array}$ & $\begin{array}{l}530 \\
0.58 \\
\end{array}$ \\
\hline
\end{tabular}

The table shows estimates for the following regression: $\left(\mathrm{F}_{\mathrm{t}, \mathrm{T}}-\mathrm{S}_{\mathrm{t}}\right) / \mathrm{S}_{\mathrm{t}}-r_{t, T}=\alpha_{t}+\beta_{1} E M_{t}+\beta_{2} I N V_{t}+\beta_{3} \sigma_{t}+\sum \delta_{m} d_{m}+\varepsilon_{t}$. The regression is estimated using OLS with HAC standard errors (Bartlett kernel, Newey-West fixed bandwidth=6.0). The coefficients of the seasonal dummies are not shown. The seasonal dummy variables have significant coefficients for gasoline from January to February (positive) and from April to November (negative), for heating oil from January to April (negative) and from June to November (positive); for propane from December to February (negative) and from May to October (positive) and for natural gas from January to February (negative) and from August to November (positive). The sample period is 1/02/1987-7/29/2011 for crude oil, heating oil and gasoline; 1/16/1997-7/28/2011 for natural gas; 2/10/1994$4 / 09 / 2009$ for propane. $*, * *, * * *$ indicate that the coefficient is statistically significant at $10 \%, 5 \%$ and $1 \%$ levels. Standard errors are in parentheses. 
Table 4.8 shows estimation results for the expected returns regression in equation (8). The results show that basis positively predicts expected returns for energy commodities. All coefficient estimates of basis based are positive and statistically significant at the $1 \%$ level. The results for the risk premium regression in equation (9) are statistically unreliable. Fama and French (1987) argue that variation in the basis is low compared to variation in realized risk premium, leading to imprecise estimates of the relation between the basis and the premium. Table 4.8 also shows the state of the economy predicts returns of energy commodities. Coefficient estimates of the ADS index and the NBER recession dummy are statistically significant in the daily regression. These results imply that expected returns over a three-month horizon increase in good economic times and decline in recessions. The expected price decline over a three-month horizon in recessions ranges from about $5.2 \%$ for propane to about $20.3 \%$ for natural gas. Conversely, the ADS index positively predicts returns, with coefficient estimates ranging from about 3.6 for crude oil to about 6.6 for natural gas. 
Table 4.8

Regression Results for Expected Returns (Daily Data)

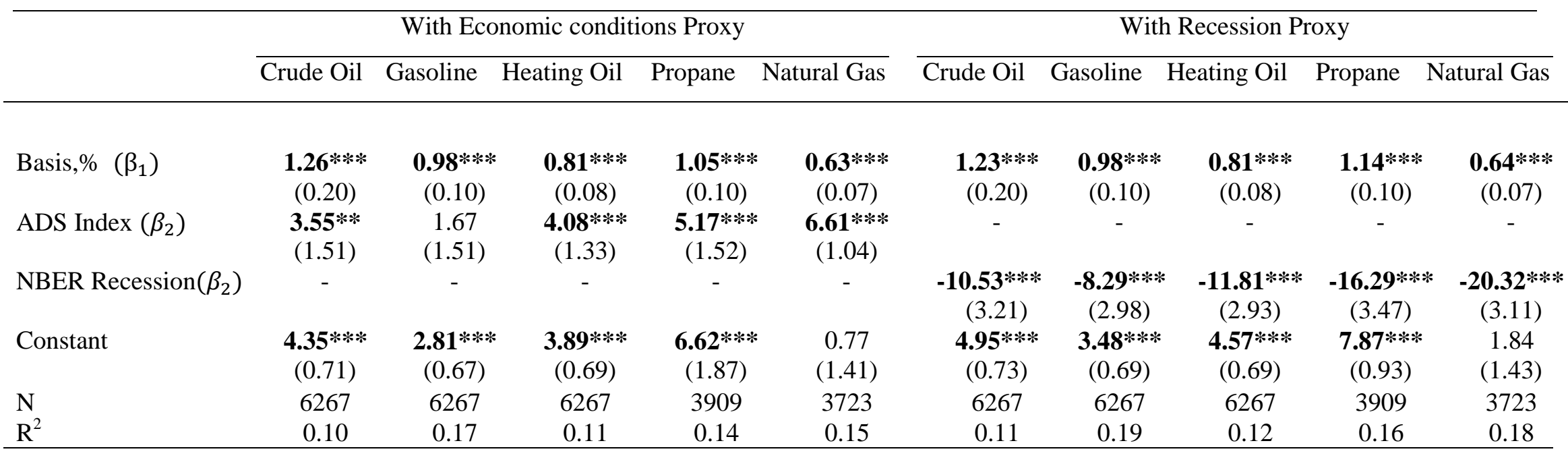

The table shows estimates for the following regression: $\left(S_{T}-S_{t}\right) / S_{t}=\alpha+\beta_{1}$ Basis $_{t}+\beta_{2} E M_{t}+v_{t}$. The regression is estimated using OLS with HAC standard errors (Bartlett kernel, Newey-West fixed bandwidth=6.0). The sample period is 1987-2011 for crude oil and heating oil; $1990-2011$ for gasoline; 1997-2011 for natural gas; March 4, 1993 to December 29, 2011 for propane.

$*, * *, * * *$ indicate that the coefficient is statistically significant at $10 \%, 5 \%$ and $1 \%$ levels. Standard errors are in parentheses. 


\subsection{Conclusions}

This study finds a significant effect from the state of the national economy on interestadjusted basis and expected returns of major energy commodities. First, energy interest-adjusted basis and returns exhibit a business cycle pattern. Interest-adjusted basis of energy commodities tend to be negative and returns over a three-month horizon tend to be positive around businesscycle peaks. The signs of interest-adjusted basis and returns reverse during recession. Regression results confirm that interest-adjusted basis tend to decrease and the expected returns increase when economic conditions are strong. Conversely, interest-adjusted basis increase and expected returns fall during economic contractions.

Second, indirect and direct tests for the behavior of futures and spot prices for energy commodities show that when inventory is low, spot prices are more variable than futures prices; changes in petroleum spot and futures prices tend to be larger; spot and futures price returns are less correlated. These results confirm predictions of the theory of storage. However, when inventory is high, changes in crude oil and natural gas prices tend to be larger. This evidence contradicts the theory of storage. I suggest that permanent supply and demand shocks strongly affect the oil and gas prices at high inventories that are insufficient to absorb those shocks. The regression results for petroleum commodities show large positive and statistically significant effects of the inventory on interest-adjusted basis at low inventory levels. This relation is insignificant at high inventory levels. In addition, energy return volatility negatively affects the basis when the inventory is low. Finally, the state of the national economy predicts expected spot returns, implying that future spot energy prices contain information about energy basis and economic conditions. 
Taken together, the main results for petroleum commodities support the theory of storage. Our major finding is to show that the variation of futures and spot prices for energy commodities are affected by national business conditions regardless of the level of inventories. The results for natural gas are somewhat different, suggesting that factors other than storage and macroeconomic conditions exert a strong influence on price dynamics in the evolving natural gas market. Further research is needed to directly examine the response of energy spot and futures prices to demand and supply shocks. 


\section{Chapter 5}

\section{CONCLUSIONS}

This dissertation addresses three topics in energy resource economics on micro, regional and national levels, namely investment decisions and economic feasibility of alternative fuel technologies, spatial dependence in the state wholesale gasoline markets, and the tradeoffs among energy prices, the inventory, and the state of the national economy. The overall goal for this research is to investigate the main economic and policy determinants that guide the allocation of energy resources and energy commodity markets.

The main finding on micro-economic analysis of coal and biomass to liquids (CBTL) investment decisions is that economic uncertainty is the key determinant of the investment decisions for this emerging CBTL technology. When economic uncertainty is taken into account there is little evidence of commercial viability for CBTL plants in the U.S. in the near-term despite a positive net present value from the traditional DCF analysis. The micro-economic analysis suggests deferring investment into the CBTL plant until better economic conditions, including reduction in capital expenditures, providing substantial subsidies, switch to less expensive energy inputs (f.e. natural gas), and creation of better product mix. Yet, the economic and policy decisions must be made under consideration of uncertainty.

The main finding on spatial panel econometric analysis of the spatial effects in the state wholesale gasoline markets is that the wholesale gasoline margin and price changes are spatially dependent across the 48 contiguous states. This means that the wholesale gasoline pricing decision is not only market driven but also significantly influenced by the spatial dependence and regional competition. Because the spatially dependent wholesale gasoline markets vary across states, the gasoline pricing is also influenced through the spatial spillovers. In presence of spatial 
dependence, changes in wholesale gasoline margin and prices are directly affected by the inventory, gasoline content regulation and refinery outages on the state level. The spillover effects play an important role in wholesale gasoline markets through changes in inventories in neighboring states.

The main finding on empirical analysis of energy prices, the inventory and the business cycle is that the state of the national economy significantly affects the energy futures and spot markets for crude oil, gasoline, heating oil, propane and natural gas. The short run effects show that the energy interest-adjusted basis decrease and expected returns increase when economic conditions are strong. Conversely, the basis increase and expected returns fall in recessions. These short-run effects are supported by the business-cycle behavior of the relative variation of three month futures and spot prices for energy commodities: interest-adjusted basis tends to be negative and the expected returns are positive near a business cycle peak. The basis becomes positive and the expected returns fall in a recession. The other finding is that the inventory affects the energy interest-adjusted basis for petroleum commodities when the inventory level is low, whereas at high inventory levels the effect of the inventory on the basis is weak, as predicted by the theory of storage.

\subsection{Directions for Future Research}

There are two possible directions for future research on micro-economic analysis of CBTL investment decisions. First, most of the ongoing research has been concerned with uncertainty of economic determinants relevant to the large-scale energy project. However, this essay did not consider the uncertainty of the carbon component of lifecycle greenhouse gas emissions. Also, the employed real options model does not answer a key question regarding 
economic feasibility of this technology if less expensive input (e.g. natural gas) would be an option. Addressing the uncertainty of the price of carbon dioxide associated with CBTL facilities and the option to switch to the less expensive input would contribute greatly towards future research. Second, the environmental concern associated with investment into large-scale energy projects has been little addressed. In essence, it is difficult to account for environmental concern in investment decisions as long as explicit expressions for environmental component would be incorporated into real options model.

An important direction on spatial econometric analysis which might be taken is the development of spatial panel econometric techniques for dealing with the endogeneity. In a study by Allers and Elhorst (2011) a spatial analysis is being used to estimate a linear expenditure system with endogenous interaction effects among jurisdictions based on cross-section data. However, the designed spatial econometric techniques cannot be used for panel data. With respect to the state wholesale gasoline markets many endogenous variables can be instrumented if spatial panel 2-SLS and 3-SLS techniques would be developed. The spatial panel econometric analysis would be much more advanced if the behavior of variables would be possibly determined using the spatial time series tests, such as unit root panel tests of Levin, Lin and Chu, Im, Pesaran and Shin, and Fisher, Granger causality test etc.

There are two possible courses which future research on energy prices, the inventory and the business cycle could take place. First, further research is needed to directly examine the response of energy spot and futures prices to demand and supply shocks. Kilian and Murphy (2011) find that the energy futures and spot prices are affected by speculative demand shock and supply shock, but very little by demand shock. An interesting future direction would be to check whether the relative impact of the permanent demand and supply shocks on the basis depend on 
the level of the inventory and the business cycle stage. Second, it would be critical to account for possible causality of energy prices and the state of the economy. If there is a bi-directional causality between the relative variation of futures and spot prices and the state of the economy, then it would be possible to provide a causal analysis that connects the interest-adjusted basis to the states of the economy. Finally, it would be interesting to check if the state of the economy affects other commodities. An interesting related future research would be to see if the countercyclical movements of the inventory and pro-cyclical behavior of the commodity prices would hold over the future business cycle. 


\section{References}

Allers, Maarten A. and Paul J. Elhorst. 2011. "A simultaneous equations model of fiscal policy interactions." Journal of Regional Science, 51(2): 271-291.

Anselin, Luc. 1988. Spatial Econometrics: Methods and Models. Dordrecht: Kluwer Academic Publishers.

Anselin, Luc, Bera Anil K., Florax Raymond, and Mann J. Yoon. 1996. "Simple Diagnostic Tests for Spatial Dependence." Regional Science and Urban Economics, 26(1): 77-104.

Anselin, Luc, Le Gallo Julie, and Hubert Jayet. 2008. "Spatial Panel Econometrics," In Matyas L. and P. Sevestre, The Econometrics of Panel Data: Fundamentals and Recent Developments in Theory and Practice. Dordrecht: Springer-Verlag Berlin Heidelberg: 625-57.

Aruoba, Borağan S., Diebold Francis X., and Scotti Chiara. 2009. "Real Time Measurement of Economic conditions." Journal of Business and Economic Statistics, 27: 417-427.

Baard Energy, 2007. Ohio River Clean Fuels. Project Summary. Available at: http://www.ohiocitizen.org/campaigns/coal/baard/Baard-FundingSources.pdf; accessed 4 August 2013.

Bartis, James T., Camm Frank, and David S. Ortiz. 2008. Producing Liquid Fuels from Coal: Prospects and Policy Issues. RAND Corporation, MG-754-AF/NETL. Santa Monica, California.

Basistha, Arabinda and Alexander Kurov. 2008. "Macroeconomic Cycles and the Stock Market's Reaction to Monetary Policy." Journal of Banking \& Finance, 32: 2606-2616.

Belli, Pedro, Anderson Jock, Barnum Howard, Dixon John, and Jee-Peng Tan. 1998. Handbook on Economic Analysis of Investment Operations. Operational Core Services Network, Learning and Leadership Center.

Blyth, William. 2010. "The Economics of Transition in the Power Sector." OECD/IEA. Available at: http://www.iea.org/publications/freepublications/publication/economics_of_transition. pdf; accessed 4 August 2013.

Borenstein, Severin and Andrea Shepard. 1996. "Dynamic Pricing in Retail Gasoline Markets." The RAND Journal of Economics, 429-51.

Brown, Jennifer, Hastings Justine, Mansur Erin, and Sofia B. Villas-Boas. 2008. "Reformulating Competition? Gasoline Content Regulation and Wholesale Gasoline Prices." Journal of Environmental Economics and Management, 55(1): 1-19. 
Burke, Paul and Shuhei Nishitateno. 2013. "Gasoline prices, gasoline consumption, and newvehicle fuel economy: Evidence for a large sample of countries." Energy Economics, 36: $363-370$.

Chakravorty, Ujjayant and Celine Nauges. 2005. "Boutique Fuels and Market Power." Department of Economics, Emory University (Atlanta) 41.

Chakravorty, Ujjayant, Nauges Celine, and Alban Thomas. 2008. "Clean Air Regulation and Heterogeneity in U.S. Gasoline Prices." Journal of Environmental Economics and Management, 55(1): 106-22.

Charlene, Kalenkoski and Donald, Lacombe. 2012. "Minimum Wages and Teen Employment: A Spatial Panel Aproach." Papers in Regional Science, 1-11.

Chauvet, Marcelle and Jeremy Piger. 2008. "A Comparison of the Real-Time Performance of Business Cycle Dating Methods." Journal of Business \& Economic Statistics, 26: 42-49.

Chouinard, Hayley and Jeffrey M. Perloff. 2007. "Gasoline Price Differences: Taxes, Pollution Regulations, Mergers, Market Power, and Market Conditions." The B.E. Journal of Economic Analysis \& Policy, 7(1): 1-26.

Darmstadter, Joel. 2010. "The Prospective Role of Unconventional Liquid Fuels." Resources for the Future, Washington, DC. Available at: http://nepinstitute.org/get/RFF_Reports/Background-Papers/RFF-NEPI-DarmstadterAltLiquidFuels.pdf; accessed 4 August 2013.

Dixit, Avinash.1992. "Investment and Hysteresis." Journal of Economic Perspectives. 6: 107-32.

Dixit, Avinash and Robert Pindyck. 1994. Investment under Uncertainty. NJ.: Princeton University Press.

Doyle, Joseph J. and Krislert Samphantharak. 2008. "\$2.00 Gas! Studying the Effects of a Gas Tax Moratorium." Journal of Public Economics, 92: 869-884.

Duffy, Michael. 2007. Estimated Costs for Production, Storage and Transportation of Switchgrass. Iowa State University, University Extension. Available at: http://www2.econ.iastate.edu/research/webpapers/paper_12917.pdf; accessed 4 August 2013.

EIA, 2011. Annual Energy Outlook 2011. Energy Information Administration. U.S. Department of Energy, Washington DC. DOE/EIA-0383.

Elhorst, Paul J. 2010a. "Spatial Panel Data Models," In: Fischer M. and A. Getis, Handbook of Applied Spatial Analysis: Software Tools, Methods and Applications. Berlin Heidelberg New York: Springler-Verlag: 377-405.

Elhorst, Paul J. 2010b. "Matlab Software for Spatial Panels," In: the IVth World Conference of the Spatial Econometrics Association (SEA). Chicago: 1-22. 
Fama, Eugene F. and Kenneth R. French. 1988. "Business Cycles and the Behavior of Metals Prices." The Journal of Finance, 43 (5): 1075-1093.

Fama, Eugene F. and Kenneth R. French. 1987. "Commodity Futures Prices: Some Evidence on Forecast Power, Premiums, and the Theory of Storage." The Journal of Business, 60 (1): 55-73.

Gilbert, Richard J. and Justine S. Hastings. 2006. "Market Power, Vertical Integration, and the Wholesale Price of Gasoline." Journal of Industrial Economics, 53(4): 469-92.

Gorton, Gary B., Fumio Hayashi, and Geert K. Rouwenhorst. 2013. "The Fundamentals of Commodity Futures Returns." Review of Finance, 17 (1): 35-105.

Gorton, Gary B. and Geert K. Rouwenhorst. 2006. "Facts and Fantasies about Commodity Futures." Financial Analysts Journal, 62(2): 47-68.

Hileman, James, Ortiz David, Bartis James, Wong Hsin, Donohoo Pearl, Weiss Malcolm, and Ian Waitz. 2009. Near-Term Feasibility of Alternative Jet Fuels. RAND Corporation and Massachusetts Institute of Technology.

Hong, Harrison G. and Motohiro Yogo. 2012. "What Does Futures Market Interest Tell Us about the Macroeconomy and Asset Prices?" Journal of Financial Economics, 105 (3): 473490.

Hotelling, Harold. 1931. "The Economics of Exhaustible Resources." The Journal of Political Economy, 39 (2):137-175.

Karrenbrock, Jeffrey. 1991. "The Behavior of Retail Gasoline Prices: Symmetric or Not?." Federal Reserve Bank of St. Louis Review, 73(4): 19-29.

Keynes, John Maynard. 1930. A Treatise on Money. In The applied theory of money: New York, Harcourt, Brace [1930].

Kilian, Lutz and Daniel P. Murphy. 2011. "The Role of Inventories and Speculative Trading in the Global Market for Crude Oil." University of Michigan.

Klier, Thomas and Joshua Linn. 2009. "The Price of Gasoline and New Vehicle Fuel Economy: Evidence from Monthly Sales Data." American Economic Journal: Economic Policy, 2(3): 134-53.

Kucher, Oleg and Jerald Fletcher. 2011. "Economic Feasibility and Investment Decisions of Coal and Biomass to Liquids." 30th USAEE/IAEE North American Conference, October 9-12, 2011, Washington, DC. Available at: http://www.usaee.org/usaee2011/submissions/OnlineProceedings/5854Kucher_and_Fletcher_USAEE_2011.pdf; accessed 4 August 2013.

Kucher, Oleg and Alex Kurov. 2012. "Energy Basis, Returns and the Business Cycle." $31^{\text {st }}$ USAEE/IAEE North American Conference, November 4-7, 2012, Austin. Available at: http://www.usaee.org/usaee2012/submissions/OnlineProceedings/Kucher_Kurov_2012US AEE.pdf; accessed 4 August 2013. 
Lacombe, Donald J. 2010. Matlab Code for the Panel Model Performance of the Lagrange Multiplier Tests for a Spatially Lagged Dependent Variable.

LeSage, James and Robert Kelley Pace. 2009. Introduction to Spatial Econometrics. Chapman and Hall/CRC.

Lewis, Matthew. 2009. "Temporary Wholesale Gasoline Price Spikes Have Long-Lasting Retail Effects: The Aftermath of Hurricane Rita." Journal of Law and Economics, 52: 581-605.

Litzenberger, Robert H. and Nir Rabinowitz. 1995. "Backwardation in Oil Futures Markets: Theory and Empirical Evidence." Journal of Finance, 50 (5): 1517-1545.

Mcdonald, Robert and Daniel Siegel. 1986. The Value of Waiting to Invest. Quarterly Journal of Economics. 101(4): 707-28.

Merrow, Edward, 2011. Industrial Megaprojects: Concepts, Strategies, and Practices for Success. John Wiley \& Sons.

Mun, Jonathan, 2006. Modeling Risk: Applying Monte Carlo Simulation, Real Options Analysis, Forecasting, and Optimization Techniques. John Wiley \& Sons, Inc., Hoboken.

NETL, 2007. Increasing Security and Reducing Carbon Emissions of the U.S. Transportation Sector: A Transformational Role for Coal with Biomass. National Energy Technology Laboratory, U.S. Department of Energy, DOE/NETL-2007/1298.

NETL, 2009. Affordable Low-Carbon Diesel Fuel from Domestic Coal and Biomass, DOE/NETL-2009/1349. Available at: http://www.netl.doe.gov/energyanalyses/pubs/CBTL\%20Final\%20Report.pdf; accessed 4 August 2013.

NETL, 2011. Power Systems Financial Model Version 6.6 User's Guide. National Energy Technology Laboratory, U.S. Department of Energy, DOE/NETL-2011/1492. Available at: www.netl.doe.gov/energy-analyses/refshelf/PubDetails.aspx?Action=View\&PubId=382; accessed 4 August 2013.

NETL, 2011. Production of Zero Sulfur Diesel Fuel from Domestic Coal: Configurational Options to Reduce Environmental Impact. U.S. Department of Energy, DOE/NETL-2012/1542 .

Ng, Victor K. and Stephen Craig Pirrong. 1996. "Price Dynamics in Refined Petroleum Spot and Futures Markets." Journal of Empirical Finance, 2(4):359-388.

Pindyck, Robert. 1991. Irreversibility, Uncertainty, and Investment. Journal of Economic Literature, XXIX: 1110-11148.

Pindyck, Robert. 1999. The Long-Run Evolution of Energy Prices. The Energy Journal, 202: 128.

Pindyck, Robert. 2001. "The Dynamics of Commodity Spot and Futures Markets: A Primer." The Energy Journal, 22(3): 1-30. 
Pirotte, Alain and Jean-Loup Madre. 2009. "Gasoline Demand and Price Elasticities: A Panel Data Analysis on French Regions " In: The 12th International Conference on Travel Behaviour Research. Jaipur, India.

Rentech, Inc., 2008. Synthetic Fuel Initiatives. 3rdAnnual Coal-to-Liquids \& Gas-to-Liquids Conference.

Rothwell, Geoffrey. 2006. A Real Options Approach to Evaluating New Nuclear Power Plants. The Energy journal. 27: 37-54.

Samuelson, Paul A. 1965. "Proof that properly anticipated prices fluctuate randomly." Industrial Management Review, 6(2): 41-49.

Serletis, Apostolos and Asghar Shahmoradi. 2006. "Futures trading and the storage of North American natural gas." OPEC Energy Review, 30(1): 19-26.

Serletis, Apostolos and Vaughn Hulleman. 1994. "Business cycles and the behavior of energy prices." The Energy Journal, 15: 125-134.

Stronzik, Marcus, Rammerstorfer Margarethe, and Anne Neumann. 2009. "Does the European natural gas market pass the competitive benchmark of the theory of storage? Indirect tests for three major trading points." Energy Policy, 37 (12): 5432-5439.

U.S. EPA. 1994. "Regulation of Fuels and Fuel Additives: Standards for Reformulated and Conventional Gasoline," Environmental Protection Agency, EPA Federal Register,

Vita, Michael G. 2000. "Regulatory Restrictions on Vertical Integration and Control: The Competitive Impact of Gasoline Divorcement Policies." Journal of Regulatory Economics, 18(3): 217-33.

Working, Holbrook. 1933. "Price Relations between July and September Wheat Futures at Chicago since 1885." Wheat Studies of the Food Research Institute, 9 (6): 187-274.

Working, Holbrook. 1949. "The Theory of Price of Storage." The American Economic Review, 39 (6): 1254-1262.

Yang, Ming, Blyth William, Bradley Richard, Bunn Derek, Clarke Charlie, and Tom Wilson. 2008. Evaluating the Power Investment Options with Uncertainty in Climate Policy. Energy Economics. 30: 1933-1950. 